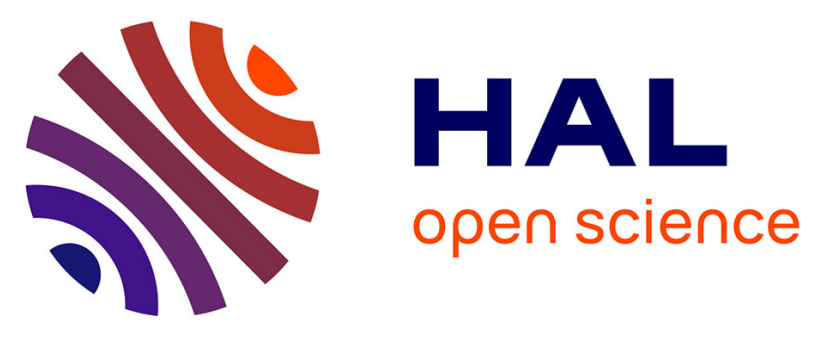

\title{
Isolation and identification of ten new sildenafil derivatives in an alleged herbal supplement for sexual enhancement
}

\author{
Gaëtan Assemat, Stéphane Balayssac, Véronique Gilard, Nathalie
}

Martins-Froment, Isabelle Fabing, Frédéric Rodriguez, Yves Génisson, Robert

Martino, Myriam Malet-Martino

\section{To cite this version:}

Gaëtan Assemat, Stéphane Balayssac, Véronique Gilard, Nathalie Martins-Froment, Isabelle Fabing, et al.. Isolation and identification of ten new sildenafil derivatives in an alleged herbal supplement for sexual enhancement. Journal of Pharmaceutical and Biomedical Analysis, 2020, 191, pp.113482. 10.1016/j.jpba.2020.113482 . hal-02966885

\section{HAL Id: hal-02966885 \\ https://hal.science/hal-02966885}

Submitted on 1 Dec 2020

HAL is a multi-disciplinary open access archive for the deposit and dissemination of scientific research documents, whether they are published or not. The documents may come from teaching and research institutions in France or abroad, or from public or private research centers.
L'archive ouverte pluridisciplinaire $\mathbf{H A L}$, est destinée au dépôt et à la diffusion de documents scientifiques de niveau recherche, publiés ou non, émanant des établissements d'enseignement et de recherche français ou étrangers, des laboratoires publics ou privés. 
1 Isolation and identification of ten new sildenafil derivatives in an alleged herbal supplement for sexual enhancement

3

4 Gaëtan Assemat ${ }^{1}$, Stéphane Balayssac ${ }^{1}$, Véronique Gilard ${ }^{1}$, Nathalie Martins-Froment ${ }^{2}$, 5

6

7

$8{ }^{1}$ Equipe RMN Biomédicale, ${ }^{3}$ Plate-forme Chromatographie, ${ }^{4}$ Bio-informatique, ${ }^{5}$ Equipe 9 MoNALISA, Laboratoire SPCMIB (UMR CNRS 5068), Université Paul Sabatier, 118 route de 10 Narbonne, 31062 Toulouse cedex, France

$11{ }^{2}$ Service Commun de Spectrométrie de Masse, Université Paul Sabatier, 118 route de

15 Equipe RMN Biomédicale, Laboratoire SPCMIB (UMR CNRS 5068), Université Paul 16 Sabatier, 118 route de Narbonne, 31062 Toulouse cedex, France 


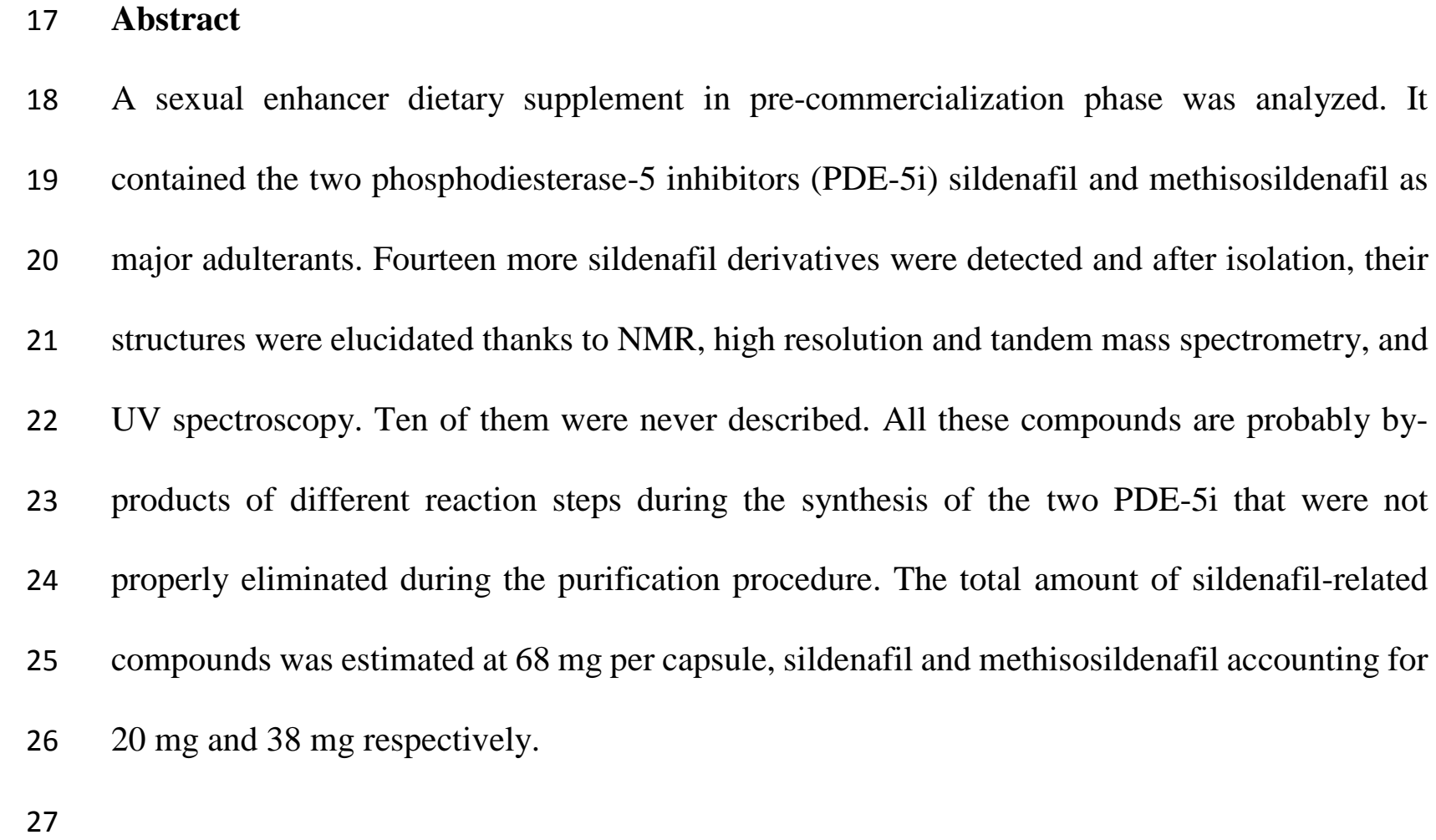




\section{Introduction}

Nowadays, consumers' keen interest in plant food supplements stems from their sometimes inaccurate perception that these products are safe because of their natural origin. In the absence of strict and uniform regulation and control of these products, unscrupulous manufacturers may fraudulently add active substances to these herbal preparations to increase the desired pharmacological effect. The phenomenon of adulteration of sexual enhancer dietary supplements with synthetic phosphodiesterase-type 5 inhibitors (PDE-5i), whether approved (sildenafil, tadalafil, vardenafil) or unapproved (their analogues), has been widely documented [1-4]. Since the detection of homosildenafil, the first analogue reported in literature in 2003 as adulterant in a dietary supplement [5], their number has regularly increased to 80 in March 2017 [6] and continues to increase, as evidenced by recent studies [see for example 7-9].

In the present study, sildenafil and fifteen analogues were isolated from a dietary supplement intended for marketing, using Supercritical Fluid Chromatography (SFC) and Liquid Chromatography (LC) purification methods. All of the compounds were then fully identified by means of ultraviolet (UV) spectroscopy, mass spectrometry (MS), and ${ }^{1} \mathrm{H}$ and ${ }^{13} \mathrm{C}$ nuclear magnetic resonance (NMR). To our knowledge, ten of these compounds are new and have never been reported in literature.

\section{Experimental}

\subsection{Materials}

One dietary supplement in pre-commercialization phase was submitted for analysis. Its composition was claimed as follows: raspberry (Rubus idaeus) 25\%, Solomon's seal (Polygonatum sibiricum) rhizome 25\%, common yam (Dioscorea opposita) rhizome 20\%, barbary wolfberry (Lycium chinense) fruit 15\%, cassia (Cinnamomum cassia) bark $15 \%$. Twenty-four capsules containing each $360 \pm 20 \mathrm{mg}$ of brown powder were used for this study. 
All chromatographic solvents (RS-HPLC-Preparative grade for purification steps with preparative HPLC and RS-HPLC-GOLD-Ultra gradient grade for analytical purposes) were purchased from Carlo Erba (27100 Val de Reuil, France). Authentic standards of sildenafil and methisosoldenafil were supplied by TRC (North York, ON, Canada). All other chemicals and reagents used as well as the NMR reference for internal chemical shift and quantification (sodium 2,2,3,3-tetradeutero-3-(trimethylsilyl) propanoate (TSP)) were supplied by Sigma Aldrich (St. Louis, MO, USA). Deuterated solvents were obtained from Euriso-Top (91194 Saint Aubin, France).

\subsection{Purification of active compounds}

\subsubsection{Sample preparation prior to SFC experiments}

A preliminary analysis showed that the sample contained a sort of tar which could prevent purification or complicate further purification steps. To get rid of it, a first preextraction procedure was implemented. The powder from 1 capsule was treated in two steps. It was first extracted with $3 \mathrm{~mL}$ of a $\mathrm{CH}_{3} \mathrm{CN}: \mathrm{H}_{2} \mathrm{O}(80: 20 \mathrm{v} / \mathrm{v})$ mixture, vortexed for $15 \mathrm{~s}$, sonicated for $10 \mathrm{~min}$ and centrifuged $(3000 \mathrm{rpm})$ for $5 \mathrm{~min}$ at room temperature. The supernatant (2800 $\mu \mathrm{L})$ was collected and transferred into a glass tube. In a second step, the pellet was re-extracted with the same protocol using $1 \mathrm{~mL}$ of solvent. The supernatants were then pooled and the solution was evaporated to dryness. This procedure was repeated for 24 capsules. For SFC purification, $2.9 \mathrm{~g}$ of the residual powder were dissolved by sonication in $58 \mathrm{~mL}$ of methanol. Before injection, samples were filtered on $0.45 \mu \mathrm{m}$ GHP membranes.

\subsubsection{Preparative SFC}

All preparative SFC separations were carried out on a BetaSil Diol-100 (250 x 21.2 mm, $5 \mu \mathrm{m}$ ) column using a Berger Multigram II Preparative SFC system (Mettler Toledo, Viroflay, 
France) and the SFC ProNTo software. Preparative SFC was operated with an elution gradient 80 at a back pressure of $100 \mathrm{bar}$, a temperature of $40^{\circ} \mathrm{C}$, a flow rate of $42.5 \mathrm{~mL} \mathrm{~min}^{-1}$ and a UV detection at $235 \mathrm{~nm}$. The gradient started by an isocratic elution of $\mathrm{CO}_{2}$ and $10 \%$ methanol containing $0.5 \%(\mathrm{v} / \mathrm{v})$ isopropylamine during $0.5 \mathrm{~min}$, and the organic modifier percentage was then increased to $28 \%$ at $8 \mathrm{~min}$ and remained at this value until $15 \mathrm{~min}$. At last the column was re-equilibrated in the initial elution conditions from 16 to 20 min (Table 1). 116 injections of $25 \mathrm{mg}$ of raw extract dissolved in $500 \mu \mathrm{L}$ of methanol were done. Seven fractions were collected as indicated in the chromatogram of Fig. 1A, i.e. 3-6 min (A), 6.05-6.45 $\min (\mathrm{B}), 6.5-7.8 \mathrm{~min}$ (C), 7.85-8.75 $\min (\mathrm{D}), 8.8-10.1 \min (\mathrm{E}), 10.15-11.45 \min (\mathrm{F})$ and 11.5-13.2 $\min (\mathrm{G})$. All fractions were then evaporated to dryness.

\subsubsection{Preparative $L C$}

Each SFC fraction was dissolved either in the starting LC eluent (D, E, F, G) or in a mixture of the starting LC eluent and methanol (B, C) or acetonitrile (A) (Table 1). Purifications were performed on a Waters Prep 150 LC System instrument (Waters Corporation, Milford, MA, USA) equipped with a 2545 Binary Gradient pump, a 2707 autosampler, a 2998 photodiode array (PDA) detector and a WFC III fraction collector. Data were processed using the Chromscope software. Columns and elution conditions for preparative LC are reported in Table 1 and chromatograms are shown in Fig. 1B. UV detection was set at $235 \mathrm{~nm}$ for all experiments. Two compounds (15 and 16) were collected in the same fraction. All fractions recovered were lyophilized.

\subsubsection{Analytical Ultra High Performance Liquid Chromatography (UHPLC)}

Each LC fraction was dissolved in methanol at a concentration of $\approx 0.5 \mathrm{mg} / \mathrm{mL}$ and its purity was controlled by UHPLC using a Waters Acquity UHPLC system equipped with a 
binary solvent delivery pump, an auto sampler, a PDA detector, a QDa mass detector and the Empower 3 software. The analytical conditions are reported in Table 1. UV spectra were obtained from these UHPLC analyses.

\subsection{NMR and MS characterization of the dietary supplement and the purified compounds}

\subsubsection{NMR}

Two to $7 \mathrm{mg}$ of each lyophilized final fraction were solubilized in $1 \mathrm{~mL}$ of a $111 \mathrm{CD}_{3} \mathrm{CN}: \mathrm{D}_{2} \mathrm{O}(80: 20 \mathrm{v} / \mathrm{v})$ mixture, and the solution was vortexed for $15 \mathrm{~s}$ and sonicated for 10 $112 \min$. To achieve the solubilisation of compounds 9 and $14,5 \mu \mathrm{L}$ of a $0.5 \mathrm{M} \mathrm{NaOD}$ solution 113 were added. Thirty $\mu \mathrm{L}$ of a $5 \mathrm{mM}$ solution of TSP in $\mathrm{D}_{2} \mathrm{O}$ as an internal reference for chemical 114 shift $(\delta)$ measurement were added before the NMR analysis.

For the quantitative determination of sildenafil derivatives in the dietary supplement (done in triplicate), around $10 \mathrm{mg}$ of powder were accurately weighed and $1 \mathrm{~mL}$ of deuterated methanol $\left(\mathrm{CD}_{3} \mathrm{OD}\right)$ was added. The suspension was submitted to vortex agitation for $15 \mathrm{~s}$, sonication for $10 \mathrm{~min}$, magnetic stirring for $20 \mathrm{~min}$ and it was then centrifuged (5 min, 3000 $\mathrm{rpm})$. Thirty $\mu \mathrm{L}$ of a $5 \mathrm{mM}$ solution of TSP were added to $800 \mu \mathrm{L}$ of supernatant and the solution was transferred into a $5 \mathrm{~mm}$ NMR tube.

NMR spectra were recorded on a Bruker Avance 500 spectrometer (Bruker Biospin AG, Fallanden, Switzerland) equipped with a $5 \mathrm{~mm}$ cryoprobe at $298 \mathrm{~K}$. The structural elucidation of purified sildenafil derivatives was achieved thanks to one-dimensional $\left(1 \mathrm{D} ;{ }^{1} \mathrm{H}\right.$ and $\left.{ }^{13} \mathrm{C}\right)$ and two-dimensional (2D; gCOSY, gHSQC, gHMBC and NOESY) experiments. The 1D ${ }^{1} \mathrm{H}$ NMR spectra of the dietary supplement were acquired with inverse gated decoupling for ${ }^{13} \mathrm{C}$ using a 126 GARP sequence. Acquisition parameters were as follows: number of scans 32, pulse width 10.7 $127 \mu$ s (flip angle $90^{\circ}$ ), acquisition time $1.56 \mathrm{~s}$, spectral width $10500 \mathrm{~Hz}, 32 \mathrm{~K}$ data points, and 128 relaxation delay $4 \mathrm{~s}$; the recording time was thus $\approx 4 \mathrm{~min}$. The NMR assignment of sildenafil 
derivatives in the dietary supplement was done by adding successively the previously purified and identified compounds. For quantitative NMR experiments, the relaxation delay was lengthened to $15 \mathrm{~s}$ for a full relaxation of the ${ }^{1} \mathrm{H}$ resonances and the number of scans was raised to 128 . NMR data were processed using the TOPSPIN 3.1 software.

\subsubsection{High-Resolution Mass Spectrometry (HRMS)}

Each lyophilized final fraction was dissolved in $\mathrm{CH}_{3} \mathrm{CN}: \mathrm{H}_{2} \mathrm{O}(80: 20 \mathrm{v} / \mathrm{v})$ and analyzed after direct infusion using a Waters XEVO G2 QTOF mass spectrometer with electrospray ionization in positive $\left(\mathrm{ESI}^{+}\right)$and negative $\left(\mathrm{ESI}^{-}\right)$modes. For both modes, the instrument parameters were as follows: for MS analysis, cone voltage $30 \mathrm{~V}$, source temperature $110^{\circ} \mathrm{C}$,

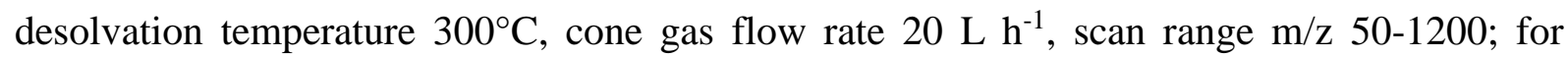
MS/MS analysis, three different collision energies (15, 25 and $35 \mathrm{~V})$ were applied with the cone voltage maintained at $30 \mathrm{~V}$ and the spectra were acquired with a mass precursor ion selection of $3 \mathrm{Da}$. All analyses were performed using the lockspray, which ensured accuracy and reproducibility. Leucine enkephalin $\left(1 \mathrm{ng} \mu \mathrm{L}^{-1}\right)$ introduced by a lockspray at $3 \mu \mathrm{L} \mathrm{min}{ }^{-1}$ was used as the lockmass generating reference ions at $\mathrm{m} / \mathrm{z} 556.2771$ or 554.2615 in positive or negative mode respectively. The MassLynx software was used to calculate the most probable chemical formula and the theoretical exact mass of the molecular and fragment ions by comparison with their measured accurate ionic masses. The elemental formula of each ion was confirmed by the agreement between the experimental and calculated values within a relative mass error (RME) $<3$ ppm or between 3 and 5 ppm for respectively $93 \%$ and $7 \%$ of ions with 
a molecular weight $>100$ Da and $<5$ ppm or between 5 and 10 ppm for $69 \%$ and $31 \%$ of ions with a molecular weight $<100 \mathrm{Da}$.

\subsection{Molecular modelling}

The chemical structures were sketched (hybridization, hydrogenation, some geometry optimizations) using ChemAxon Marvin 17.25 (2017, ChemAxon, http://www.chemaxon.com). In order to generate a coarse-grained conformational sampling, compounds 1-5 were submitted to the calculation plugins (conformers, molecular dynamics) of Marvin using standard parameter sets. The structures were merged in SDF libraries using inhouse software and imported in BIOVIA Discovery Studio Client (DSV) release 2016, Dassault Systèmes (https://www.3dsbiovia.com/) software. DSV was used to align molecules using a reference group and to measure interatomic distances for structures of interest (i.e. lowest energy conformers or frames). Molecular graphics were also produced using DSV.

\section{Results}

\subsection{Preliminary ${ }^{1} H$ NMR analysis of the dietary supplement}

As soon as the dietary supplement was received for control in our lab, its ${ }^{1} \mathrm{H}$ NMR analysis was performed as usually [1] in order to detect a possible adulteration. The ${ }^{1} \mathrm{H}$ NMR spectrum clearly showed that the herbal mixture was not natural as expected from its claimed composition. The presence of two main contaminants could be deduced from the highest signals that were assigned to sildenafil (12) and methisosildenafil (1) thanks to our in-house NMR database. Nonetheless, our attention was caught by the numerous minor signals whose 172 multiplicity and chemical shift could be compatible with those of PDE-5i analogues. To get rid 173 of carbon satellites that increase spectrum complexity, a ${ }^{13} \mathrm{C}$ GARP broadband decoupled ${ }^{1} \mathrm{H}$ NMR spectrum was acquired, which confirmed the presence of minor adulterants (Fig. 2). 
In order to determine their structures, the dietary supplement was purified and the compounds detected were isolated. The main issue encountered in the purification of this complex mixture was the huge concentration differences of the various analytes as illustrated in the NMR spectrum where large and small signals co-exist. To overcome this difficulty and after some unsuccessful attempts using both reverse and normal LC (results not shown), we chose to work in two steps using a first SFC pre-fractionation followed by LC purifications.

\subsection{Purification of the dietary supplement}

The SFC purification was done using a BetaSil diol phase. This polar stationary phase and the chosen elution mode provided sharp enough peaks and satisfactory chromatographic resolution and retention times. The use of basic elution conditions allowed the reduction of peak tailing for molecules containing amine groups. Seven fractions were collected from 3 to 13.2 min as shown in Fig. 1A.

Each SFC fraction was then purified by preparative LC. All experimental conditions are gathered in Table 1 and chromatograms are illustrated in Fig. 1B. The chromatographic conditions were chosen after a screening step using neutral or acidic medium and two stationary phases Kromasil C18 and CSH C18. The elution gradient was optimized for each separation.

The two steps of purification with polar (SFC) and non-polar (LC) chromatographic 193 phases led to the purification of 16 compounds. The purity of each preparative LC fraction 194 (except that containing compounds $\mathbf{1 5}$ and $\mathbf{1 6}$ which could not be separated) was evaluated from 195 the UHPLC-UV chromatograms performed in routine analytical conditions and was in the range $19688.8-99.3 \%$ (mean 96.3\%). It can be noticed that 14 products eluted between 2.07 and 2.92 min 197 (Table 2), which also justifies the use of two orthogonal chromatographic methods that provided 198 complementary selectivity to achieve the purification. 


\subsection{Characterization of purified compounds}

The chemical structures of the two major adulterants methisosildenafil (1) and sildenafil

(12) deduced from the ${ }^{1} \mathrm{H}$ NMR analysis of the raw dietary supplement (vide supra) were confirmed by their UV ( $\lambda_{\max } \approx 225$ and $\left.295 \mathrm{~nm}[10]\right)$, HRMS $\left([\mathrm{M}+\mathrm{H}]^{+} 489.2277\right.$ and 475.3126 respectively) and 1D and 2D NMR spectra (Fig. 3, Tables 3-5). Some clues on the structures of the other isolated compounds could be deduced from their UV and HRMS characteristics.

The UV spectrum of compound 2 with the same profile and $\lambda_{\max }$ than those of compounds $\mathbf{1}$ and $\mathbf{1 2}$ indicated that its structure also displays the pyrazolo[4,3-d]pyrimidine-7one ethoxyphenyl (or propoxyphenyl) sulfonamide moiety [10]. By comparison with the UV profiles of the 64 selected PDE-5i reported by the USP [10], it can be excluded that the chromophore of the other compounds is that of pyrazolopyrimidine-7-thione sulfonamide analogues, pyrazolopyrimidine-7-one or -7-thione with acetyl moieties, or of tadalafil or vardenafil derivatives. Nevertheless, similar chromophoric skeletons are observed for compounds 4/5/13, $6 / \mathbf{7}$ and to a lesser extent $\mathbf{3}, \mathbf{8 / 9 / 1 4}$, and 10/11 (Fig. 3).

\subsubsection{MS and MS/MS analysis}

The $\mathrm{ESI}^{+}$accurate mass data of parent and fragment ions of all the isolated compounds are gathered in Table 3. Some characteristic ESI ${ }^{+}$MS/MS spectra together with the structure of fragment ions are illustrated in Fig. 4A. The MS/MS fragmentations show the presence of a small (or very small) peak at $\mathrm{m} / \mathrm{z}$ 166.0973-166.0985 corresponding to the molecular formula $\mathrm{C}_{8} \mathrm{H}_{12} \mathrm{~N}_{3} \mathrm{O}^{+}$whose proposed structure (Fig. 4B) is characteristic of the fragmentation of the pyrazolo[4,3-d]pyrimidine-7-one moiety of the sildenafil derivatives [11] and not of the 222 isomeric vardenafil skeleton that leads to fragmentation ions at $\mathrm{m} / \mathrm{z} 169$ and 151 [12]. 223 Moreover, a peak at $\mathrm{m} / \mathrm{z} 299.1137-299.1151$ corresponding to the molecular formula $224 \mathrm{C}_{15} \mathrm{H}_{15} \mathrm{~N}_{4} \mathrm{O}_{3}{ }^{+}$is found in the fragmentation of all the compounds, except $\mathbf{1 5}$ and $\mathbf{1 6}$. Its intensity 
225 is markedly lower for compounds $\mathbf{2 - 7}$ and $\mathbf{1 3}$ but remarkably higher for compounds 8-11 and

14 than for methisosildenafil (1) and sildenafil (12). The structure of this ion (Fig. 4B and 4C) involves the occurrence of a pyrazolopyrimidine-7-one sulfonamide moiety (or that of the isomeric vardenafil structure which has already been excluded (see above)).

In comparison with the fragmentation profile of the dimethylpiperazine moiety of methisosildenafil 1 which generates major peaks at $\mathrm{m} / \mathrm{z} 113,99,84$ and 71 (the latter being characteristic of such a piperazine structure $[13,14])$, it can be stated that compounds $\mathbf{3 , 4 , 8}$ and 10 bear a dimethylpiperazine entity. Compounds 2, 5, 7, 9 and $\mathbf{1 1}$ display the same fragmentation peaks (except that the ion at $\mathrm{m} / \mathrm{z} 99$ is replaced by two ions at m/z 100 and 98) but also the presence of two intense additional ions at m/z 141 and 127 corresponding respectively to molecular formulae $\mathrm{C}_{8} \mathrm{H}_{17} \mathrm{~N}_{2}{ }^{+}$and $\mathrm{C}_{7} \mathrm{H}_{15} \mathrm{~N}_{2}{ }^{+}$(Fig. 4A and 4D for the proposed structures of the fragment ions). The increase of 28 and $14 \mathrm{~m} / \mathrm{z}$ units with respect to the fragmentation ion of the dimethylpiperazine moiety at m/z 113 (molecular formula $\mathrm{C}_{6} \mathrm{H}_{13} \mathrm{~N}_{2}{ }^{+}$) suggests the insertion of an ethyl group on the piperazine ring. Moreover, the presence of a product ion at $\mathrm{m} / \mathrm{z} 72$ (as intense as the ion at $\mathrm{m} / \mathrm{z} 71$ ), characteristic of the fragmentation of a N-ethylpiperazinyl group [13,14], is a good indication of the presence of a dimethyl-N-ethylpiperazine moiety. In comparison with the fragmentation of the $\mathrm{N}$-methylpiperazine sulfonamide moiety of sildenafil 12 that gives peaks at m/z 163, 100, 99, 70 and 58 [12,13], it can be concluded that this entity is part of the structure of compounds $\mathbf{1 3}$ and $\mathbf{1 4}$ (Fig. 4A and 4D). The HRMS and MS/MS spectra of compounds 15 and 16 (not separated) do not show the presence of any fragmentation ion coming from piperazine or other amine substituent [13].

Compounds 2, 3, 4, 6 and 11 with a $[\mathrm{M}+\mathrm{H}]^{+}$ion at $\mathrm{m} / \mathrm{z}$ 517.2587-517.2600 suggesting 247 the molecular formula $\mathrm{C}_{25} \mathrm{H}_{37} \mathrm{~N}_{6} \mathrm{O}_{4} \mathrm{~S}^{+}$are characterized by a gain of 28 mass units compared to 248 methisosildenafil 1 at $\mathrm{m} / \mathrm{z} 489.2277\left(\mathrm{C}_{23} \mathrm{H}_{33} \mathrm{~N}_{6} \mathrm{O}_{4} \mathrm{~S}^{+}\right)$, thus demonstrating the presence of a 249 supplementary ethyl group. Compounds 5 and 7 with $[\mathrm{M}+\mathrm{H}]^{+}$ions at $\mathrm{m} / \mathrm{z} 545.2920$ and 
545.2922 suggesting the molecular formula $\mathrm{C}_{27} \mathrm{H}_{41} \mathrm{~N}_{6} \mathrm{O}_{4} \mathrm{~S}^{+}$are characterized by a gain of 56 mass units compared to methisosildenafil, thus indicating the presence of two additional ethyl groups. Because the HRMS/MS spectrum of compound $\mathbf{2}$ only shows product ions corresponding to methisosildenafil (m/z 489) and its characteristic fragment ions (m/z 432, 377, $311,299,283$ ) as well as those of dimethyl-N-ethylpiperazine (Fig. 4B), it is therefore a methisosildenafil derivative with an ethyl group on the nitrogen atom of the piperazine ring (MSildEt ${ }^{\mathrm{N} 26}$ ). MS/MS spectra of compounds 3-7 show (i) product ions corresponding to methisosildenafil and its fragment ions cited above, (ii) those of dimethyl or dimethyl-N-ethyl piperazine moiety, and (iii) additional peaks at m/z 460, 405, 339 (340 for compound 3) and 327, i.e. 28 mass units greater than those at $\mathrm{m} / \mathrm{z} 432,377,311$ and 299, thus demonstrating that they all have an ethyl group located on the pyrazolopyrimidine part (Fig. 4B). As only tiny peaks at m/z 141, 127 and 72 are detected, it can be considered that compounds 3 and $\mathbf{4}$ do not have the ethyl group on the piperazine ring and therefore have it elsewhere, i.e. on the pyrazolopyrimidine skeleton. Compounds 5 and $\mathbf{7}$ have two ethyl groups, one on the piperazine moiety and the other on the pyrazolopyrimidine skeleton. Although its molecular mass is in agreement with the presence of only one additional ethyl group compared to methisosildenafil, the fragmentation of compound $\mathbf{6}$ is surprising because it shows the characteristic signals of ethyl groups on the piperazine ring ( $\mathrm{m} / \mathrm{z} 141,127$ and 72, although less intense than for $\mathbf{2}, \mathbf{5}$ and 7 for which the presence of the ethyl group on the piperazine ring is well established), and on the pyrazolopyrimidine skeleton (m/z 460, 405, 339 and 327). A possible explanation of these observations is proposed below. The MS/MS spectrum of compound 11 shows major product ions at $\mathrm{m} / \mathrm{z} 327,311,299$ and 283, and less abundant peaks characteristic of the dimethyl-N-ethyl piperazine fragmentation at m/z 141, 127, 100, 98, 72 and 71 (Fig. 4C and 4D). The ions at $\mathrm{m} / \mathrm{z} 299$ and 283 result from the loss of a $\mathrm{C}_{2} \mathrm{H}_{4}$ moiety from ions at $\mathrm{m} / \mathrm{z} 327$ and 311, respectively. If ions at $\mathrm{m} / \mathrm{z} 311,299$ and 283 are well-known fragments of 
methisosildenafil, the ion at $\mathrm{m} / \mathrm{z} 327$ is only observed with compounds $\mathbf{3 - 7}$ for which it was unambiguously demonstrated (except for compound 6) that the pyrazolopyrimidine skeleton bears an ethyl group. Compound $\mathbf{1 1}$ has thus two ethyl groups, one on the piperazine ring and the second on the pyrazolopyrimidine skeleton, which implies that its benzene ring is not substituted by an ethoxy group but by a hydroxyl group. Moreover, the absence of the ion at $\mathrm{m} / \mathrm{z} 489\left([\mathrm{M}+\mathrm{H}]^{+}\right.$of methisosildenafil $)$in the MS/MS spectrum, in contrast to what is observed with compounds 2-7, confirms that the structure of compound $\mathbf{1 1}$ does not derive from that of methisosildenafil.

Compound 10 with the same $[\mathrm{M}+\mathrm{H}]^{+}$molecular ion than methisosildenafil at $\mathrm{m} / \mathrm{z}$ 489.2292 has the same fragments ions as compound $\mathbf{1 1}$ except that the piperazine product ions are those of a dimethylpiperazine entity. Therefore, it is most likely a methisosildenafil derivative with an ethyl group on the pyrazolopyrimidine ring and an $\mathrm{OH}$ substituent on the benzene ring. The $[\mathrm{M}+\mathrm{H}]^{+}$molecular ion at $\mathrm{m} / \mathrm{z} 461.1973$ of compound $\mathbf{8}$, corresponding to the molecular formula $\mathrm{C}_{21} \mathrm{H}_{29} \mathrm{~N}_{6} \mathrm{O}_{4} \mathrm{~S}^{+}$, is 28 mass units lower than that of methisosildenafil $\left(\mathrm{C}_{23} \mathrm{H}_{33} \mathrm{~N}_{6} \mathrm{O}_{4} \mathrm{~S}^{+}\right)$. Its MS/MS spectrum shows prominent fragment ions at $\mathrm{m} / \mathrm{z} 347,299$ and 283 , and all the characteristic product ions of the dimethylpiperazine ring. The loss of this piperazine entity produces the fragment at $\mathrm{m} / \mathrm{z} 347$ and the further loss of $\mathrm{SO}_{2}$ leads to the ion at $\mathrm{m} / \mathrm{z} 283$. As no fragment ions correspond to the loss of an ethyl group, it can be concluded that compound 2938 is a methisosildenafil derivative with an $\mathrm{OH}$ instead of an ethoxy group on the benzene ring 294 (MSildOH). Compound 9 displays the same molecular formula $\left(\mathrm{C}_{23} \mathrm{H}_{33} \mathrm{~N}_{6} \mathrm{O}_{4} \mathrm{~S}^{+} ;[\mathrm{M}+\mathrm{H}]^{+}\right.$ 295 489.2292) than methisosildenafil, the same fragment ions at m/z 347, 299 and 283 than 296 compound 8, and the characteristic product ions of the dimethyl-N-ethylpiperazine moiety. It 297 can therefore be stated that it is a methisosildenafil derivative with the ethoxy group on the 298 benzene cycle replaced by an $\mathrm{OH}$, and a dimethyl-N-ethylpiperazine entity (MSildOHEt $\left.{ }^{\mathrm{N} 26}\right)$. 
The molecular ions $[\mathrm{M}+\mathrm{H}]^{+}$of compounds $13(\mathrm{~m} / \mathrm{z} 503)$ and $14(\mathrm{~m} / \mathrm{z} 447)$ are

respectively 28 mass units higher and lower in comparison to that of sildenafil (12) at m/z 475 . The MS/MS spectra of the two ions show the presence of N-methylpiperazine product ions $(\mathrm{m} / \mathrm{z}$ 163, 100, 99, 70 and 58). This is a good indication that compound $\mathbf{1 3}$ bears an additional ethyl group on the sildenafil skeleton and shows that compound $\mathbf{1 4}$ is a sildenafil derivative whose ethoxy group on the benzene ring is replaced by a hydroxyl group ( $\mathrm{SildOH})$.

It should be noted that the ion at $\mathrm{m} / \mathrm{z} 299$ is much more intense in the MS/MS spectra of compounds with the benzene ring substituted by a hydroxyl (8-11 and 14) rather than by an ethoxy group (compare the spectrum from 11 to all other spectra presented in Fig. 4A), this observation being able to be considered as a good indication of the presence of a hydroxyl group on the benzene ring. Indeed, the ion at $\mathrm{m} / \mathrm{z} 299$ results from a well described fragmentation mechanism of sulfonamides involving a rearrangement of the $\mathrm{SO}_{2}$ group resulting in the loss of SO [15]. But if the fragmentation of the ion at m/z 347 of MSildOH (8), $\operatorname{MSildOHEt}^{\mathrm{N} 26}(\mathbf{9})$ or

SildOH (14) leads directly by this way to the ion at $\mathrm{m} / \mathrm{z} 299$, that of the ion at $\mathrm{m} / \mathrm{z} 377$ of methisosildenafil (1) or sildenafil (12) for example, requires a subsequent loss of $\mathrm{C}_{2} \mathrm{H}_{6}$ for the formation of the ion at $\mathrm{m} / \mathrm{z} 299$ [16] (Fig. 4B and 4C). The same is true for the ion at $\mathrm{m} / \mathrm{z} 327$ (299 + ethyl) which is more intense for compounds $\mathbf{1 0}$ and $\mathbf{1 1}$ than for compounds 3-7 (compare the spectrum of $\mathbf{1 1}$ with the spectrum of $\mathbf{4}$ in Fig. 4A).

Only a low amount of the mixture of compounds $\mathbf{1 5}$ and $\mathbf{1 6}$ was obtained after the various steps of purification and our attempts to separate them were unfruitful. The MS spectrum of the mixture shows two $[\mathrm{M}+\mathrm{H}]^{+}$peaks, one very intense at $\mathrm{m} / \mathrm{z} 313.1663$ (compound 15) and a second much less intense at $\mathrm{m} / \mathrm{z} 341.1980$ (compound 16), corresponding respectively to molecular formulae $\mathrm{C}_{17} \mathrm{H}_{21} \mathrm{~N}_{4} \mathrm{O}_{2}{ }^{+}$and $\mathrm{C}_{19} \mathrm{H}_{25} \mathrm{~N}_{4} \mathrm{O}_{2}{ }^{+}$. The MS/MS spectrum of the parent ion at $\mathrm{m} / \mathrm{z} 341$ generates characteristic peaks of the fragmentation of the pyrazolopyrimidine skeleton of sildenafil derivatives at $\mathrm{m} / \mathrm{z} 313$ and $285\left(\mathrm{C}_{15} \mathrm{H}_{17} \mathrm{~N}_{4} \mathrm{O}_{2}{ }^{+}\right)$involving two successive 
losses of an ethyl group, whereas the MS/MS of the parent ion at m/z 313 produces a fragment ion at $\mathrm{m} / \mathrm{z} 285$ corresponding to the loss of only one ethyl group (Fig. 4B). Moreover, these two compounds do not have any piperazine or other amine entity (see above). All these findings are in accordance with a sildenafil-type structure in which the piperazine ring and the sulfonyl group are removed. Compound 15 is thus desulfosildenafil (DeSild) and compound 16, DeSild with an additional ethyl group on the pyrazolopyrimidine skeleton.

Table 4 reports the measured accurate masses of the parent and fragment ions in negative ESI mode. Two characteristic ESI- MS/MS spectra together with the structure of fragment ions are illustrated in Fig. S1. First, it can be noticed that compounds 3-7 and $\mathbf{1 3}$ are not ionized. The fragmentation of $[\mathrm{M}-\mathrm{H}]^{-}$molecular ions of methisosildenafil (1) and sildenafil (12) at m/z 487 and 473 produces ions respectively at 459 and 445 (loss of $\mathrm{C}_{2} \mathrm{H}_{4}$ ), 310 (loss of the piperazine- $\mathrm{SO}_{2}$ moiety) and 282 (successive loss of these two entities). This sequential fragmentation pathway involves the neutral loss of ethylene from the ethoxyphenyl substituent and the homolytic cleavage of the $\mathrm{C}_{\text {phenyl- }} \mathrm{S}$ bond already reported for sildenafil or vardenafil and their derivatives [17]. Compound $2\left(\mathrm{MSildEt}^{\mathrm{N} 26}\right)$ follows exactly the same fragmentation process confirming that the additional ethyl group compared to methisosildenafil is well located on the piperazine ring (Fig. S1). In contrast, compounds 8, 9 and 14 only show the loss of a piperazine- $\mathrm{SO}_{2}$ entity, which suggests that the ethoxy substituent on the benzene ring is replaced by an $\mathrm{OH}$ group. Thus, from the values of the molecular ion and of the eliminated piperazine- $\mathrm{SO}_{2}$ group, it can be concluded that (i) compound $\mathbf{8}$ which undergoes the loss of a dimethylpiperazine-SO $\mathrm{SO}_{2}$ entity is methisosildenafil with a hydroxyl substituent instead of an ethoxy on the benzene ring (MSildOH), (ii) compound 9 with the loss of a dimethyl-Nethylpiperazine- $\mathrm{SO}_{2}$ moiety is $\mathrm{MSildOH}$ with an additional ethyl group on the piperazine ring $\left(\mathrm{MSildOHEt}^{\mathrm{N} 26}\right)$, and (iii) compound $\mathbf{1 4}$ with the loss of a methylpiperazine- $\mathrm{SO}_{2}$ is sildenafil with an $\mathrm{OH}$ instead of an ethoxy group on the benzene cycle (SildOH). MS/MS of the molecular 
ions $[\mathrm{M}-\mathrm{H}]^{-}$of all the compounds, except 15, generate a small peak at $\mathrm{m} / \mathrm{z} 298$ due to the loss

350 of their piperazine-SO moiety (compounds 8-11 and 14) and an additional loss of $\mathrm{C}_{2} \mathrm{H}_{4}$ (compounds 1, 2 and 12) (Fig. S1B and S1C) and corresponding to the molecular formula $\mathrm{C}_{15} \mathrm{H}_{14} \mathrm{~N}_{4} \mathrm{O}_{3}{ }^{-}$whose structure might be similar to that of the ion at $\mathrm{m} / \mathrm{z} 299$ observed in $\mathrm{ESI}^{+}$ mode (Fig. 4B and 4C). This is a good indication of the replacement of the ethoxy group on the benzene ring (present in compounds $\mathbf{1}, \mathbf{2}$ and 12) by a hydroxyl group in compounds 8-11 and 14. Moreover, the detection of an ion at $\mathrm{m} / \mathrm{z} 326$ (molecular formula $\mathrm{C}_{17} \mathrm{H}_{18} \mathrm{~N}_{4} \mathrm{O}_{3}{ }^{-}$with a structure similar to that of the ion at m/z 327 observed in $\mathrm{ESI}^{+}$mode (Fig. 4B and 4C)) for compounds $\mathbf{1 0}$ and 11, indicates that they bear an ethyl group located on the pyrazolopyrimidine skeleton. In the MS spectrum of the mixture of compounds 15 and 16, only the molecular ion $[\mathrm{M}-\mathrm{H}]^{-}$at $\mathrm{m} / \mathrm{z} 311$ of compound 15 is detected and its MS/MS fragmentation confirms the presence of an ethoxy group (loss of $\mathrm{C}_{2} \mathrm{H}_{4}$ ) and the absence of piperazine or other amine entity as well as of the $\mathrm{SO}_{2}$ group.

In summary, the careful analysis of the data obtained by HRMS and HRMS/MS allows the unambiguous identification of five compounds $\left(2\left(\mathrm{MSildEt}^{\mathrm{N} 26}\right), 8(\mathrm{MSildOH}), \mathbf{9}\right.$ $\left(\mathrm{MSildOHEt}^{\mathrm{N} 26}\right), 14(\mathrm{SildOH})$ and 15 (DeSild)). On the other hand, for the other eight compounds $(3-5,7,10,11,13$ and 16), the MS data only show that they bear an ethyl group on the pyrazolopyrimidine moiety. Compound 6 cannot be identified because its MS data lead to conflicting conclusions. An NMR study was therefore required to determine the exact structure of all these compounds and to confirm and validate the structures proposed from the MS data.

\subsection{2. ${ }^{1} \mathrm{H}$ and ${ }^{13} \mathrm{C}$ NMR analysis}

The ${ }^{1} \mathrm{H}$ and ${ }^{13} \mathrm{C}$ NMR data of all the isolated compounds are reported in Table 5. The assignments of the resonances were performed thanks to 1D and 2D (COSY, HSQC, HMBC, NOESY) NMR experiments. 
${ }^{1}$ H NMR spectra (Fig. 5) of compounds 2-11 all display, like methisosildenafil (1), the characteristic doublet (two for compounds $\mathbf{3}, \mathbf{4}$ and 5) of the methyl groups on the piperazine ring $\left(\mathrm{CH}_{3} 29\right.$ and 30) between 0.99 and $1.26 \mathrm{ppm}$, thus allowing to assume they are methisosildenafil derivatives. In the same way, ${ }^{1} \mathrm{H}$ NMR spectra of compounds $\mathbf{1 3}$ and $\mathbf{1 4}$ exhibit, like sildenafil (12), at $\delta \approx 2.2 \mathrm{ppm}$ the characteristic singlet of the methyl group $\left(\mathrm{CH}_{3}\right.$ 29) linked to the N26 of the piperazine ring, thus indicating that they are sildenafil derivatives. Compared to ${ }^{1} \mathrm{H}$ NMR spectra of methisosildenafil or sildenafil, those of compounds $2, \mathbf{3 , 4}, \mathbf{6}$ and $\mathbf{1 3}$ reveal the presence of additional characteristic resonances of one ethyl group [a triplet accounting for 3 protons (H32) and a quadruplet (or two quadruplet doublets (qd)) for 2 protons (H31)], or two ethyl groups for compounds 5 and 7 (H31/32, and H33/34). It is highly likely that these ethyl groups are positioned on the main nucleophilic sites of methisosildenafil or sildenafil derivatives, namely the oxygen and nitrogen atoms of the pyrazolo[4,3-d]pyrimidine moiety and the $\mathrm{NH}$ group of the piperazine moiety. The ${ }^{1} \mathrm{H}$ and ${ }^{13} \mathrm{C}$ NMR characteristics of the $\mathrm{CH}_{2}$ of the ethyl group should thus give a good indication of its location on the methisosildenafil or sildenafil skeleton. For compound 2, the H31 quadruplet at 2.84 ppm shows an HMBC correlation with the $\mathrm{C} 25 / \mathrm{C} 27(54.9 \mathrm{ppm}$ ) of the piperazine ring (Fig. 6A), thus confirming that $\mathrm{C}_{2} \mathrm{H}_{5}$ is positioned on the $\mathrm{N} 26$ of the piperazine moiety (MSildEt ${ }^{\mathrm{N} 26}$ ). For compound $\mathbf{3}$, the two H31 protons appear as two qd at 4.14 and $3.96 \mathrm{ppm}$. Although close to the quadruplet of the $\mathrm{CH}_{2}(\mathrm{H} 20)$ of the ethoxy group on the benzene ring $(4.23 \mathrm{ppm})$, the two $\mathrm{CH}_{2}$ entities can easily be distinguished by their ${ }^{13} \mathrm{C}$ resonances at 47.8 (C31) and $68.1 \mathrm{ppm}(\mathrm{C} 20)$. The HMBC correlations between the qd and C5 and C9 (158.4 and $130.5 \mathrm{ppm}$ ) demonstrate that the N4 of the pyrazolopyrimidine moiety bears the ethyl group (Fig. 6B) $\left(\mathrm{MSildEt}^{\mathrm{N} 4}\right)$. For compound 4, the $\mathrm{CH}_{2}(\mathrm{H} 31)$ resonances show the same pattern than for compound $\mathbf{3}$ with two qd at 4.12 and $3.62 \mathrm{ppm}$ for the protons and a ${ }^{13} \mathrm{C}$ signal at $43.5 \mathrm{ppm}$. The $\mathrm{HMBC}$ correlations between $\mathrm{CH}_{2}$ (H31) and C5 (153.1 ppm) and C7 (157.1 ppm) are the proof of the presence of the ethyl group 
on the N6 of the pyrazolopyrimidine moiety (Fig. 6C) $\left(\mathrm{MSildEt}^{\mathrm{N} 6}\right)$. For compound 6 , the strong ${ }^{1} \mathrm{H}$ and ${ }^{13} \mathrm{C}$ deshielding of the $\mathrm{CH}_{2}(\mathrm{H} 31 / \mathrm{C} 31)$ signals, respectively at 4.65 and $66.4 \mathrm{ppm}$, of the additional ethyl group is characteristic of an O-ethyl entity which can be distinguished from the $\mathrm{CH}_{2}$ of the ethoxy group on the benzene ring (H20/C20) thanks to the ${ }^{1} \mathrm{H}$ NMR $\mathrm{H} 20 \delta$ at 4.21 ppm, the ${ }^{13} \mathrm{C}$ NMR C20 $\delta$ at $67.9 \mathrm{ppm}$ being non discriminant. The HMBC correlation between the $\mathrm{CH}_{2}(\mathrm{H} 31)$ and $\mathrm{C} 7(159.1 \mathrm{ppm})$ confirms that the ethyl group is linked to the $\mathrm{O} 7$ of the pyrazolopyrimidine entity (Fig. 6D) $\left(\mathrm{MSildEt}^{\mathrm{O}}{ }^{\mathrm{T}}\right)$. Hence, a N26-ethyl substitution leads to ${ }^{1} \mathrm{H}$ and ${ }^{13} \mathrm{C} \mathrm{CH}_{2}$ resonances respectively at $\approx 2.8$ and $42.5 \mathrm{ppm}$. An N-ethyl location on the pyrazolopyrimidine entity gives rise to two distinct ${ }^{1} \mathrm{H}$ qd signals, meaning that the two $\mathrm{CH}_{2}$ protons are inequivalent (discussed below). One of the two qd and the ${ }^{13} \mathrm{C}$ resonance are more deshielded when the substitution is on N4 compared to N6 $\left(\Delta \delta \approx+0.33\right.$ ppm for ${ }^{1} \mathrm{H}$ and +4.3 ppm for ${ }^{13} \mathrm{C}$ ). An O7-ethyl substitution leads to ${ }^{1} \mathrm{H}$ and ${ }^{13} \mathrm{C} \mathrm{CH}_{2}$ signals respectively at $\approx 4.7 \mathrm{pm}$ and $66.5 \mathrm{ppm}$. From these considerations on the ${ }^{1} \mathrm{H}$ and ${ }^{13} \mathrm{C}$ chemical shifts, it is possible to conclude that compound $\mathbf{1 3}$ is sildenafil substituted by an ethyl group on N6 $\left(\operatorname{SildEt}^{\mathrm{N} 6}\right)$. Regarding the two additional ethyl groups in compounds $\mathbf{5}$ and 7, one is located on the N26 of the piperazine cycle and the other is either on the N6 (5) $\left(\mathrm{MSildEt}^{\mathrm{N} 6} \mathrm{Et}^{\mathrm{N} 26}\right)$ or on the $\mathrm{O} 7(\mathbf{7})$ of the pyrazolopyrimidine skeleton $\left(\mathrm{MSildEt}^{\mathrm{O} 7} \mathrm{Et}^{\mathrm{N} 26}\right)$. All these structures were unambiguously confirmed by HMBC correlations.

Ethyl signals characteristic of the $\mathrm{O}-\mathrm{CH}_{2}(20)-\mathrm{CH}_{3}(21)$ group are undetected for 418 compounds 8-11 and 14, demonstrating the replacement of the ethoxy group on the C19 of the 419 benzene ring by a hydroxyl group as shown by the $\mathrm{C} 19 \delta(166-176 \mathrm{ppm})$ deshielded with respect 420 to the $\delta$ of the $\mathrm{C} 19$ bearing an ethoxy group (163 ppm). This structural modification is also 421 confirmed by a noticeable change in the $\delta$ of the neighboring ${ }^{1} \mathrm{H}$ and ${ }^{13} \mathrm{C}$ resonances compared 422 to those of methisosildenafil (1) or sildenafil (12) (shielding for H17 and H18, and deshielding 423 for H15, C5, C18 and C19). Moreover, as no other N- or O-ethyl resonances are detected in 
compounds 8 and 14, they can be respectively identified as C19-hydroxymethisosildenafil (MSildOH) and C19-hydroxysildenafil (SildOH). Compounds 9-11, all methisosildenafil derivatives, display respectively one ethyl group characteristic of an $\mathrm{O} 7$ substitution, two ethyl groups characteristic of $\mathrm{O} 7$ and N26 substitutions, and one ethyl group characteristic of an N26 substitution. Therefore, they are identified as MeSildOH bearing O7- (10) $\left(\mathrm{MSildOHEt}^{\mathrm{O} 7}\right)$, O7and N26- (11) (MSildOHEt $\left.{ }^{\mathrm{O}} \mathrm{Et}^{\mathrm{N} 26}\right)$, and N26- (9) $\left(\mathrm{MSildOHEt}^{\mathrm{N} 26}\right)$ ethyl groups, all the structures being confirmed by HMBC correlations. The NMR spectra of the mixture of compounds 15 and 16, compared to those of methisosildenafil or sildenafil, show for each compound the disappearance of the ${ }^{1} \mathrm{H}$ and ${ }^{13} \mathrm{C}$ signals of the piperazine ring and the appearance of an additional ${ }^{1} \mathrm{H}$ triplet doublet at $\approx 7.1 \mathrm{ppm}$, corresponding to the presence of a hydrogen atom on the $\mathrm{C} 16$ of the benzene ring instead of a sulfonamide group. Therefore, the two compounds are desulfosildenafil derivatives (sildenafil without the piperazine- $\mathrm{SO}_{2}$ moiety). Moreover, the minor compound 16 exhibits additional characteristic ${ }^{1} \mathrm{H}$ and ${ }^{13} \mathrm{C}$ signals of an ethyl group located on the N6 of the pyrazolopyrimidine skeleton. Compound $\mathbf{1 6}$ is thus identified as N6-ethyl desulfosildenafil (DeSildEt ${ }^{\mathrm{N} 6}$ ) and compound 15, predominant in the mixture, as desulfosildenafil (DeSild). The structures of all the compounds purified from the dietary supplement are illustrated in Fig. 7.

The structure of the compounds having been determined, it is possible to make a few comments on the NMR spectra, in particular on some of the proton inequivalences observed. Both protons of $\mathrm{CH}_{2} 11$ and $\mathrm{CH}_{2} 12$ of compound 3 are inequivalent leading respectively to two very close $(\Delta v=1.2 \mathrm{~Hz})$ apparent triplets for $\mathrm{CH}_{2} 11$ and apparent sextets for $\mathrm{CH}_{2} 12$. This anisochrony results from the steric hindrance of the close N4-ethyl chain as shown by the nOe interactions between both $\mathrm{CH}_{2} 11$ and $\mathrm{CH}_{2} 12$ and the two protons of $\mathrm{CH}_{2} 31$, the interaction with $\mathrm{H} 31$ at 4.14 ppm being stronger than with $\mathrm{H} 31$ at 3.96 ppm (Fig. S2A). Confronting NMR results to calculated privileged conformers confirms that each proton of $\mathrm{CH}_{2} 11$ or $\mathrm{CH}_{2} 12$ is 
closer to one of the two protons 31 than to the other (Fig. S3). Moreover, an inequivalence of the two protons of $\mathrm{CH}_{2} 31$ is observed in the ${ }^{1} \mathrm{H}$ NMR spectra of all compounds that bear an $\mathrm{N}-$ ethyl group on the pyrazolopyrimidine skeleton, i.e. $\mathbf{3}, \mathbf{4}, \mathbf{5}, \mathbf{1 3}$ and $\mathbf{1 6}$. The stronger nOe interaction between one of the two H31 ( $\approx 4.15 \mathrm{ppm})$ and aromatic H15 $(\approx 7.8 \mathrm{ppm}$ for $\mathbf{3}, \mathbf{4}, \mathbf{5}$, and 13, and $7.37 \mathrm{ppm}$ for 16) explains this finding which is confirmed by the calculated distances in the privileged conformations (Fig. S2B and S3). The shielding of the H15 signal that can be noticed for these compounds $(\Delta \delta \approx-0.44$ ppm relative to methisosildenafil $\mathrm{H} 15 \delta$ for $\mathbf{3}, \mathbf{4}$, and $\mathbf{5}$, and -0.42 and -0.84 ppm compared to sildenafil H15 $\delta$ for $\mathbf{1 3}$ and 16) (Fig. 5) could also be related to these spatial interactions.

\subsubsection{Conclusive remarks}

In summary, the NMR study confirms the structures of compounds $2, \mathbf{8 , 9}, 14$ and 15 already established from MS data and makes it possible to unambiguously determine the position of the ethyl group on the $\mathrm{N}$ and/or $\mathrm{O}$ nucleophilic sites of the pyrazolo[4,3d]pyrimidine backbone for compounds 3-7, 10, 11, 13 and 16, which MS does not allow. In addition, MS does not make it possible to know whether the additional ethyl group compared to methisosildenafil in compound $\mathbf{6}$ is located on the piperazine or pyrazolopyrimidine ring. Indeed, the fragmentation of its molecular ion $[\mathrm{M}+\mathrm{H}]^{+}$produces ions characteristic of the two locations, while NMR clearly shows that it is methisosildenafil substituted by an ethyl group on the $\mathrm{O} 7$. The presence of an ethyl group on the $\mathrm{N} 26$ of the piperazine as stated by the MS/MS fragmentation of the molecular ion $[\mathrm{M}+\mathrm{H}]^{+}$can be explained by an intramolecular ethyl transfer 470 from the $\mathrm{O} 7$ atom of the pyrazolopyrimidine moiety to the $\mathrm{N} 26$ atom of the piperazine. Indeed, 471 the methyl intramolecular transfer from the piperazine nitrogen atom to the thiocarbonyl sulfur 472 atom of thiosildenafil derivatives is a dominant fragmentation pathway, while the methyl migration to the carbonyl oxygen atom of sildenafil may occur but to a very low extent [18]. 
Consequently, it can be postulated that the ethyl group on the carbonyl atom of the pyrazolopyrimidine skeleton of compound $\mathbf{6}$ can be partially transferred to the N26 of the piperazine group because when it is thus positioned, it should not migrate significantly on the carbonyl oxygen atom of methisosildenafil.

It should also be noted that identical profiles of UV spectra correspond well to molecular structures with identical chromophores (Fig. 3). The UV profile of compound 2 is similar to those of methisosildenafil (1) and sildenafil (12), indicating that, as expected, an Nethyl substitution on the piperazine ring does not alter the chromophore. Compounds $\mathbf{8}, \mathbf{9}$ and 14 with identical UV spectra are methisosildenafil or sildenafil with a hydroxyl group instead of an ethoxy group on the $\mathrm{C} 19$ of the benzene ring. Compared to methisosildenafil or sildenafil UV spectra, this replacement induces a bathochromic effect of $\approx 8 \mathrm{~nm}$ for the band at $\approx 225 \mathrm{~nm}$, whereas the band at $\approx 295 \mathrm{~nm}$ gives rise to a vibrational fine structure between 270 and $350 \mathrm{~nm}$. Compounds $\mathbf{4 , 5}$ and 13 with very similar UV spectra are N6-ethyl substituted methisosildenafil or sildenafil. The identical UV spectra of compounds $\mathbf{6}$ and $\mathbf{7}$ in one hand and $\mathbf{1 0}$ and $\mathbf{1 1}$ on the other hand are respectively characteristic of O7-ethyl substituted methisosildenafil and O7ethyl methisosildenafil with $\mathrm{OH}$ instead of $\mathrm{OC}_{2} \mathrm{H}_{5}$ on the benzene ring, this change leading to bathochromic effects of $\approx 4$ and $22 \mathrm{~nm}$ for the two main bands observed. Finally, the UV 491 spectrum of compound 3, a N4-ethyl substituted methisosildenafil, shows the same $\lambda_{\max }$ than 492 the O7-ethyl substituted methisosildenafil derivatives (compounds 6 and 7) but with a different 493 profile, the most intense band of compound 3 at $205.7 \mathrm{~nm}$ appearing as a shoulder for 494 compounds 6 and 7 at $210 \mathrm{~nm}$. 
The quantities of methisosildenafil (1), sildenafil (12), and compounds (8) (MSildOH)

and (4) (MSildEt $\left.{ }^{\mathrm{N} 6}\right)$ were easily measured from the signal areas of their aromatic protons (Fig. S4) in the conditions described in reference [1]. They account respectively for 38, 20, 5 and 3 mg per capsule, i.e. $54 \%, 32 \%, 7 \%$ and $4 \%$ of the total contaminants. The amounts of the other products could only be estimated due to the very low intensity of their ${ }^{1} \mathrm{H}$ NMR signals (except for $\mathrm{MSildEt}^{\mathrm{N} 26}$ (2) which has no distinctive resonances); they range from 0.01 to $0.50 \mathrm{mg}$ per capsule and represent $\approx 3 \%$ of the total contaminants, i.e. $\approx 2 \mathrm{mg}$ per capsule. So, each capsule contains $\approx 68 \mathrm{mg}$ of methisosildenafil- and sildenafil-related compounds, i.e. between the recommended $(50 \mathrm{mg})$ and the maximum $(100 \mathrm{mg})$ daily dose of sildenafil in patients.

\section{Discussion}

This study deals with the purification and characterization of 16 sildenafil derivatives present in a dietary supplement intended to be commercialized for improving sexual performance and alleged to be " $100 \%$ natural". Two adulterants are found in large quantities: sildenafil, the lead PDE-5i drug, and methisosildenafil, a sildenafil analogue that has never received a marketing authorization as a medicine. All other molecules possess the scaffold of sildenafil, i.e. the 5-phenyl-pyrazolo[4,3-d]pyrimidine moiety, and twelve out of fourteen bear a sulfonyl group linked to a piperazine ring (Fig. 7). Their structures mainly differ by the presence or absence of an ethyl group $\mathrm{N}$ - or $\mathrm{O}$ - linked to either the pyrazolopyrimidine or piperazine moiety. Besides sildenafil commonly found in adulterated erectile dietary supplements, five other compounds have already been described in the literature. Methisosildenafil was first reported in 2007 as an adulterant of an herbal dietary supplement [19] and MSildEt ${ }^{\mathrm{N} 26}$ (2) in 2018 in health foods analyzed by UHPLC coupled with Q-TOF-MS [20]. DeSild (15), also named imidazosagatriazinone, is known as sildenafil lactam impurity and is commercially available (CAS number 139756-21-1). However, it has never been reported 
523 in a dietary supplement. SildOH (14) is the Sildenafil Impurity C in the European

Pharmacopoeia and is also commercially available (CAS number 139755-91-2). SildEt ${ }^{\mathrm{N} 6}$ (13) was described as an impurity formed during the synthesis of sildenafil but was not thoroughly characterized [21]. The 10 other chemicals identified in this study have to our knowledge never been described in the literature.

The presence of numerous sildenafil derivatives in the dietary supplement analyzed is most probably due to its intentional adulteration with sildenafil and methisosildenafil. It can be hypothesized that the minor compounds detected are either degradation impurities ensuing from the effect of humidity and/or light during storage for instance, or by-products of different reaction steps during the synthesis of these two PDE-5i that have not been properly eliminated during the purification procedure. The second hypothesis is preferred because neither the hydrolysis nor the photodegradation of sildenafil and analogues leads to the kind of structures identified in the present study [19,22]. In order to correlate the chemical structures of the minor components identified in the dietary supplement with the different synthetic routes to sildenafil and methisosildenafil, we thus thoroughly analyzed the reaction sequences towards both APIs from the literature $[23,24]$. The preparation of sildenafil and methisosildenafil follows the same overall approach, except for the piperazine used, that is either $\mathrm{N}$-methylated or 2,6dimethylated, respectively. Two main types of synthetic routes can be distinguished, the firstgeneration ones relying on the late introduction of the sulfonamide moiety and the more recent ones based on an early sulfonylation step.

According to the chemical structures assigned to the minor compounds detected, one can subdivide the discussion into two main categories, illustrated for sildenafil in Fig. 8. The 545 first one deals with compounds $\mathbf{1 5}$ and 16, lacking the sulfonamide group. The second one 546 comprises all the other compounds that display either no ethyl radical (compounds 8 and 14) or 547 variable O- or N-ethylation patterns $(2-7,9-11,13)$. It has to be recalled that, in the case of 
methisosildenafil, the presence of the free piperazine nitrogen offers an additional opportunity for unwanted ethylation.

The presence of unsulfonylated compounds can be explained by at least two principal reaction sequences. The initial medicinal chemistry route described for sildenafil involves a late sulfonylation step [25], which is known to be reversible and thus potentially leads to desulfonylated by-products [26] (Fig. 8, pathway A). As an alternative, a late Friedel-Crafts process with sulfamoyl choride in the presence of $\mathrm{AlCl}_{3}$ was proposed to introduce the sulfonamide moiety (Fig. 8, pathway B) [23,25]. This procedure was described with only $45 \%$ yield, potentially leaving a large amount of starting reagent in the reaction medium. A neglected purification step would thus explain the presence of unsulfonylated by-products in both cases.

The occurrence of variable $\mathrm{O}$ - or N-ethylation patterns, corresponding to the second class of by-products, can be correlated with at least three different synthetic pathways. In the first possible pathway, the late sulfonylation step requires the para-chlorosulfonylation of an ethoxyphenyl intermediate with chlorosulfonic acid (Fig. 8, pathway C). The scaling-up of this reaction was reported to be troublesome because of the increased quench time of the excess of chlorosulfonic acid that leads to prolonged exposure to a large amount of hydrochloric acid [23]. The possible hydrolysis of the O-ethoxy group would explain the presence of a free phenol in compounds $\mathbf{8}, \mathbf{1 0}$ and $\mathbf{1 4}$, as previously proposed in a study on synthetic impurities of sildenafil [27]. Such conditions could in turn result in the formation of ethyl chloride susceptible 567 to alkylate the electron-rich positions of the pyrimidinone core of the molecule. Alternatively, 568 the highly acidic medium could also potentially induce a direct intra- or intermolecular 569 nucleophilic transfer of the ethoxy radical. Yet, due to the absence of nucleophilicity of the 570 protonated methisosildenafil piperazine ring nitrogen, the formation of compounds $\mathbf{2}, \mathbf{5}, \mathbf{7}, 9$ 571 and $\mathbf{1 1}$ is unlikely under these acidic conditions. The observed random distribution of ethyl 572 radicals rather suggests side-products arising from neutral or basic reaction media. 
More recent synthetic pathways of sildenafil were reported involving an early introduction of the sulfonamide moiety so as to circumvent the problems associated with the late-stage transformation. Two distinct synthetic steps that share the use of basic conditions can be proposed in this case. The first one relies on a critical intramolecular cyclization reaction, using for instance $t$ - $\mathrm{BuOK}$ in $t-\mathrm{BuOH}$, to generate the pyrazolopyrimidone core of sildenafil (Fig. 8, pathway D). The ethoxy moiety present in the benzamide precursor was described to be doubly activated by the sulfonamide and amide groups, and thus prone to intra- or intermolecular nucleophilic substitution [23,24]. This transformation would lead to either the loss of the ethyl radical or its transfer onto the different nucleophilic sites of the molecule. Another synthetic pathway was then proposed to address this issue, in which the whole synthesis is run with a free phenol group and the $\mathrm{O}$-alkylation of the phenol is postponed after the cyclisation reaction [21] (Fig. 8, pathway E). Unless a very specific neutral decarboxylative alkylation of a carbonate intermediate was used, exposure to standard alkylating agents was described to lead to pyrimidinone O- or N-ethylation, along with partial phenol alkylation, eventually giving rise to a product distribution similar to that observed in the present study.

Overall, the analysis of the reported routes towards sildenafil and methisosildenafil indicates that all the minor compounds identified in the dietary supplement can be side-products of relevant synthetic steps. It was not possible to unambiguously decipher the synthetic sequence used, or even if there was only one. This clearly indicates that the synthesis processes used by the manufacturers do not meet the standard chemical purification requirements. A similar problematic of erectile dietary supplement containing synthetic impurities in minor amounts was previously reported in two articles by Schramek et al. In the first study [28], the dietary supplement contained dithiodesmethylcarbodenafil and three impurities coming from its synthetic pathway and in the second study [29], the herbal food supplement contained 14 chemicals ( 5 never described) bearing the basic structure of sildenafil that might be process- 
related impurities or by-products of PDE-5i analogues synthesis. So, in addition to the illegal 599 falsification of the food supplement by PDE-5i, our study shows once again that manufacturers

\section{Conclusion}

The "all-natural" dietary supplement for enhancing sexual performance investigated in this study contains a mixture of two major PDE-5i adulterants, sildenafil and methisosildenafil, intentionally added to increase its effect and fourteen minor compounds. All compounds were isolated thanks to the orthogonality of SFC and LC separations and their structures elucidated using UV spectroscopy, high resolution and tandem mass spectrometry and one- and twodimensional NMR. The minor contaminants come from poor purification procedures during the 
622 different steps of sildenafil and methisosildenafil synthesis and 10 of them have never been

\section{Conflicts of interest}

The authors declare that there are no conflicts of interest.

\section{Acknowledgements}

The authors wish to acknowledge Cristina Da Costa, Jérôme Marini and Antoine Pradines (Preparative Chromatography, EVOTEC, Toulouse) as well as the French National Agency for the Safety of Medicines and Health Products (Agence Nationale de Sécurité du Médicament et des produits de santé: ANSM) for financial support (grant AAP-2012-082, convention ANSM/UPSn॰2012S071).

\section{Appendix A. Supplementary data}

Supplementary material related to this article can be found, in the online version, at doi: 637 Figure S1. (A) HRMS/MS spectra in negative ESI mode of two methisosildenafil-related 638 compounds $(2,11)$ purified from the dietary supplement analyzed. The formulae shown 639 represent the molecules and not the ions. Proposed structures of fragment ions of (B) 640 compounds with an ethoxy group on the benzene ring, (C) compounds with a hydroxyl group 641 on the benzene ring.

642 Figure S2. Parts of 2D NOESY spectra showing the spatial correlations between $\mathrm{CH}_{2} 11,12$ 643 and $\mathrm{H} 31$ for compound 3 and between $\mathrm{H} 15$ and $\mathrm{CH}_{2} 31$ for compound 4.

644 Figure S3. Representation of a privileged conformation calculated for compound 3 and 645 interatomic distances between protons of interest. 
Figure S4. Part (6.7-8.9 ppm) of the ${ }^{1} \mathrm{H}$ NMR spectrum with ${ }^{13} \mathrm{C}$ GARP broadband decoupling of the dietary supplement recorded in $\mathrm{CD}_{3} \mathrm{CN} / \mathrm{D}_{2} \mathrm{O}(80: 20$, v/v) with attribution of the signals of the identified compounds.

\section{Captions for figures}

651 Figure 1. (A) SFC-UV chromatogram on BetaSil Diol-100 column (the collection windows are 652 indicated by the vertical dashed lines). (B) Preparative LC-UV chromatograms on C18 reverse 653 phase columns. All experimental conditions are reported in Table 1. The presence of 654 compounds annotated $12 *$ and $1 *$ in $\mathrm{W} 2$ and $\mathrm{W} 3$ fractions may be due to the high concentration 655 of compounds $\mathbf{1 2}$ and $\mathbf{1}$ in the $\mathrm{C} 2$ fraction.

656 Figure 2. ${ }^{1} \mathrm{H}$ NMR spectrum with ${ }^{13} \mathrm{C}$ GARP broadband decoupling of the dietary supplement 657 recorded in $\mathrm{CD}_{3} \mathrm{CN} / \mathrm{D}_{2} \mathrm{O}(80: 20, \mathrm{v} / \mathrm{v})$. (A), (B), (C) and (D) correspond to zoomed areas 658 highlighted by boxes on the full spectrum. The main signals of sildenafil (12) and 659 methisosildenafil (1) are shown.

660 Figure 3. UV spectra of methisosildenafil (MSild), sildenafil (Sild) and their related 661 compounds purified from the dietary supplement analyzed. Spectra were obtained from the 662 UHPLC analysis of the purified fractions.

663 Figure 4. (A) HRMS/MS spectra in positive ESI mode of methisosildenafil (MSild, 1), 664 sildenafil (Sild, 12) and related compounds (2, 4, 11 and 13) purified from the dietary 665 supplement analyzed. The formulae shown represent the molecules and not the ions. Proposed 666 structures of fragment ions of (B) compounds with an ethoxy group on the benzene ring, (C) 667 compounds with a hydroxyl group on the benzene ring, (D) piperazine entities.

668 Figure 5. ${ }^{1} \mathrm{H}$ NMR spectra of methisosildenafil (MSild), sildenafil (Sild), and related 669 compounds purified from the dietary supplement analyzed. Spectra were recorded in 
$\mathrm{CD}_{3} \mathrm{CN} / \mathrm{D}_{2} \mathrm{O}(80: 20, \mathrm{v} / \mathrm{v})$ except for compounds $\mathbf{9}$ and $\mathbf{1 4}$ whose solubilization required the subsequent addition of $5 \mu \mathrm{L}$ of $0.5 \mathrm{M} \mathrm{NaOD}$ in the NMR tube. Regions 6.7-9.0 ppm (A), 2.55.0 ppm (B), 1.6-2.6 ppm (C) and 0.7-1.6 ppm (D). The intensity scale is different for the different parts of the spectrum. For compounds $\mathbf{1 5}$ and $\mathbf{1 6}$ that could not be separated, the prime symbol (') is used to mark the protons of compound 16. HOD: residual protons in $\mathrm{D}_{2} \mathrm{O}$; $\mathrm{CD}_{2} \mathrm{HCN}$ : residual protons in $\mathrm{CD}_{3} \mathrm{CN} ; \mathrm{S}_{\mathrm{CD}_{2} \mathrm{HCN}}:{ }^{13} \mathrm{C}$ satellite signals of $\mathrm{CD}_{2} \mathrm{HCN}$; ax: axial protons; eq: equatorial protons; FA: fatty acids present in the dietary supplement; $\mathrm{MeOH}$ : methanol; Ac: residual acetate from the chromatographic mobile phase; *: unknown contaminants.

Figure 6. Parts of the ${ }^{1} \mathrm{H}^{13} \mathrm{C}$ HMBC spectra of compounds 2 (A), 3 (B), 4 (C) and 6 (D). Correlations between protons $\mathrm{H} 31$ and specific carbons indicating the position of the ethyl group in the structure are marked with dashed arrows. See Fig. 7 for chemical structures and numbering. $\mathrm{MeOH}$ : methanol; HOD: residual protons in $\mathrm{D}_{2} \mathrm{O}$.

Figure 7. Chemical structures of sildenafil, methisosildenafil and their analogues purified and characterized in this study. (a) CAS registry number; (b) compound already described in reference [20]; (c) compound already described in reference [21]; (d) known as Sildenafil European Pharmacopoeia impurity C; (e) known as imidazosagatriazinone.

687 Figure 8. Possible origin of the various impurities found in the food supplement analyzed, 688 according to the main routes of synthesis of sildenafil and methisosildenafil reported in the 689 literature [21,23-27]. Pip: N-methylpiperazine or 2,6-dimethylpiperazine.

692 [1] V. Gilard, S. Balayssac, A. Tinaugus, N. Martins, R. Martino, M. Malet-Martino, 693 Detection, identification and quantification by ${ }^{1} \mathrm{H}$ NMR of adulterants in 150 herbal dietary 
supplements marketed for improving sexual performance, J. Pharm. Biomed. Anal. 102 (2015) 476-493, https://doi.org/10.1016/j.jpba.2014.10.011

[2] T. Rocha, J.S. Amaral, M.B.P.P. Oliveira, Adulteration of dietary supplements by the illegal addition of synthetic rrugs: a review, Compr. Rev. Food Sci. Food Saf. 15 (2016) 43-62, https://doi.org/10.1111/1541-4337.12173

[3] K. Skalicka-Wozniak, M.I. Georgiev, I.E. Orhan, Adulteration of herbal sexual enhancers and slimmers: the wish for better sexual well-being and perfect body can be risky, Food Chem. Toxicol. 108 (2017) 355-364, https://doi.org/10.1016/j.fct.2016.06.018

[4] I. Zuntar, A. Krivohlavek, J. Kosic-Vuksic, D. Granato, D.B. Kovacevic, P. Putnik, Pharmacological and toxicological health risk of food (herbal) supplements adulterated with erectile dysfunction medications, Curr. Opin. Food Sci. 24 (2018) 9-15, https://doi.org/10.1016/i.cofs.2018.10.012

[5] M.H. Shin, M.K. Hong, W.S. Kim, Y.J. Lee, Y.C. Jeoung, Identification of a new analogue of sildenafil added illegally to a functional food marketed for penile erectile dysfunction, Food Addit. Contam. 20 (2003) 793-796, https://doi.org/10.1080/026520303 $\underline{1000121455}$

[6] C.L. Kee, X. Ge, V. Gilard, M. Malet-Martino, M.Y. Low, A review of synthetic phosphodiesterase type 5 inhibitors (PDE-5i) found as adulterants in dietary supplements, $\mathrm{J}$. Pharm. Biomed. Anal. 147 (2018) 250-277, https://doi.org/10.1016/j.jpba.2017.07.031

[7] J. Yun, K.J. Shin, J. Choi, K. Kwon, C.H. Jo, Identification and structural elucidation of a new sildenafil analogue, dithiopropylcarbodenafil, from a premixed powder intended as a dietary supplement, J. Chromatogr. B Analyt. Technol. Biomed. Life Sci. 1072 (2018) 273-281, https://doi.org/10.1016/j.jchromb.2017.11.029

[8] H-C. Lee, Y-L. Lin, Y-C. Huang, C-F. Tsai, D-Y. Wang, Identification of a new tadalafil analogue, N-3-hydroxypropylnortadalafil, in a supplement product, J. Pharm. Biomed. Anal. 158 (2018) 257-261, https://doi.org/10.1016/j.jpba.2018.05.049

[9] Y. Gu, Q. Hu, J. Sun, H. Yu, H. Pan, X. Zhao, S. Ji, Isolation and identification of a new sildenafil analogue, hydroxycarbodenafil, found as an adulterant in a health supplement, J. Pharm. Biomed. Anal. 185 (2020) 113222, https://doi.org/10.1016/j.jpba.2020.113222

[10] A. Bzhelyansky, USP General Chapter <2251> Revision Bulletin: Screening for undeclared drugs and drug analogues (2016), https://doi.org/10.13140/RG.2.1.1357.5286

[11] H. Yu, Q. Hu, J. Sun, R. Feng, S. Zhang, J. Zhang, X. Mao, S. Ji, Qualitative analysis of illegally adulterated sildenafil and related compounds in dietary supplements by ultra-high performance liquid chromatography-quadrupole-time-of-flight mass spectrometry, Sepu (China)/Chin. J. Chromatogr. 36 (2018) 1005-1017, https://doi.org/10.3724/ SP.J.1123.2018.04031

[12] S.R. Gratz, B.M. Gamble, R.A. Flurer, Accurate mass measurement using Fourier transform ion cyclotron resonance mass spectrometry for structure elucidation of designer drug analogs of tadalafil, vardenafil and sildenafil in herbal and pharmaceutical matrices, Rapid Commun. Mass Spectrom. 20 (2006) 2317-2327, https://doi.org/10.1002/rcm.2594

[13] C. Mustazza, A. Borioni, A.L. Rodomonte, M. Bartolomei, E. Antoniella, P. Di Martino, L. Valvo, I. Sestili, E. Costantini, M.C. Gaudiano, Characterization of sildenafil analogs by MS/MS and NMR: a guidance for detection and structure elucidation of phosphodiesterase-5 inhibitors, J. Pharm. Biomed. Anal. 96 (2014) 170-186, https://doi.org/10.1016/j.jpba.2014. $\underline{03.038}$

[14] C.L. Kee, X. Ge, M.Y. Low, Application of Orbitrap-mass spectrometry to differentiate isomeric sildenafil- and thiosildenafil-like analogues used for the adulteration of dietary supplements, Food Addit. Contam. Part A 32 (2015) 1737-1748, https://doi.org/10.1080/ $\underline{19440049.2015 .1062923}$ 
[15] S. Pleasance, P. Blay, M.A. Quilliam, G. O'Hara, Determination of sulfonamides by liquid chromatography, ultraviolet diode array detection and ion-spray tandem mass spectrometry with application to cultured salmon flesh, J. Chromatogr. 558 (1991) 155-173. [16] W.M.A. Niessen, Fragmentation of toxicologically relevant drugs in positive-ion liquid chromatography-tandem mass spectrometry, Mass Spectrom. Rev. 30 (2011) 626-663, https://doi.org/10.1002/mas.20332

[17] P. Jankovics, S. Lohner, A. Darcsi, J. Németh-Palotás, S. Béni, Detection and structure elucidation of hydroxythiovardenafil as an adulterant in a herbal dietary supplement, J. Pharm. Biomed. Anal. 74 (2013) 83-91, https://doi.org/10.1016/j.jpba.2012.10.013 [18] J.C. Reepmeyer, Direct intramolecular gas-phase transfer reactions during fragmentation of sildenafil and thiosildenafil analogs in electrospray ionization mass spectrometry, Rapid Commun. Mass Spectrom. 23 (2009) 927-936, https://doi.org/10.1002/rcm.3948 [19] J.C. Reepmeyer, J.T. Woodruff, D.A. d'Avignon, Structure elucidation of a novel analogue of sildenafil detected as an adulterant in an herbal dietary supplement, J. Pharm. Biomed. Anal. 43 (2007) 1615-1621, https://doi.org/10.1016/j.jpba.2006.11.037 [20] X-B. Wang, J. Zheng, J-J. Li, H-Y. Yu, Q-Y. Li, L-H. Xu, M-J. Liu, R-Q. Xian, Y-E. Sun, B-J. Liu, Simultaneous analysis of 23 illegal adulterated aphrodisiac chemical ingredients in health foods and Chinese traditional patent medicines by ultrahigh performance liquid chromatography coupled with quadrupole time-of-flight mass spectrometry, J. Food Drug Anal. 26 (2018) 1138-1153, https://doi.org/10.1016/j.jfda.2018.02.003

[21] I.V.S. Kumar, G.S. Ramanjaneyulu, V.H. Bindu, Synthesis of sildenafil citrate and process related impurities, Lett. Org. Chem. 8 (2011) 668-673, https://doi.org/10.2174/ 157017811799304304 [22] P. Eichhorn, S. Pérez, J. Aceña, P. Gardinali, J.L. Abad, D. Barceló, Identification of phototransformation products of sildenafil (Viagra) and its N- demethylated human metabolite under simulated sunlight, J. Mass Spectrom. 47 (2012) 701-711, https://doi.org/10.1002/ jms.2998 [23] P.J. Dunn, Synthesis of commercial phosphodiesterase(V) inhibitors, Org. Process Res. Dev. 9 (2005) 88-97, https://doi.org/10.1021/op040019c and references cited therein [24] M.A. Gouda, W.S. Hamama, Overview of the synthetic routes to sildenafil and its Analogues, Synth. Commun. 47 (2017) 1269-1300, http://dx.doi.org/10.1080/00397911.2017. 1307987 and references cited therein

[25] M. Baumann, I.R. Baxendale, An overview of the synthetic routes to the best selling drugs containing 6-membered heterocycles, Beilstein J. Org. Chem. 9 (2013) 2265-2319, https://doi.org/10.3762/bjoc.9.265 [26] A.V. Raghava Reddy, G. Srinivas, C. Takshinamoorthy, B. Gupta Peruri, A. Naidu, A facile, improved synthesis of sildenafil and its analogues, Sci. Pharm. 84 (2016) 447-455, https://doi.org/10.3390/scipharm84030447 [27] S.R. Patil, B. Satyanarayana, K. Amrutia, M. Biswas, J.N. Sangshetti, S. Pathakokila, S.S. Powar, A.S. Bobade, P.P. Reddy, R. Agarwal, D.B. Shinde, Identification, synthesis, and strategy for reduction of process related potential impurities in sildenafil citrate, Res. j. pharm. biol. chem. sci. 8 (2017) 1374-1380

[28] N. Schramek, U. Wollein, W. Eisenreich, Identification of new synthetic PDE-5 inhibitors analogues found as minor components in a dietary supplement, J. Pharm. Biomed. Anal. 96 (2014) 45-53, https://doi.org/10.1016/j.jpba.2014.03.023

[29] N. Schramek, U. Wollein, W. Eisenreich, Pyrazolopyrimidines in 'all-natural' products for erectile dysfunction treatment: the unreliable quality of dietary supplements, Food Addit. Contam. Part A 32 (2015) 127-140, https://doi.org/10.1080/19440049.2014.992980

[30] E.L. Bakota, A.T. Kelly, J.P. Walterscheid, D.R. Phatak, A case report of fatal desmethyl carbodenafil toxicity, J. Anal. Toxicol. 41 (2017) 250-255, https://doi.org/10.1093/jat/bkw128 


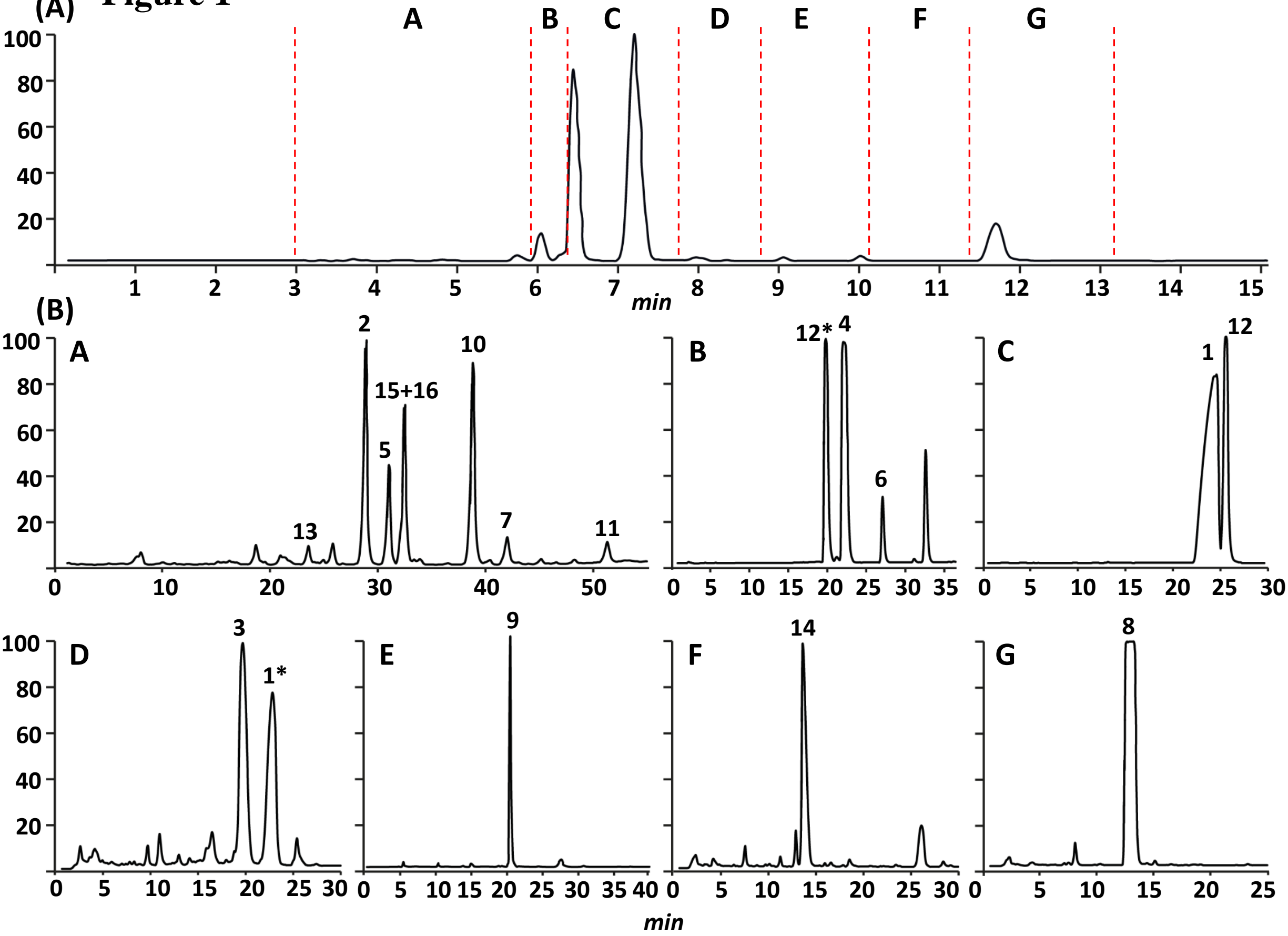


Figure 2

(A)

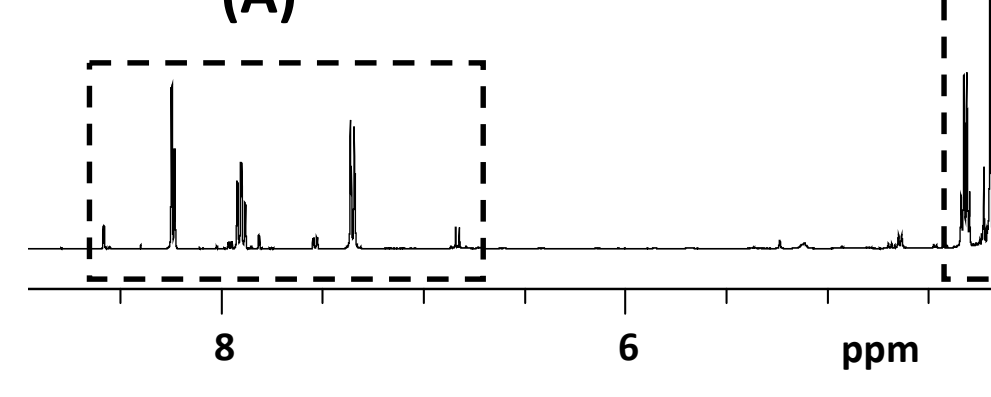

1

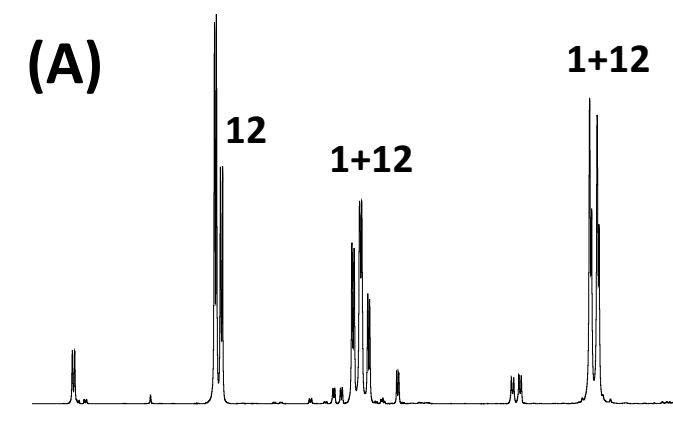

(B)

(B)

| HOD 
Figure 3
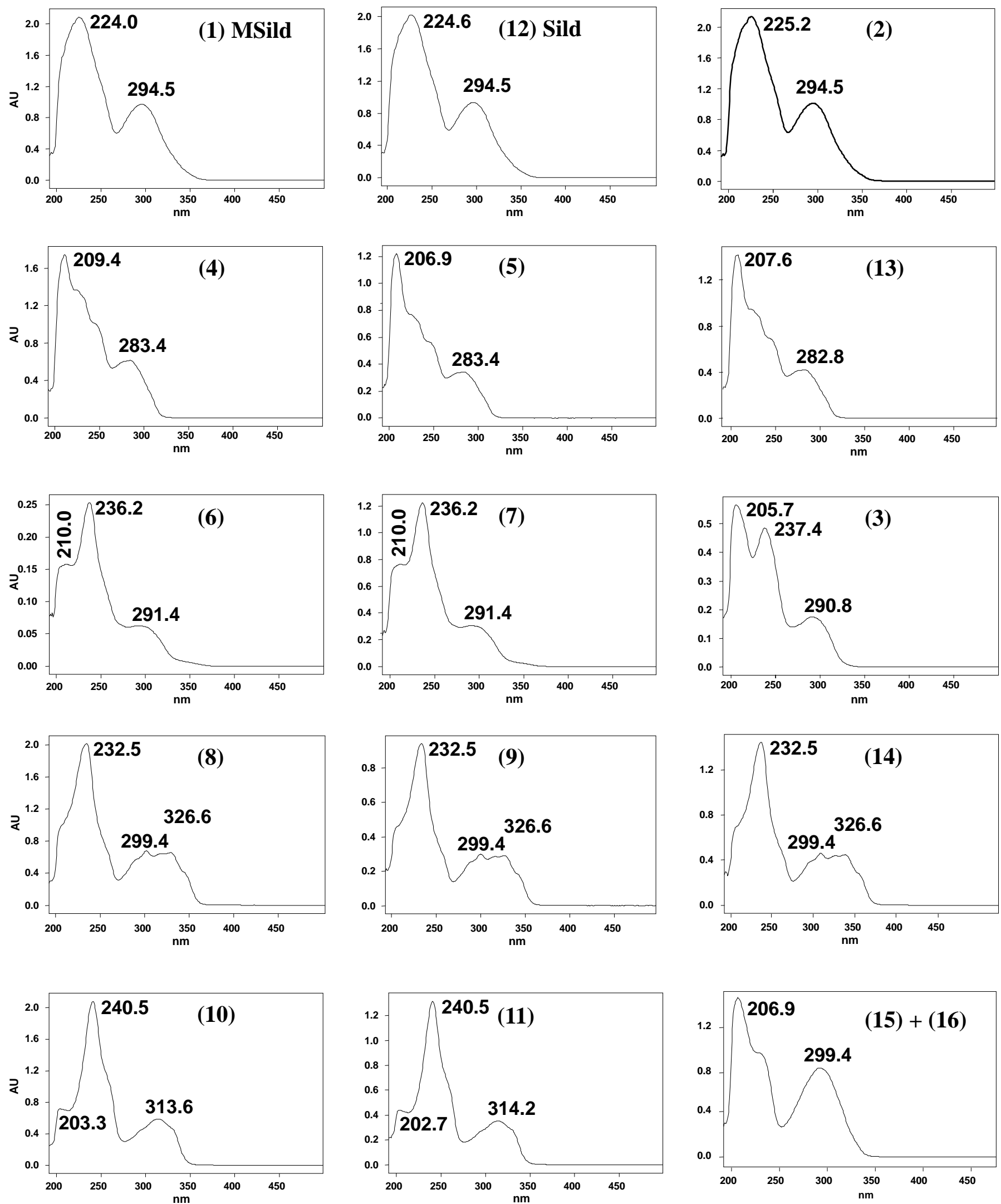


\section{(A) $\quad$ Figure 4}

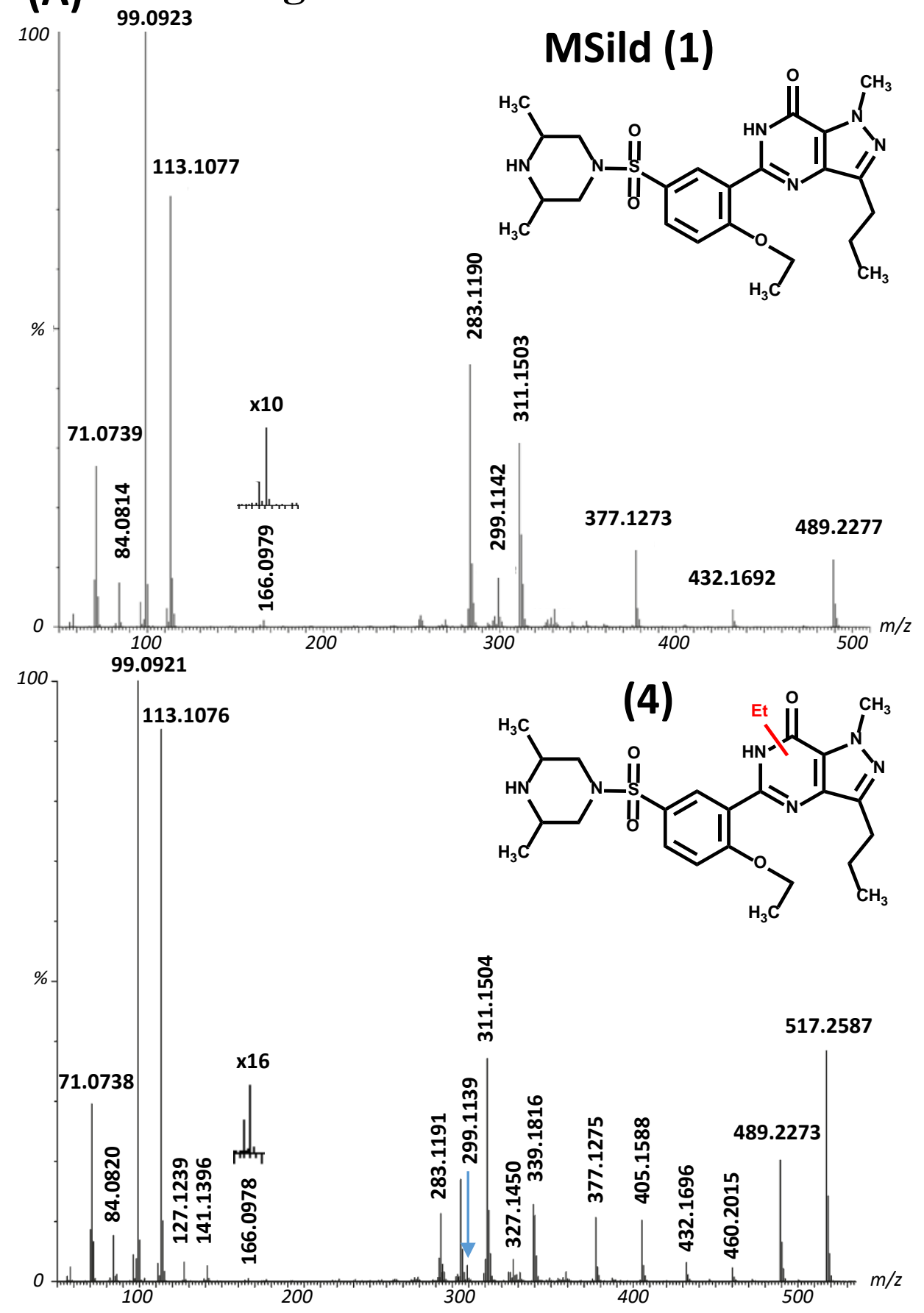

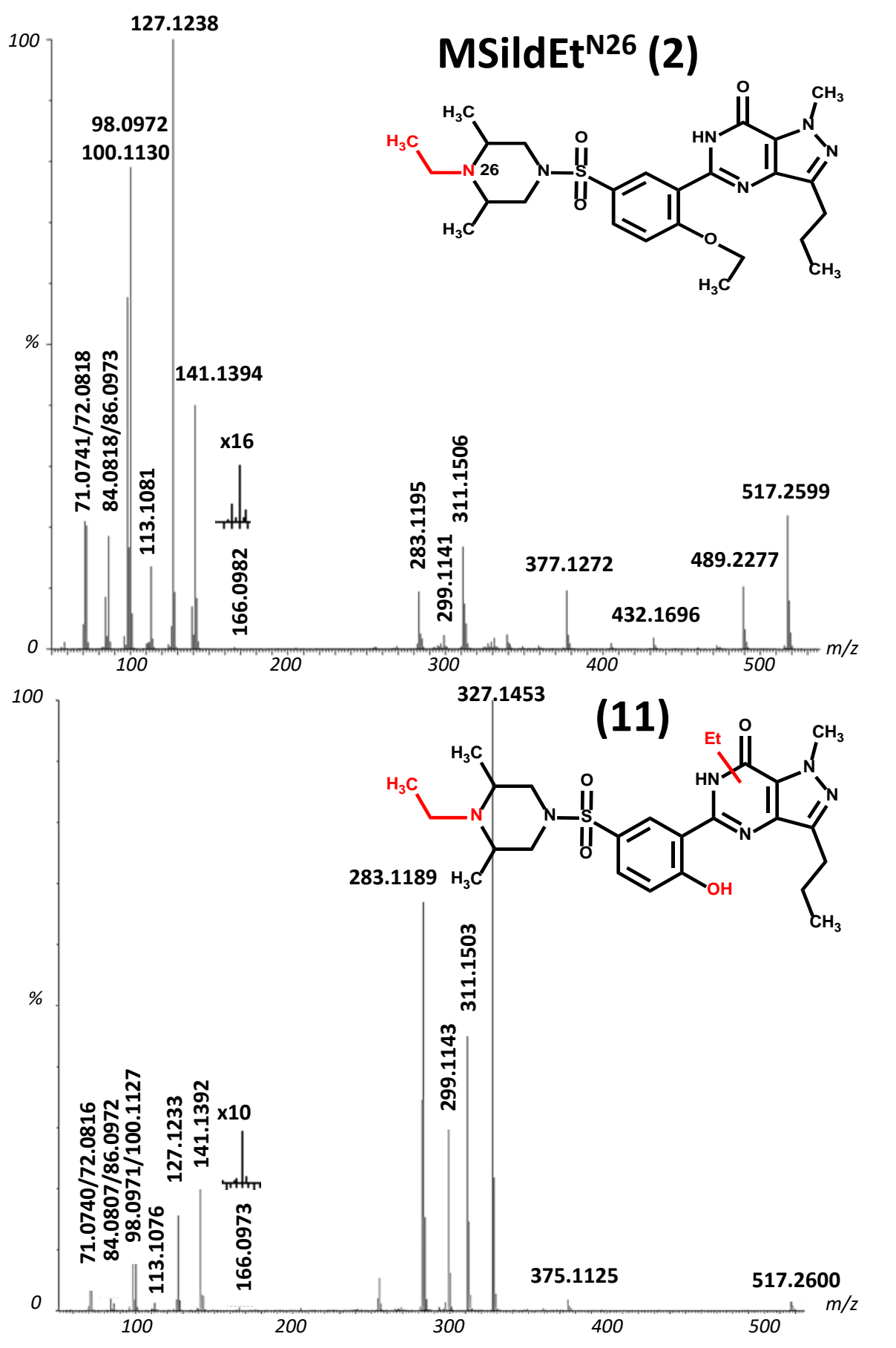




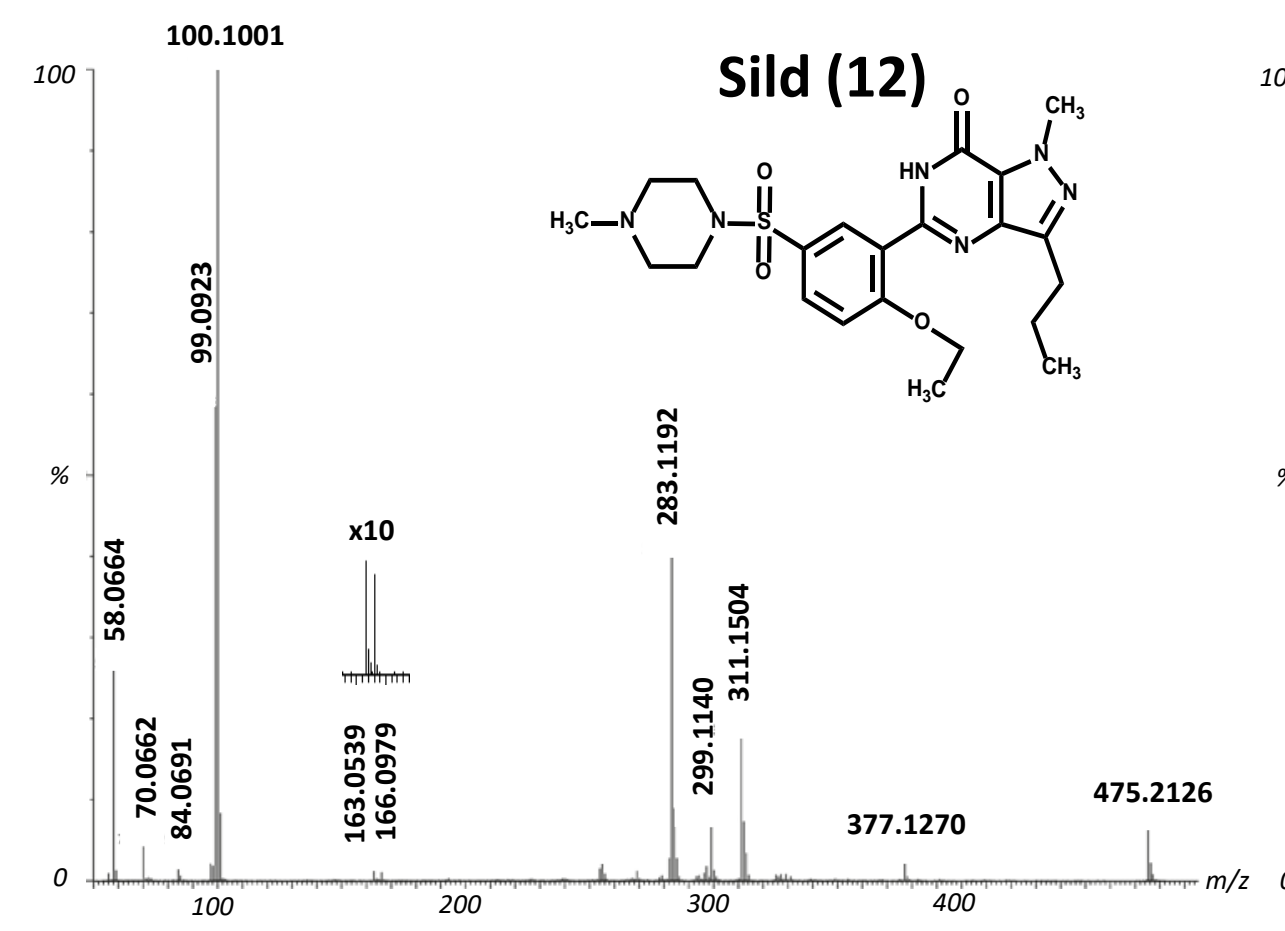

100.1001
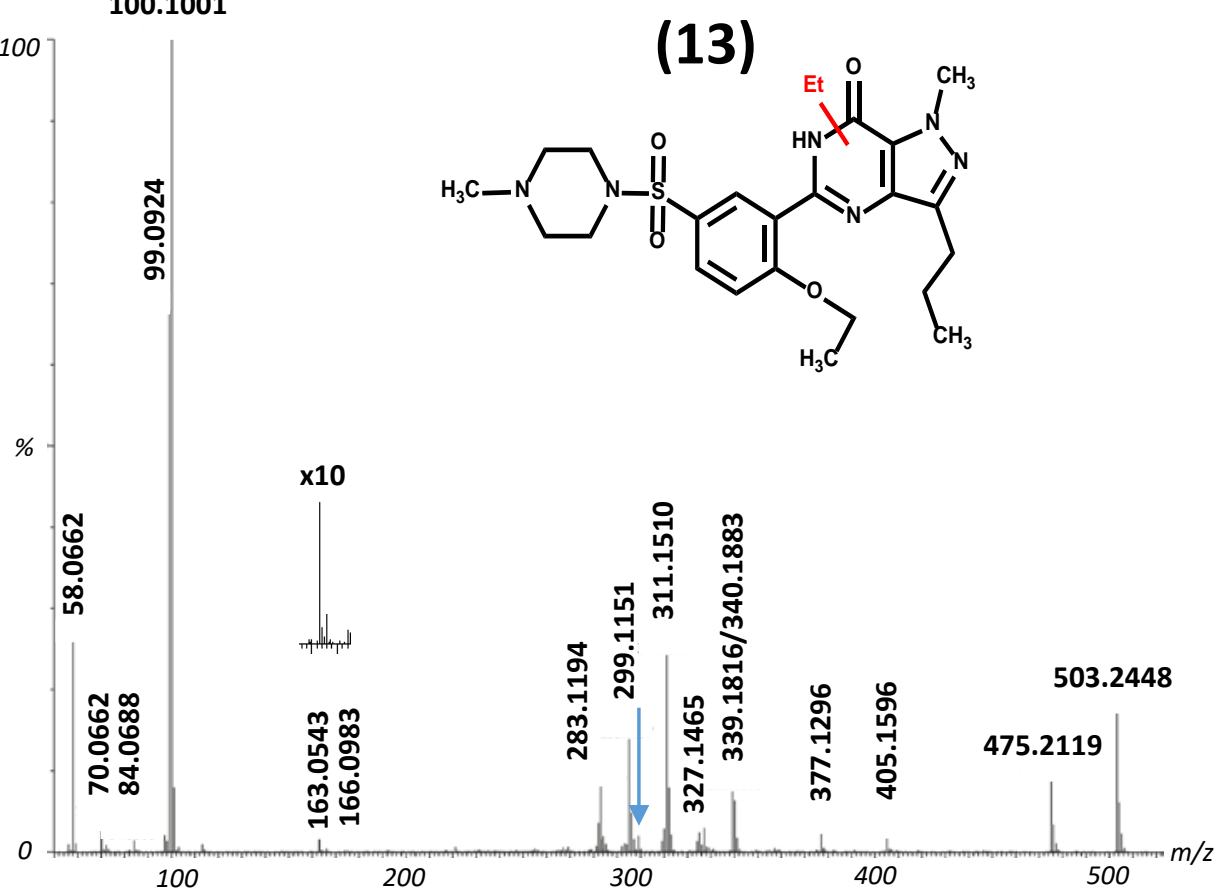
(B)

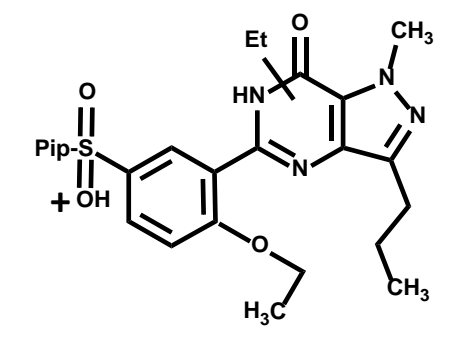

$\mathrm{m} / \mathrm{z}$ without ethyl group on the pyrazolopyrimidine moiety Pip A: 2,6-dimethylpiperazine Pip B: N1-ethyl-2,6-dimethylpiperazine Pip C: N-methylpiperazine<smiles>CCCc1nn(C)c2c(=O)[nH]c(-c3cc(S(=O)(=O)O)ccc3OCC)nc12</smiles>

377

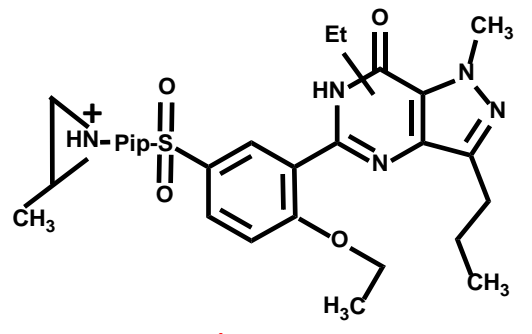

$\mathrm{m} / \mathrm{z}$ with ethyl group

517

545

503 $432^{m / z} 460$

432 $\mathrm{m} / \mathrm{z} 166$

Common to all

compounds

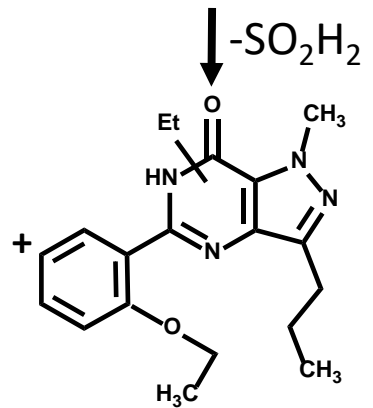

m/z 311339 $\checkmark-\mathrm{C}_{2} \mathrm{H}_{4}$

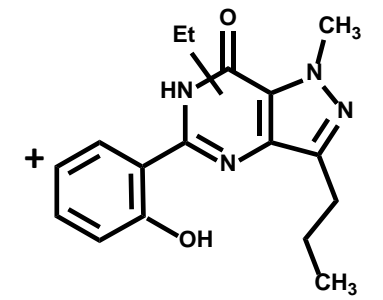

$\mathrm{m} / \mathrm{z} \quad 283 \quad 311$

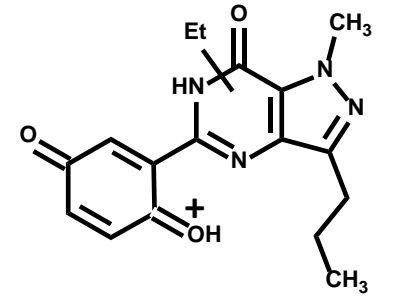

$\mathrm{m} / \mathrm{z}$

$299 \quad 327$

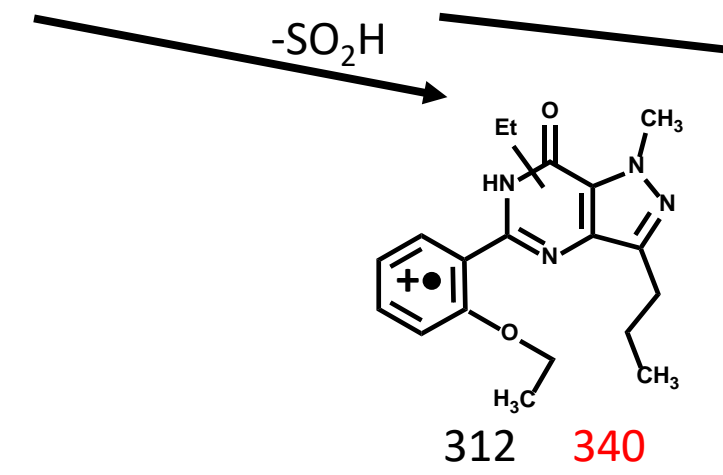

$-\mathrm{SO}_{2}$
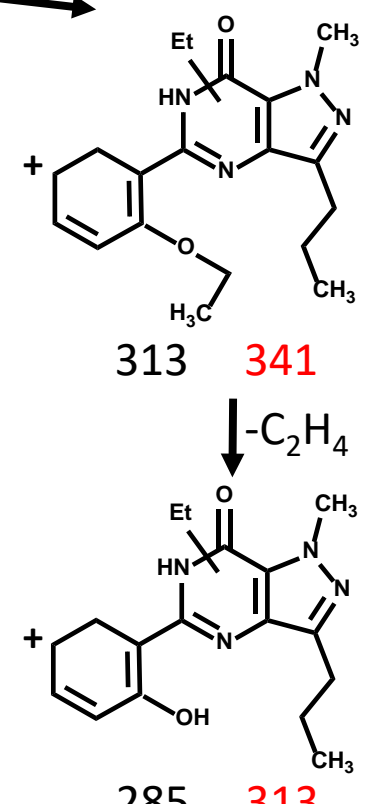

$285 \quad 313$ 
(C)

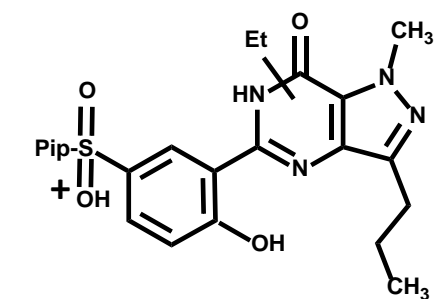

$m / z$ without ethyl group on the pyrazolopyrimidine moiety Pip A: 2,6-dimethylpiperazine

Pip B: N1-ethyl-2,6-dimethylpiperazine Pip C: N-methylpiperazine

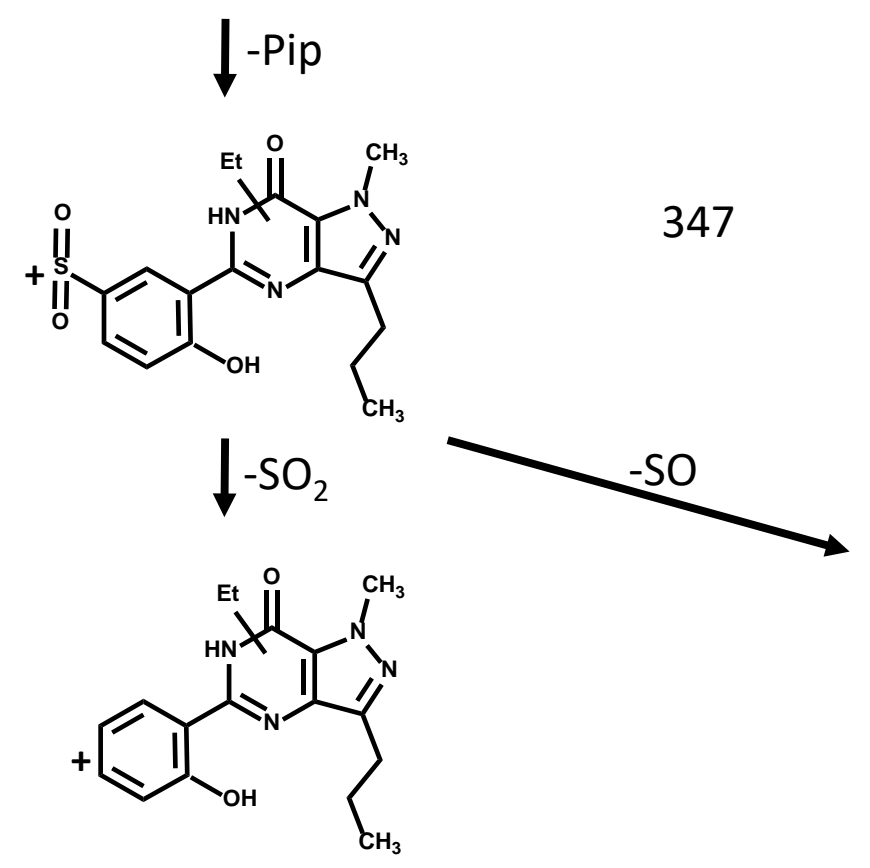

$\mathrm{m} / \mathrm{z} \quad 283 \quad 311$ $\mathrm{m} / \mathrm{z}$ with ethyl group 489

517

489

447

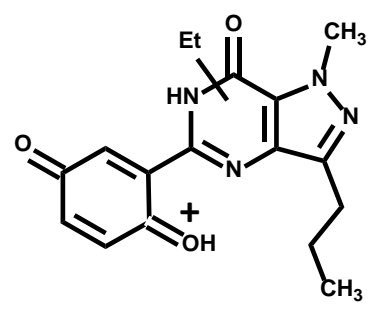

$299 \quad 327$ 
(D)

- 2,6-dimethylpiperazine

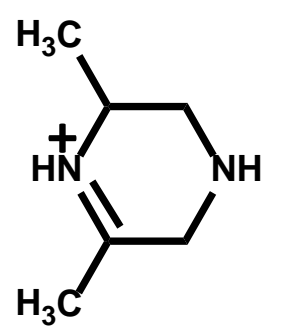

$\mathrm{m} / \mathrm{z} 113$

$\mathrm{C}_{6} \mathrm{H}_{13} \mathrm{~N}_{2}{ }^{+}$

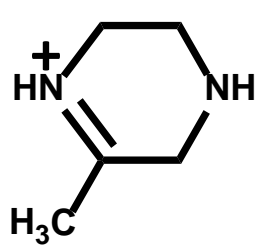

99

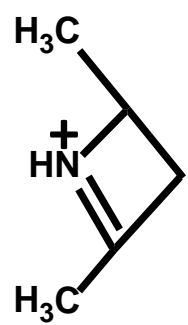

84.0813

$\mathrm{C}_{5} \mathrm{H}_{10} \mathrm{~N}^{+}$

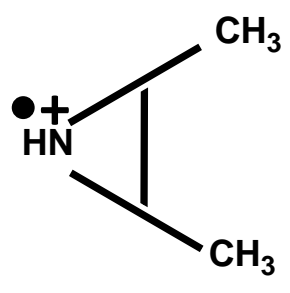

71

$\mathrm{C}_{4} \mathrm{H}_{9} \mathrm{~N}^{+\bullet}$

- N1-ethyl-2,6-dimethylpiperazine
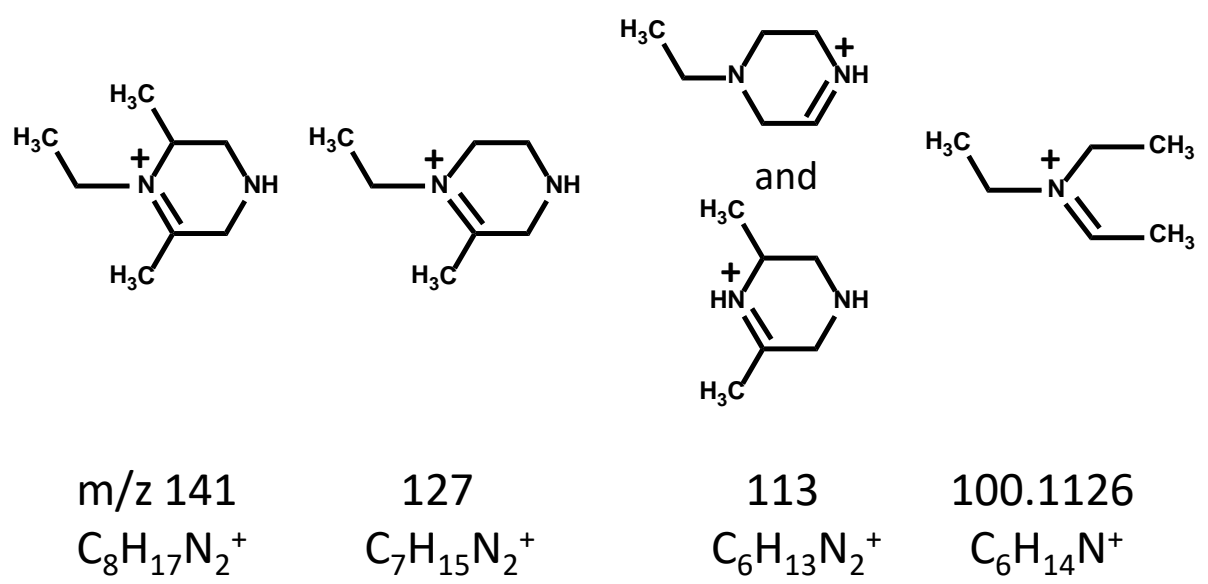

$\mathrm{m} / \mathrm{z} 141$

$\mathrm{C}_{7} \mathrm{H}_{15} \mathrm{~N}_{2}{ }^{+}$
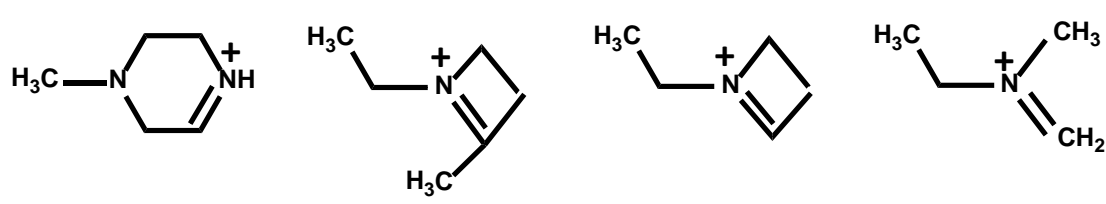

72

and

98

$$
\mathrm{C}_{6} \mathrm{H}_{12} \mathrm{~N}^{+}
$$
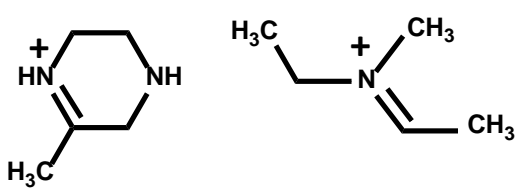

99

$\mathrm{C}_{5} \mathrm{H}_{11} \mathrm{~N}_{2}{ }^{+}$ and

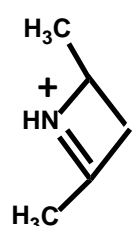

84.0813

$\mathrm{C}_{5} \mathrm{H}_{10} \mathrm{~N}^{+}$
$\mathrm{C}_{4} \mathrm{H}_{10} \mathrm{~N}^{+}$

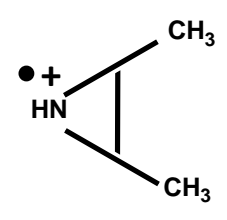

71

$\mathrm{C}_{4} \mathrm{H}_{9} \mathrm{~N}^{+\bullet}$

- N1-methylpiperazine

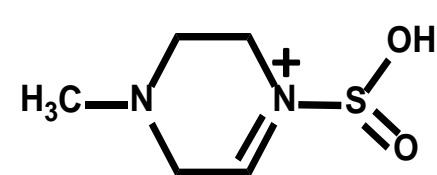

$\mathrm{m} / \mathrm{z} 163$

$\mathrm{C}_{5} \mathrm{H}_{11} \mathrm{~N}_{2} \mathrm{O}_{2} \mathrm{~S}^{+}$

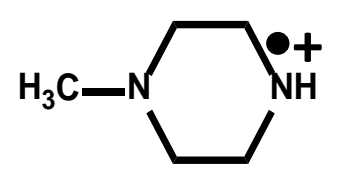

100.1000

$\mathrm{C}_{5} \mathrm{H}_{12} \mathrm{~N}_{2}{ }^{+\bullet}$

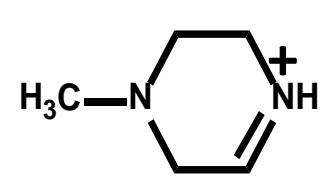

99

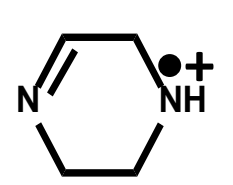

84.0688

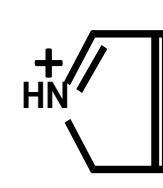

70

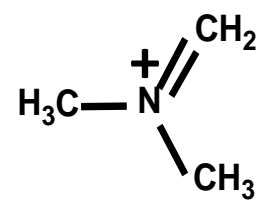

58

The two ions at $\mathrm{m} / \mathrm{z} 70$ and 58 are also observed with 2,6dimethylpiperazine and N1-ethyl-2,6-

$\mathrm{C}_{5} \mathrm{H}_{11} \mathrm{~N}_{2}^{+}$ 
Figure 5

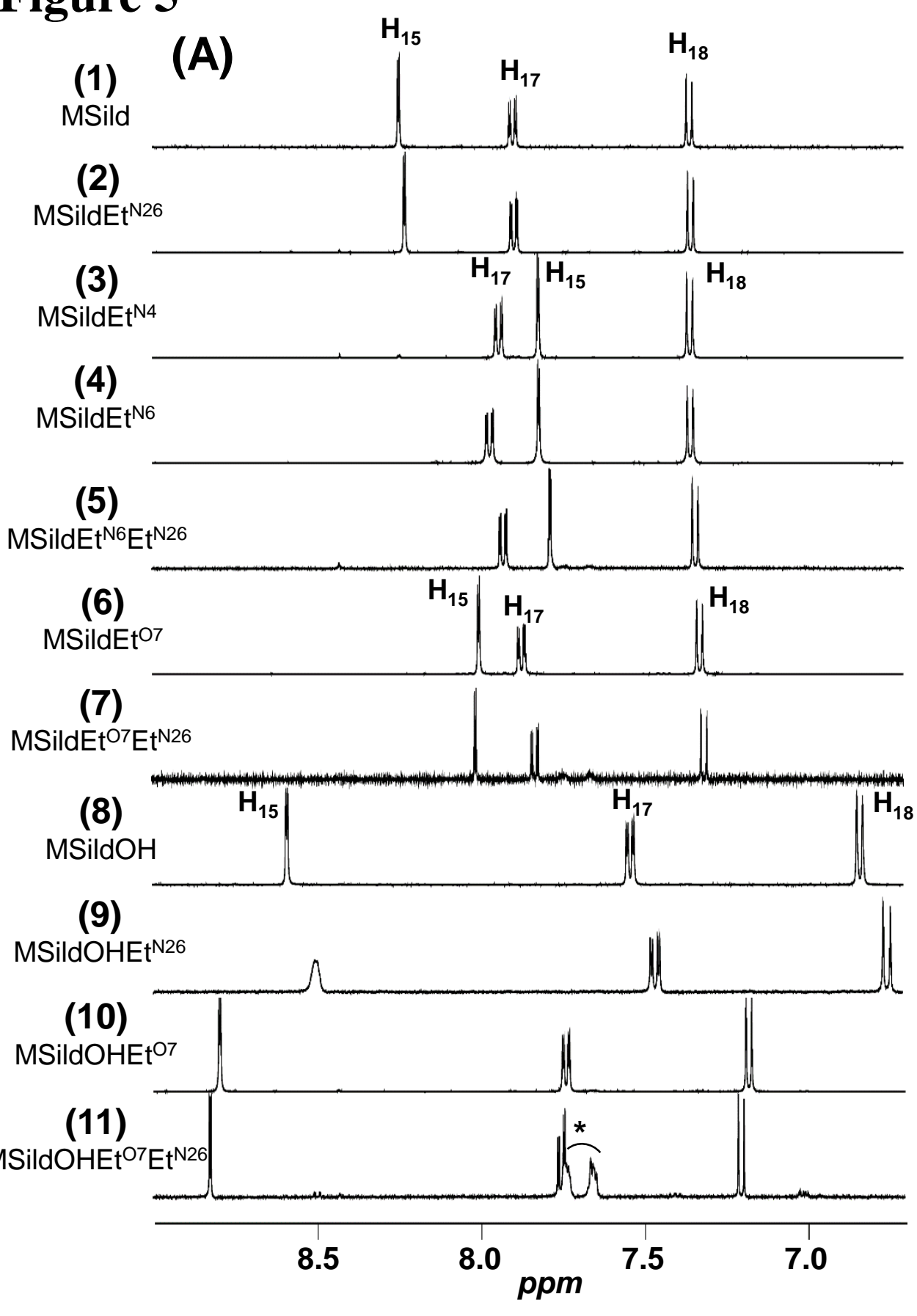

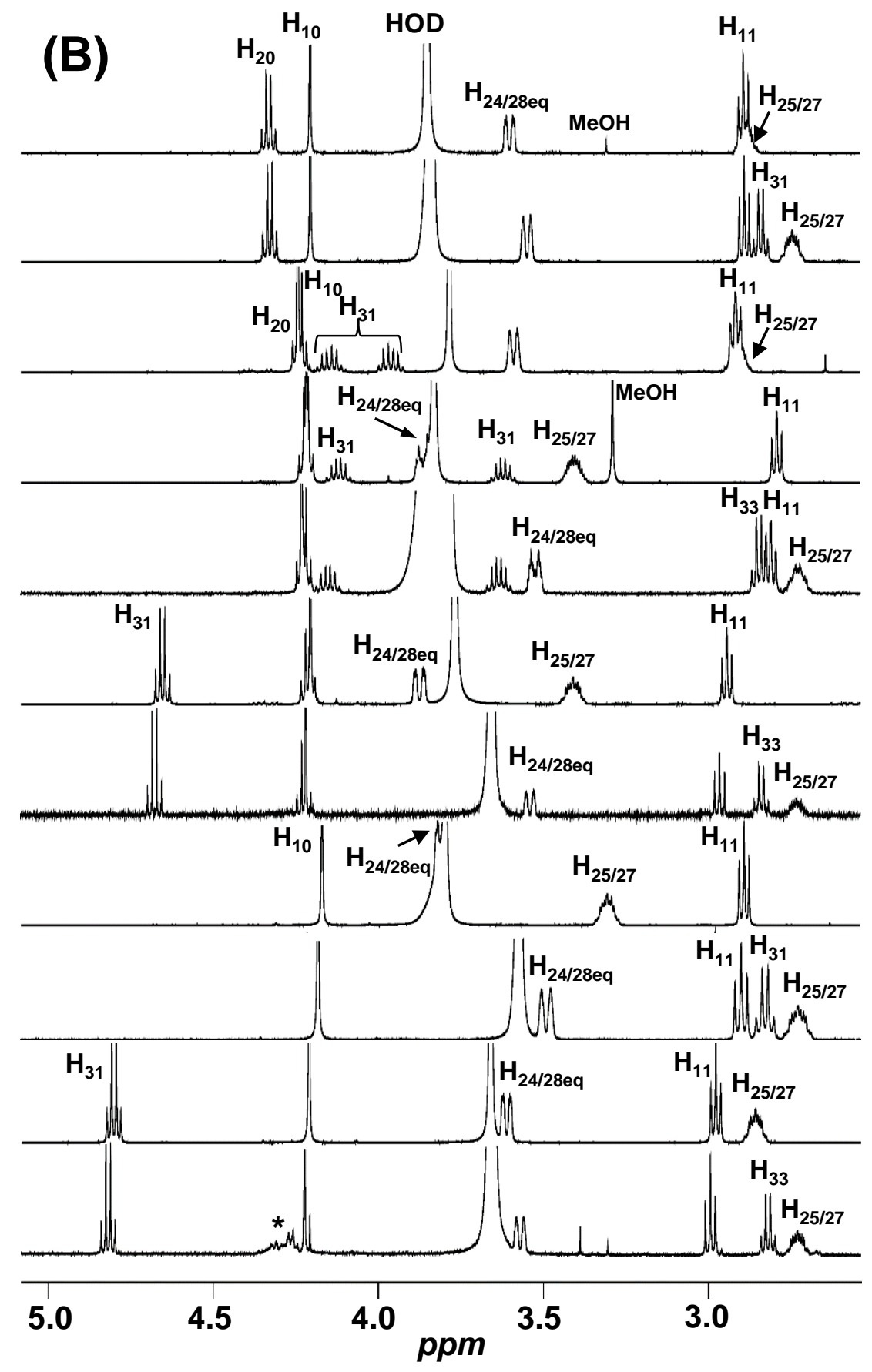


Figure 5

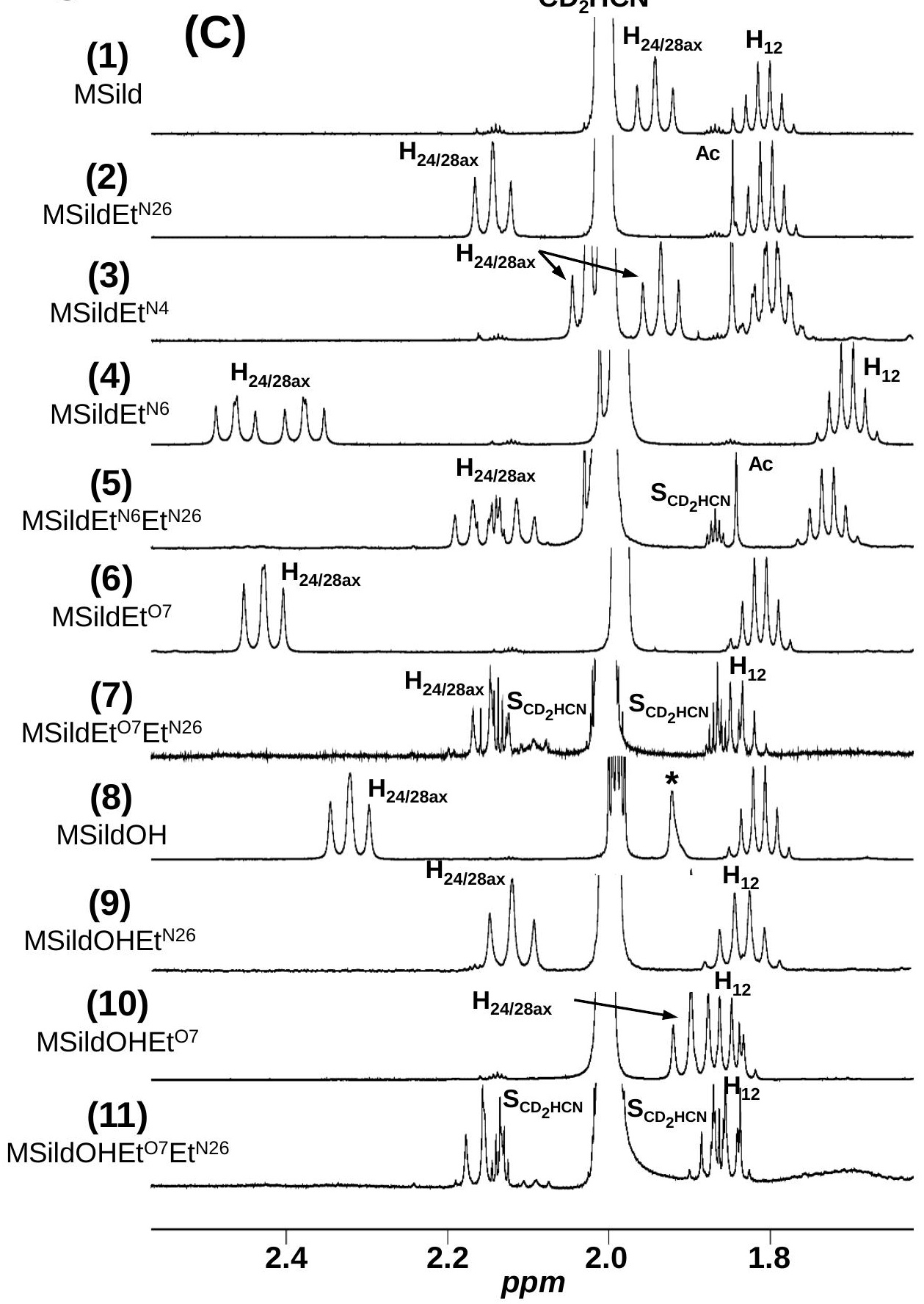

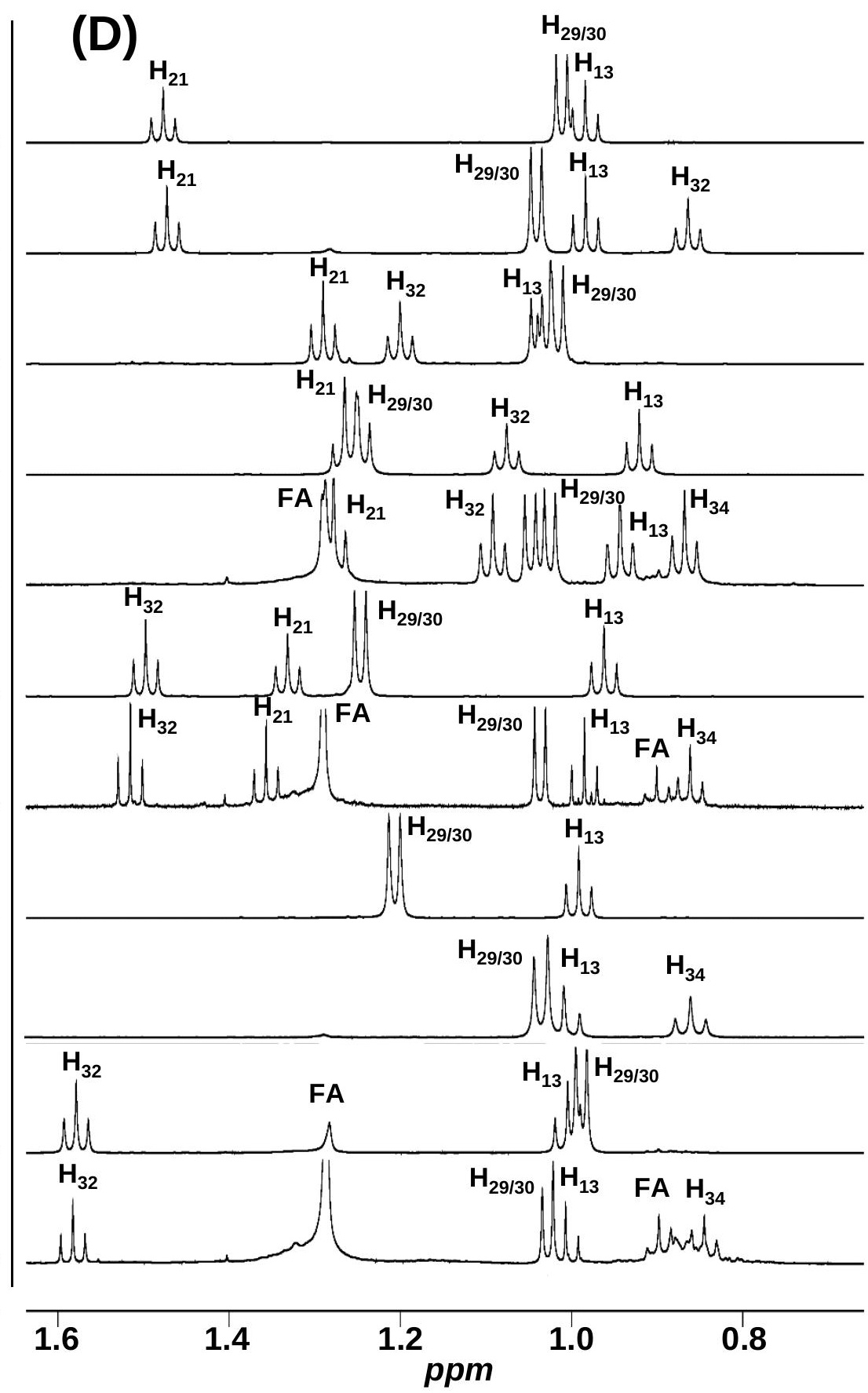


Figure 5

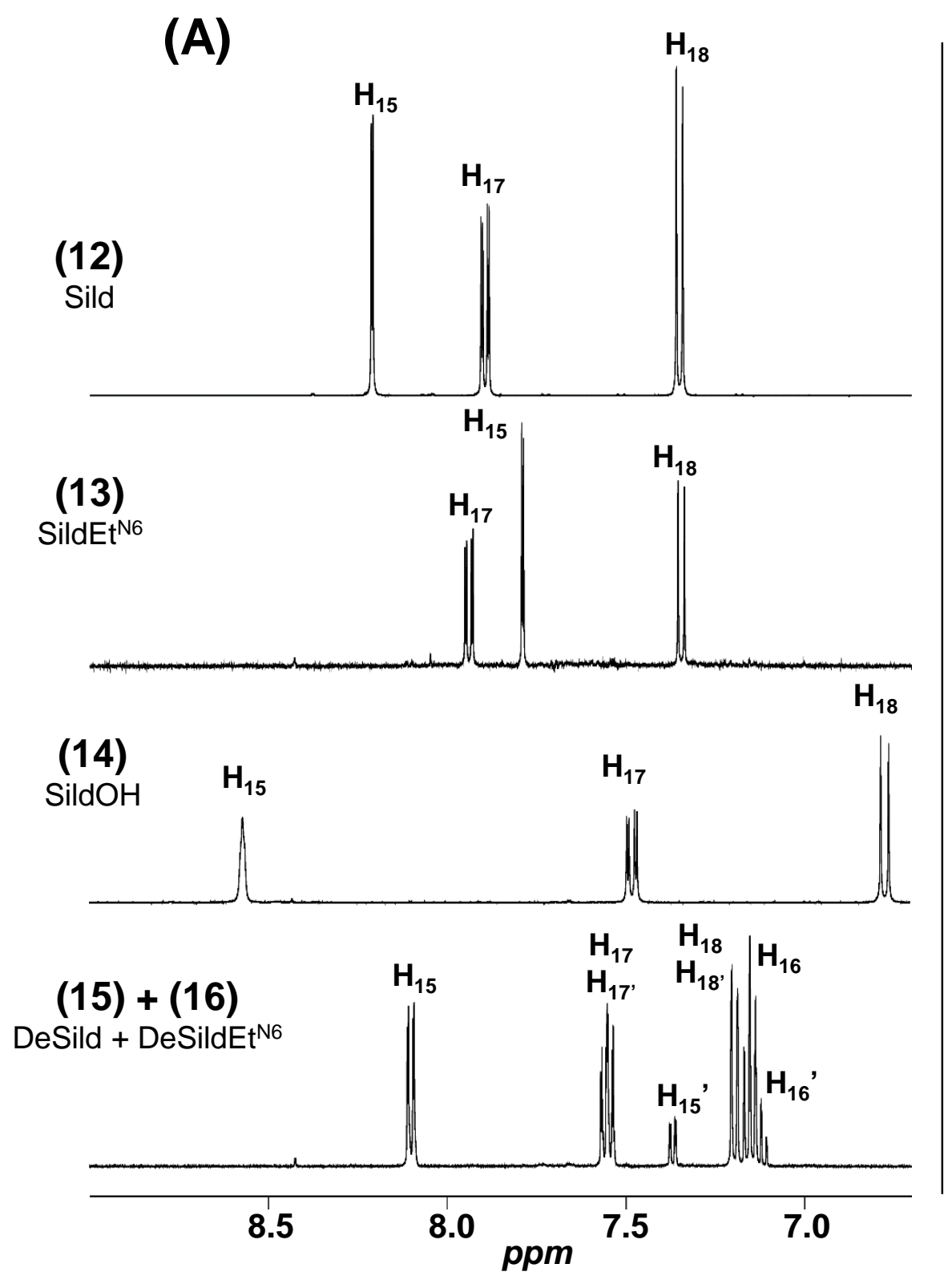

(B)

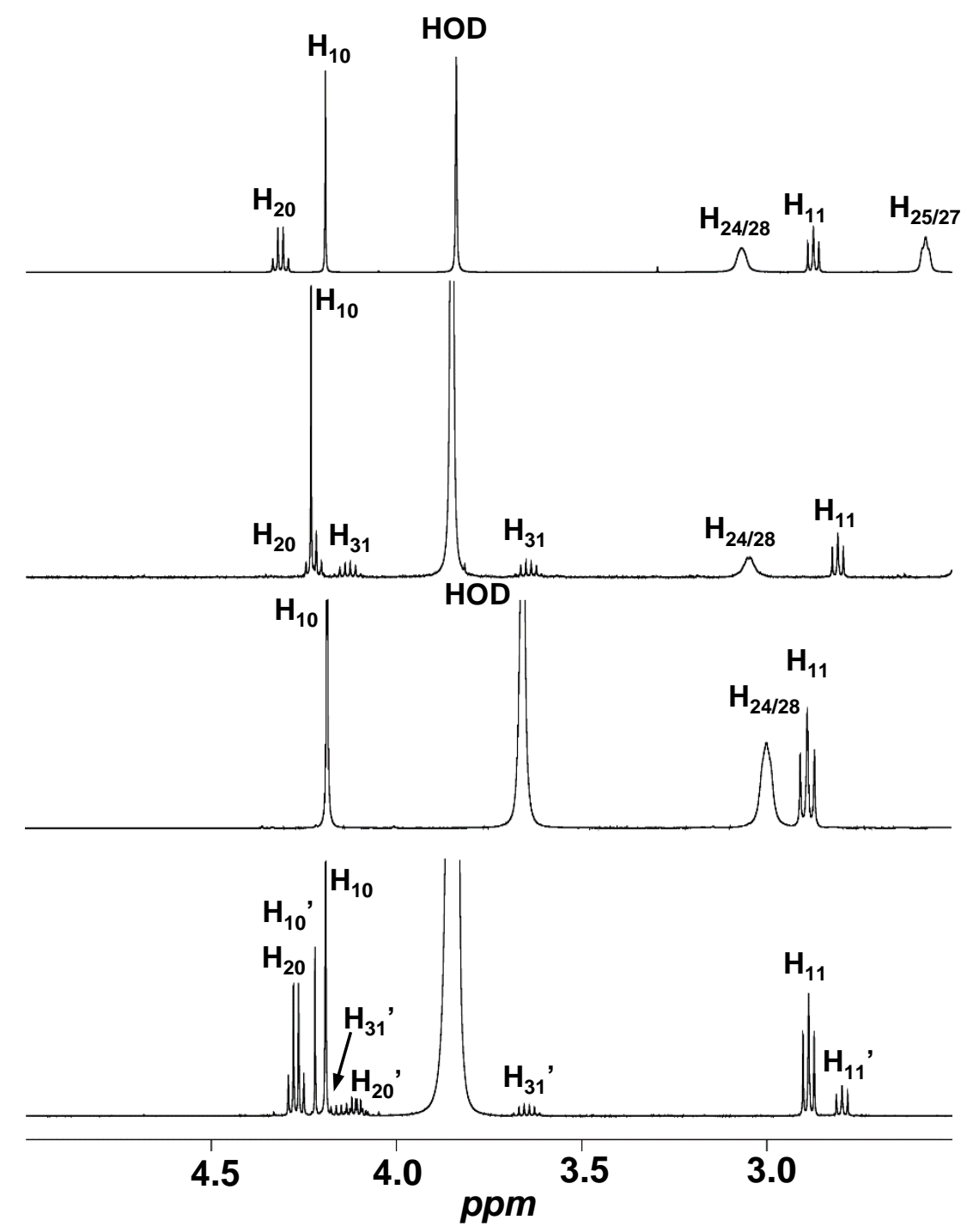


Figure 5

(C)

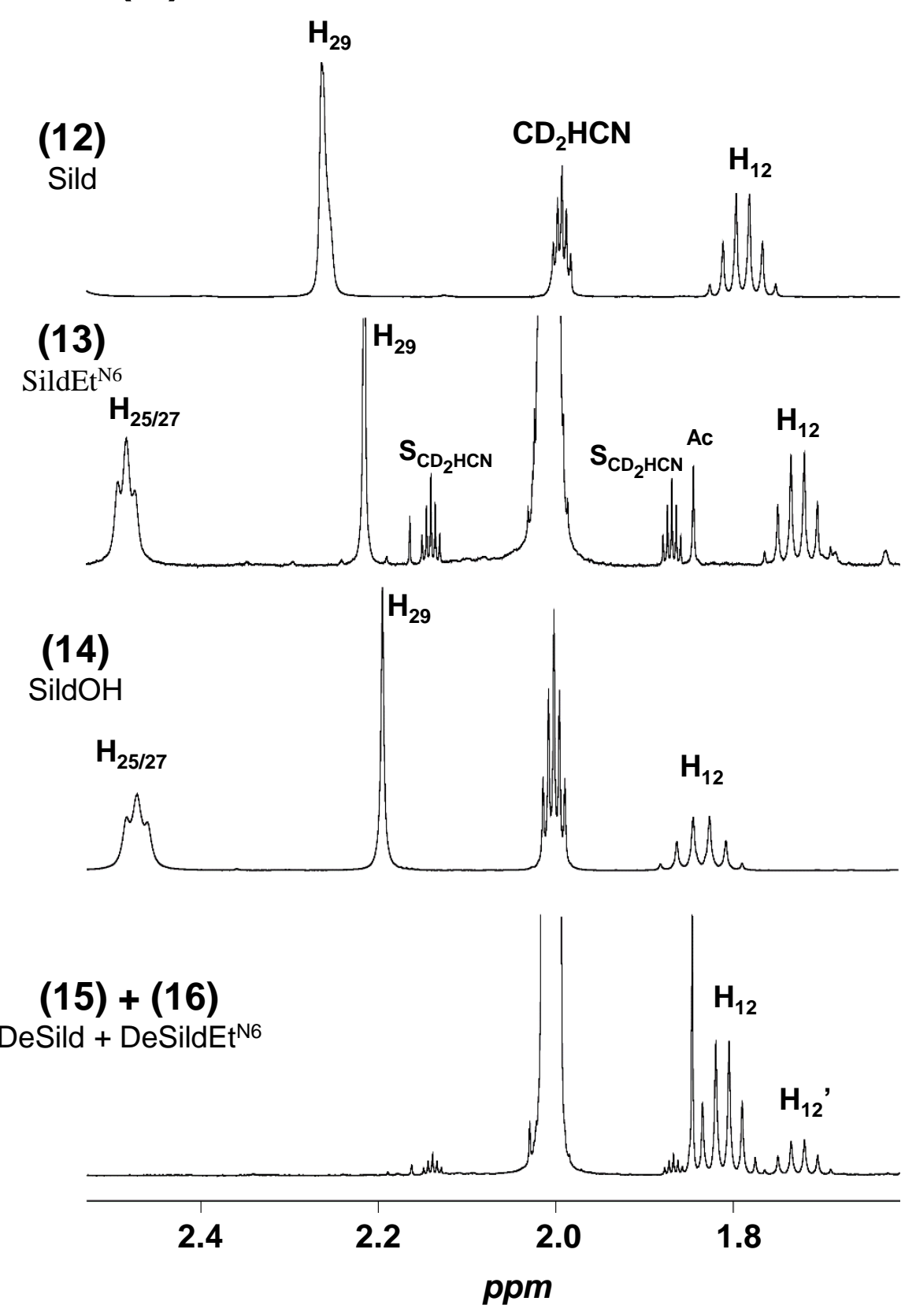

(D)
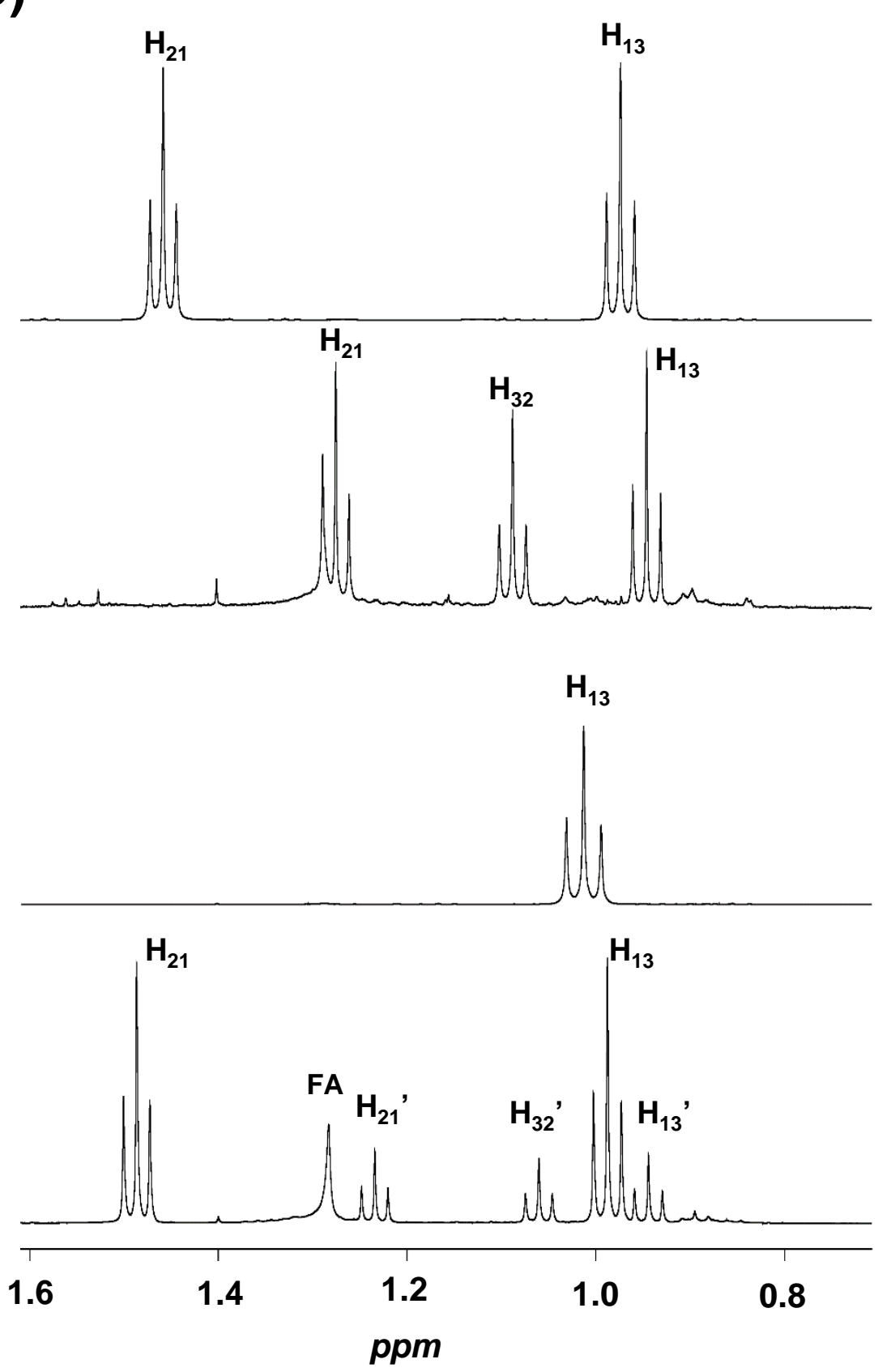
Figure 6

(A)

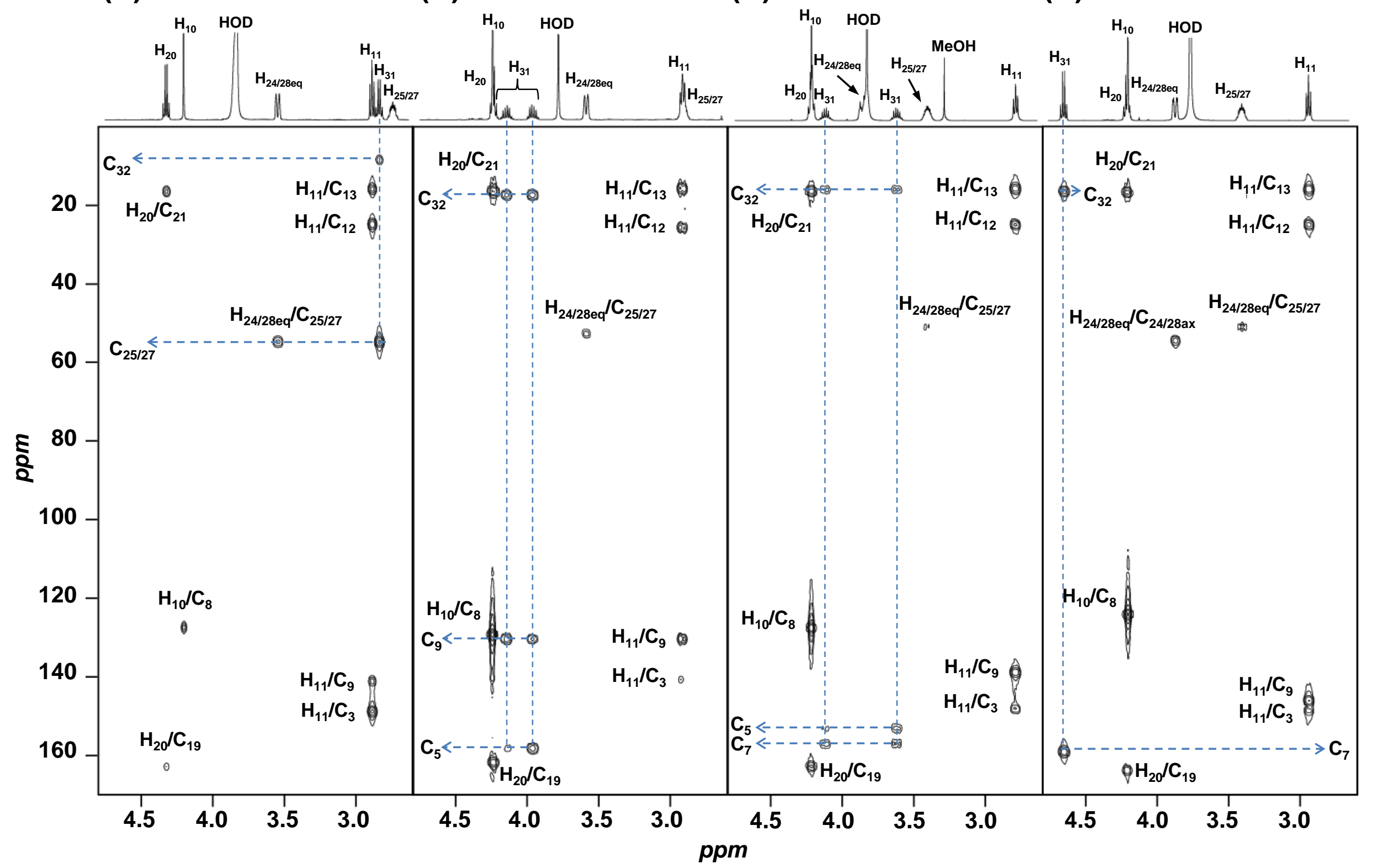

$\begin{array}{lll}\text { (B) } \text { MSildEt }^{\mathrm{N4}} \text { (3) } & \text { (C) } \operatorname{MSildEt}^{\mathrm{N6}} \text { (4) } & \text { (D) } \operatorname{MSildEt}^{\mathrm{O} 7} \text { (6) }\end{array}$
$t^{\mathrm{N} 26}(2)$ $\mathrm{H}_{3127}$ (

\section{$\begin{array}{r:c}\mathrm{H}_{20} / \mathrm{C}_{21} & \\ \mathrm{C}_{32}<--0 & 0\end{array}$}




\section{Figure 7}

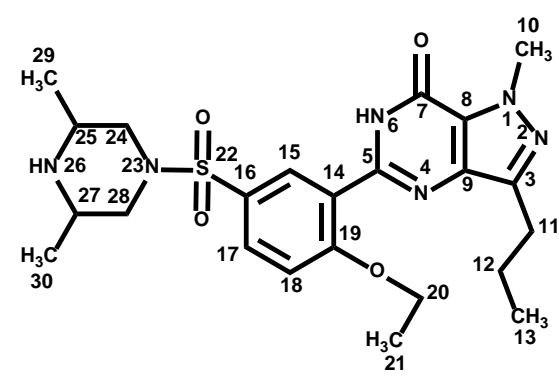

(1) MSild

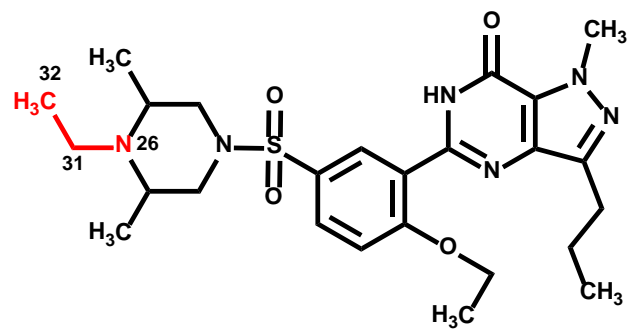

(2) MSildEt ${ }^{\mathrm{N} 26}$

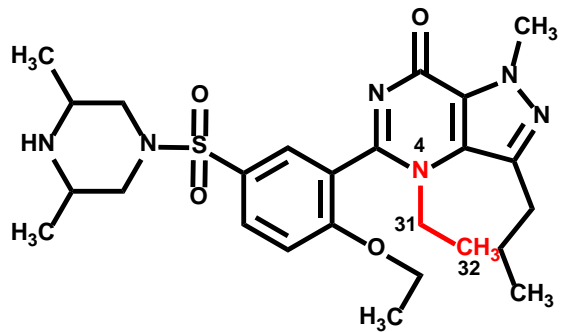

(3) MSildEt ${ }^{\mathrm{N} 4}$

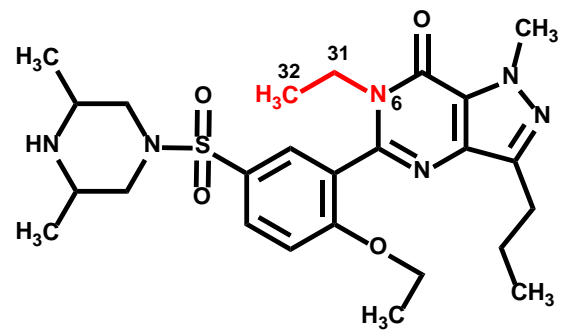

(4) MSildEt ${ }^{\mathrm{N} 6}$

Methisosildenafil [496835-35-9] (a)<smiles>CCCc1nn(C)c2c(=O)n(CC)c(-c3cc(S(=O)(=O)N4CC(C)N(CC)[C@H](C)C4)ccc3OCC)nc12</smiles>

(5) MSildEt ${ }^{\mathrm{N} 6} \mathrm{Et}^{\mathrm{N} 26}$

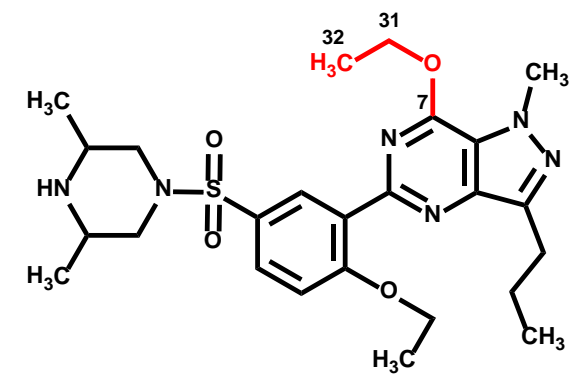

(6) MSildEt ${ }^{07}$ 07-ethyl-methisosildenafil<smiles>CCCc1nn(C)c2c(OCC)nc(-c3cc(S(=O)(=O)N4CC(C)N(CC)C(C)C4)ccc3OCC)nc12</smiles>

(7) MSildEt ${ }^{07} \mathrm{Et}^{\mathrm{N} 26}$ 07,N26-diethyl-methisosildenafil

N6,N26-diethyl-methisosildenafil<smiles>CCCc1nn(C)c2c(=O)[nH]c(-c3cc(S(=O)(=O)N4CC(C)N[C@H](C)C4)ccc3O)nc12</smiles>

(8) MSildOH

O-desethyl-methisosildenafil<smiles>CCCc1nn(C)c2c(=O)[nH]c(-c3cc(S(=O)(=O)N4CC(C)N(CC)[C@H](C)C4)ccc3O)nc12</smiles>

(9) MSildOHEt ${ }^{\mathrm{N} 26}$ N26-ethyl-O-desethylmethisosildenafil<smiles>CCCc1nn(C)c2c(OCC)nc(-c3cc(S(=O)(=O)N4CC(C)NC(C)C4)ccc3O)nc12</smiles>

(10) MSildOHEt ${ }^{07}$ 07-ethyl-0-desethylmethisosildenafil<smiles>CCCc1nn(C)c2c(OCC)nc(-c3cc(S(=O)(=O)N4CC(C)N(CC)[C@H](C)C4)ccc3O)nc12</smiles>

(11) MSildOHEt ${ }^{07} \mathrm{Et}^{\mathrm{N26}}$ 07,N26-diethyl-O-desethylmethisosildenafil 


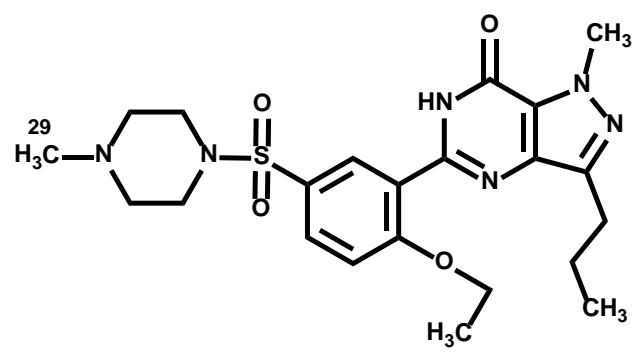

(12) Sild

Sildenafil

[139755-83-2] $^{\text {(a) }}$

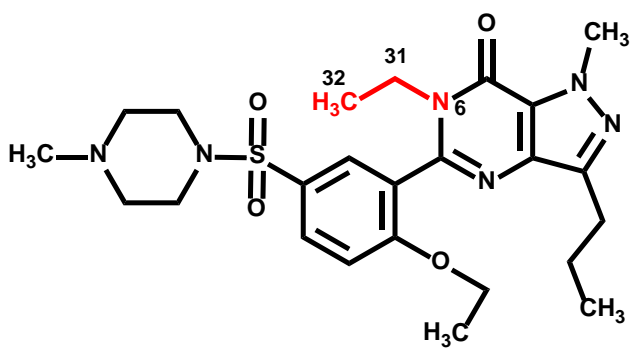

(13) SildEt ${ }^{\mathrm{N} 6}$

N6-ethyl-sildenafil (c)

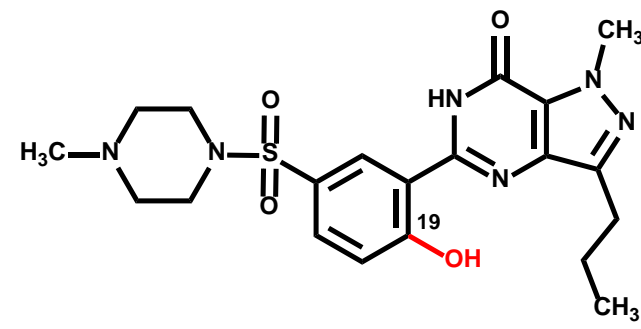

(14) SildOH

O-desethyl-sildenafil [139755-91-2] $^{(\mathrm{a}, \mathrm{d})}$

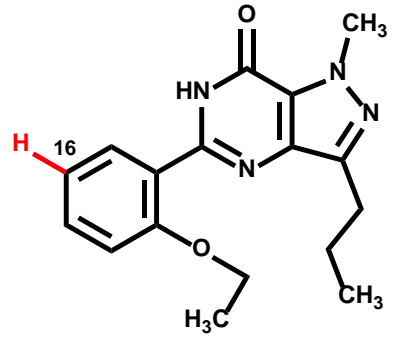

(15) DeSild

Desulfosildenafil [139756-21-1] $^{(\mathrm{a}, \mathrm{e})}$

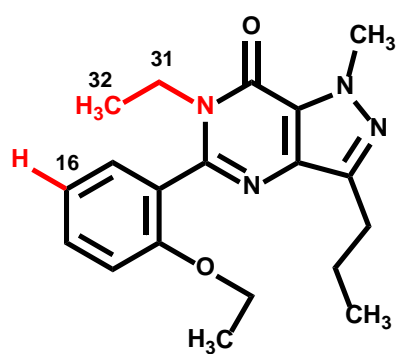

(16) DeSildEt ${ }^{\mathrm{N}}$

N6-ethyl-desulfosildenafil 
Figure 8

Sildenafil $\left(R_{1}=M e, R_{2}=H\right)$ Methisosildenafil $\left(R_{1}=H, R_{2}=M e\right)$

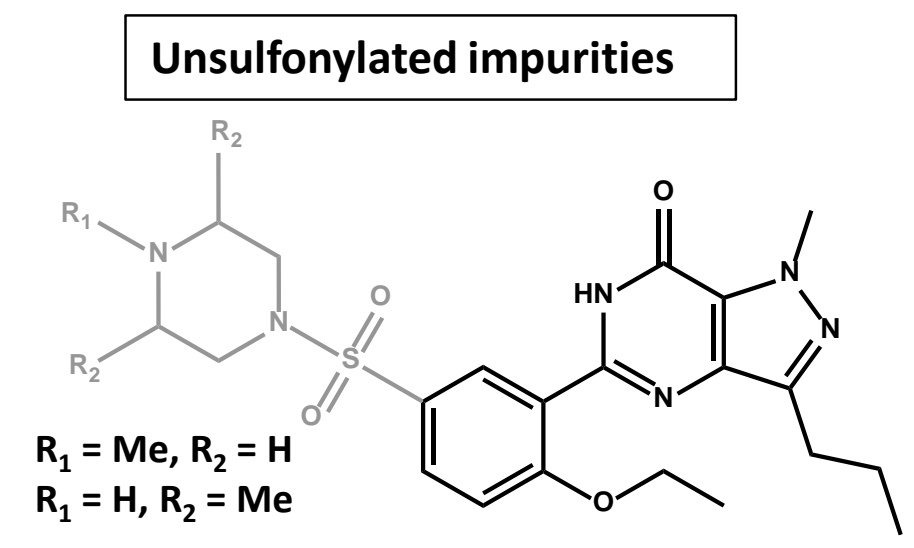

(A)

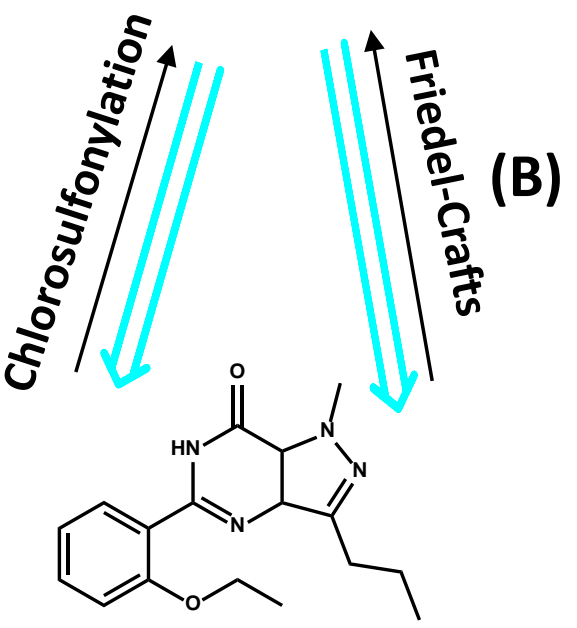

Reversible transformation Incomplete conversion

15,16

Late sulfonylation

Early sulfonylation<smiles>[R]C1CN(S(=O)(=O)c2ccc(OCC)c(-c3nc4c(CCC)nn(C)c4c(=O)[nH]3)c2)CC([R])N1[R]</smiles>

Randomly ethylated impurities

$$
\begin{gathered}
R_{1}=M e, R_{2}=H \\
R_{1}=H \text { or Et, } R_{2}=M e
\end{gathered}
$$

(C)
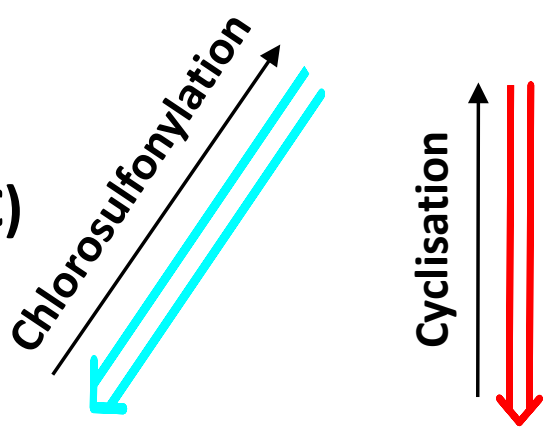

(D)

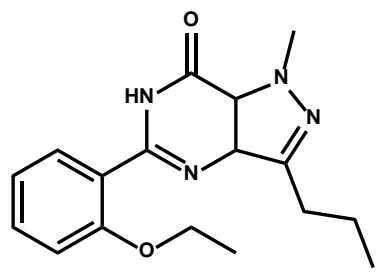

Nucleophilic transfer under acidic conditions

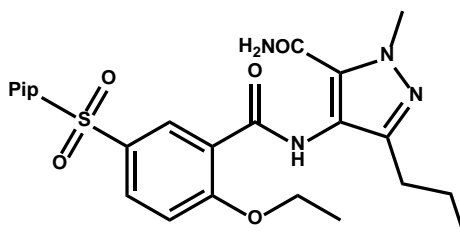

Nucleophilic transfer under basic conditions

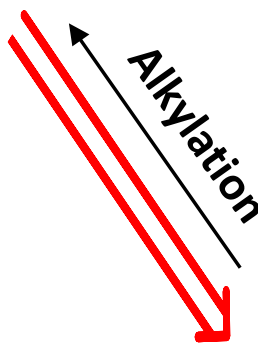

(E)

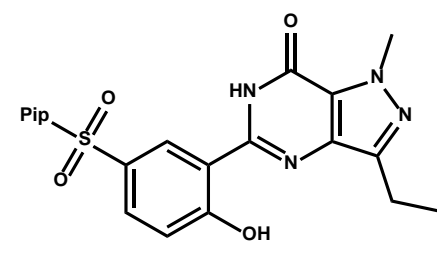

Unselective alkylation 


\section{Author statement}

Gaëtan Assemat: Methodology, Validation, Investigation, Writing-original draft preparation, Visualization. Stéphane Balayssac: Methodology, Validation, Investigation, Visualization, Supervision. Véronique Gilard: Validation, Writing-original draft preparation, Visualization, Supervision, Funding acquisition. Nathalie-Martins-Froment: Investigation. Isabelle Fabing: Investigation. Frédéric Rodriguez: Formal analysis. Yves Génisson: Writing-review and editing. Robert Martino: Writing-review and editing. Myriam Malet-Martino: Conceptualization, Writing-review and editing, Supervision, Funding acquisition. 
Table 1. Chromatographic conditions for purification of sildenafil and its 15 analogues from the dietary supplement analyzed.

\begin{tabular}{|c|c|c|c|c|c|c|c|c|c|c|c|c|c|c|}
\hline & & \multirow{2}{*}{\multicolumn{2}{|c|}{$\frac{\text { SFC conditions }^{\mathrm{a}}}{\text { Raw }}$}} & \multicolumn{9}{|c|}{ Preparative LC conditions $^{\mathrm{a}}$} & \multirow{2}{*}{\multicolumn{2}{|c|}{ Analytical UHPLC $^{\mathrm{a}}$}} \\
\hline Fraction used & & & & \multicolumn{2}{|c|}{ A } & \multicolumn{2}{|c|}{$\mathrm{B}$} & $\mathrm{C}$ & $\mathrm{D}$ & $E$ & $\mathrm{~F}$ & $\mathrm{G}$ & & \\
\hline Instrument & & \multicolumn{2}{|c|}{$\begin{array}{c}\text { Berger Multigram II } \\
\text { preparative SFC }\end{array}$} & \multicolumn{2}{|c|}{ Waters Prep 150 LC } & \multicolumn{2}{|c|}{$\begin{array}{c}\text { Waters Prep } 150 \\
\text { LC } \\
\end{array}$} & \multicolumn{2}{|c|}{ Waters Prep 150 LC } & \multicolumn{3}{|c|}{ Waters Prep 150 LC } & \multicolumn{2}{|c|}{ Waters Acquity UHPLC } \\
\hline Column & & \multicolumn{2}{|c|}{ BetaSil Diol-100 } & \multicolumn{2}{|c|}{ Kromasil C18 } & \multicolumn{2}{|c|}{$\mathrm{CSH} \mathrm{C18}$} & \multicolumn{2}{|c|}{ Kromasil C18 } & \multicolumn{3}{|c|}{ Kromasil C18 } & \multicolumn{2}{|c|}{ Acquity UHPLC CSH C18 } \\
\hline \multirow{2}{*}{ Mobile phase } & (A) & \multicolumn{2}{|c|}{$\mathrm{CO}_{2}$ (100 bar) } & \multicolumn{2}{|c|}{$\begin{array}{c}10 \mathrm{mM} \text { ammonium } \\
\text { acetate }\end{array}$} & \multicolumn{2}{|c|}{$\begin{array}{l}0.1 \%(\mathrm{v} / \mathrm{v}) \mathrm{TFA}^{\mathrm{e}} \\
\text { in water }\end{array}$} & \multicolumn{2}{|c|}{$\begin{array}{c}10 \mathrm{mM} \text { ammonium } \\
\text { acetate }\end{array}$} & \multicolumn{3}{|c|}{$\begin{array}{c}10 \mathrm{mM} \text { ammonium } \\
\text { acetate }\end{array}$} & \multicolumn{2}{|c|}{$0.1 \%(\mathrm{v} / \mathrm{v}) \mathrm{TFA}^{\mathrm{e}}$ in water } \\
\hline & (B) & \multicolumn{2}{|c|}{$\begin{array}{c}0.5 \%(\mathrm{v} / \mathrm{v}) \\
\text { isopropylamine } \\
\text { in methanol }\end{array}$} & \multicolumn{2}{|c|}{$\begin{array}{c}10 \%(\mathrm{v} / \mathrm{v}) \text { of } 100 \mathrm{mM} \\
\text { ammonium acetate } \\
\text { in acetonitrile }\end{array}$} & \multicolumn{2}{|c|}{$\begin{array}{c}10 \%(\mathrm{v} / \mathrm{v}) \text { of } \\
\text { mobile phase }(\mathrm{A}) \\
\text { in acetonitrile }\end{array}$} & \multicolumn{2}{|c|}{$\begin{array}{l}10 \%(\mathrm{v} / \mathrm{v}) \text { of } 100 \mathrm{mM} \\
\text { ammonium acetate } \\
\text { in acetonitrile }\end{array}$} & \multicolumn{3}{|c|}{$\begin{array}{l}10 \%(\mathrm{v} / \mathrm{v}) \text { of } 100 \mathrm{mM} \\
\text { ammonium acetate } \\
\text { in acetonitrile }\end{array}$} & \multicolumn{2}{|c|}{$\begin{array}{l}0.1 \%(\mathrm{v} / \mathrm{v}) \mathrm{TFA}^{\mathrm{e}} \\
\text { in acetonitrile }\end{array}$} \\
\hline \multirow{6}{*}{$\begin{array}{c}\text { Gradient } \\
\text { elution profile }\end{array}$} & Step & $\min$ & $\%(\mathrm{~B})$ & $\min$ & $\%(\mathrm{~B})$ & $\min$ & $\%(\mathrm{~B})$ & $\min$ & $\%(\mathrm{~B})$ & $\min$ & & & $\min$ & $\%(\mathrm{~B})$ \\
\hline & 1 & $0-0.5$ & 10 & $0-50$ & $30-100$ & $0-40$ & $10-70$ & $0-40$ & $30-70$ & $0-40$ & & & $0-4$ & $5-95$ \\
\hline & 2 & $0.5-8$ & $10-28$ & $50-55$ & 100 & $40-41$ & $70-100$ & $40-41$ & $70-100$ & $40-41$ & & & $4-5.5$ & 95 \\
\hline & 3 & $8-15$ & 28 & & & $41-50$ & 100 & $41-50$ & 100 & $41-50$ & & & $5.5-5.51$ & 5 \\
\hline & 4 & $15-16$ & $28-10$ & & & & & & & & & & $5.51-7.3$ & 5 \\
\hline & 5 & $16-20$ & 10 & & & & & & & & & & & \\
\hline Flow rate & & \multicolumn{2}{|c|}{$42.5 \mathrm{~mL} / \mathrm{min}$} & \multicolumn{2}{|c|}{$120 \mathrm{~mL} / \mathrm{min}$} & \multicolumn{2}{|c|}{$120 \mathrm{~mL} / \mathrm{min}$} & 120 & $\mathrm{~L} / \mathrm{min}$ & & $20 \mathrm{~mL} / \mathrm{m}$ & & $0.6 \mathrm{I}$ & \\
\hline Temperature & & 40 & & & & & $\mathrm{TT}$ & & & & RT & & & \\
\hline Injection volume $^{\mathrm{f}}$ & & 0.5 & & & & & $\mathrm{~mL}$ & $40 \mathrm{~mL}$ & $10 \mathrm{~mL}$ & $10 \mathrm{~mL}$ & $12 \mathrm{~mL}$ & $8 \mathrm{~mL}$ & & \\
\hline
\end{tabular}

a UV detection at $235 \mathrm{~nm}$ and for analytical UHPLC, cone voltage of QDa mass detector used in positive mode set at $30 \mathrm{~V}$.

b $250 \mathrm{~mm} \times 21.2 \mathrm{~mm}$ i.d., $5 \mu \mathrm{m}$ particle size.

c $250 \mathrm{~mm} \times 50 \mathrm{~mm}$ i.d., $10 \mu \mathrm{m}$ particle size.

d $100 \mathrm{~mm} \times 2.1 \mathrm{~mm}$ i.d., $1.7 \mu \mathrm{m}$ particle size.

e TFA: trifluoroacetic acid.

${ }^{\mathrm{f}}$ The concentration of powder dissolved in each fraction is different: $50 \mathrm{mg} / \mathrm{mL}$ for SFC, $6.3 \mathrm{mg} / \mathrm{mL}$ for A, $8.5 \mathrm{mg} / \mathrm{mL}$ for B, $4.8 \mathrm{mg} / \mathrm{mL}$ for C, $18.6 \mathrm{mg} / \mathrm{mL}$ for D, $8.5 \mathrm{mg} / \mathrm{mL}$ for $\mathrm{E}, 6.8 \mathrm{mg} / \mathrm{mL}$ for $\mathrm{F}$ and $18.5 \mathrm{mg} / \mathrm{mL}$ for $\mathrm{G}$. 
Table 2. Retention times and masses of the parent ions $\left([\mathrm{M}+\mathrm{H}]^{+}\right)$of purified compounds in UHPLC.

\begin{tabular}{ccc}
\hline $\begin{array}{c}\text { Compound } \\
\text { number }\end{array}$ & $\begin{array}{c}\text { Retention } \\
\text { time }^{\mathrm{a}} \text { (min) }\end{array}$ & $\begin{array}{c}\text { UHPLC- } \\
\text { MS } \\
{[\mathrm{M}+\mathrm{H}]^{+}}\end{array}$ \\
\hline $\mathbf{1}$ & 2.15 & 489 \\
$\mathbf{2}$ & 2.21 & 517 \\
$\mathbf{3}$ & 2.09 & 517 \\
$\mathbf{4}$ & 2.25 & 517 \\
$\mathbf{5}$ & 2.31 & 545 \\
$\mathbf{6}$ & 2.58 & 517 \\
$\mathbf{7}$ & 2.64 & 545 \\
$\mathbf{8}$ & 2.22 & 461 \\
$\mathbf{9}$ & 2.27 & 489 \\
$\mathbf{1 0}$ & 2.86 & 489 \\
$\mathbf{1 1}$ & 2.92 & 517 \\
$\mathbf{1 2}$ & 2.07 & 475 \\
$\mathbf{1 3}$ & 2.16 & 503 \\
$\mathbf{1 4}$ & 2.15 & 447 \\
$\mathbf{1 5}$ & 3.42 & 313 \\
$\mathbf{1 6}$ & 3.42 & 341 \\
\hline
\end{tabular}

${ }^{\text {a } U H P L C ~ a n a l y t i c a l ~ c o n d i t i o n s ~ f o r ~ t h e ~ c o n t r o l ~ o f ~ t h e ~ c h e m i c a l ~ p u r i t y ~ o f ~ p r e p a r a t i v e ~ L C ~ s a m p l e s ~ a r e ~ r e p o r t e d ~ i n ~ T a b l e ~} 1$. 
Table 3. Accurate mass data of parent and fragment ions in positive ESI mode for all the compounds (Cpd) isolated from the dietary supplement analyzed. Mass of parent ion is indicated in bold.

\section{A: methisosildenafil (MSild) and compounds 2-11}

\begin{tabular}{|c|c|c|c|c|c|c|c|c|c|c|c|}
\hline \multirow{2}{*}{$\begin{array}{c}\text { Theoretical } \\
\text { mass and } \\
\text { formula }\end{array}$} & \multicolumn{11}{|c|}{ Experimental mass of parent and fragment ions (relative mass error in ppm) } \\
\hline & MSild(1) & Cpd (2) & Cpd (3) & Cpd (4) & Cpd (5) & Cpd (6) & Cpd (7) & Cpd (8) & Cpd (9) & Cpd (10) & Cpd (11) \\
\hline 545.2910 & & & & & 545.2920 & & 545.2922 & & & & \\
\hline $\mathrm{C}_{27} \mathrm{H}_{41} \mathrm{~N}_{6} \mathrm{O}_{4} \mathrm{~S}^{+}$ & & & & & $(+1.8)$ & & $(+2.2)$ & & & & \\
\hline 517.2597 & & 517.2599 & 517.2595 & 517.2587 & 517.2593 & 517.2591 & 517.2587 & & & & 517.2600 \\
\hline $\mathrm{C}_{25} \mathrm{H}_{37} \mathrm{~N}_{6} \mathrm{O}_{4} \mathrm{~S}^{+}$ & & $(+0.4)$ & $(-0.4)$ & $(-1.9)$ & $(-0.8)$ & $(-1.2)$ & $(-1.9)$ & & & & $(+0.6)$ \\
\hline 489.2284 & 489.2277 & 489.2277 & 489.2278 & 489.2273 & 489.2272 & 489.2276 & 489.2271 & & 489.2292 & 489.2292 & \\
\hline $\mathrm{C}_{23} \mathrm{H}_{33} \mathrm{~N}_{6} \mathrm{O}_{4} \mathrm{~S}^{+}$ & $(-1.4)$ & $(-1.4)$ & $(-1.2)$ & $(-2.2)$ & $(-2.5)$ & $(-1.6)$ & $(-2.7)$ & & $(+1.6)$ & $(+1.6)$ & \\
\hline 461.1971 & & & & & & & & 461.1973 & & & \\
\hline $\mathrm{C}_{21} \mathrm{H}_{29} \mathrm{~N}_{6} \mathrm{O}_{4} \mathrm{~S}^{+}$ & & & & & & & & $(+0.4)$ & & & \\
\hline 460.2019 & & & 460.2007 & 460.2015 & 460.2011 & 460.2008 & 460.2008 & & & & \\
\hline $\mathrm{C}_{22} \mathrm{H}_{30} \mathrm{~N}_{5} \mathrm{O}_{4} \mathrm{~S}^{+}$ & & & $(-2.6)$ & $(-0.9)$ & $(-1.7)$ & $(-2.4)$ & $(-2.4)$ & & & & \\
\hline 432.1700 & 432.1692 & 432.1696 & 432.1690 & 432.1696 & 432.1694 & 432.1695 & 432.1690 & & & & \\
\hline $\mathrm{C}_{20} \mathrm{H}_{26} \mathrm{~N}_{5} \mathrm{O}_{4} \mathrm{~S}^{+}$ & $(-1.9)$ & $(-0.9)$ & $(-2.3)$ & $(-0.9)$ & $(-1.4)$ & $(-1.2)$ & $(-2.3)$ & & & & \\
\hline 405.1597 & & & 405.1592 & 405.1588 & 405.1591 & 405.1591 & 405.1588 & & & & \\
\hline $\mathrm{C}_{19} \mathrm{H}_{25} \mathrm{~N}_{4} \mathrm{O}_{4} \mathrm{~S}^{+}$ & & & $(-1.2)$ & $(-2.2)$ & $(-1.5)$ & $(-1.5)$ & $(-2.2)$ & & & & \\
\hline 377.1278 & 377.1273 & 377.1272 & 377.1281 & 377.1275 & 377.1273 & 377.1277 & 377.1274 & & & & \\
\hline $\mathrm{C}_{17} \mathrm{H}_{21} \mathrm{~N}_{4} \mathrm{O}_{4} \mathrm{~S}^{+}$ & $(-1.3)$ & $(-1.6)$ & $(+0.8)$ & $(-0.8)$ & $(-1.3)$ & $(-0.3)$ & $(-1.1)$ & & & & \\
\hline 375.1127 & & & & & & & & & & 375.1127 & 375.1125 \\
\hline $\mathrm{C}_{17} \mathrm{H}_{19} \mathrm{~N}_{4} \mathrm{O}_{4} \mathrm{~S}^{+}$ & & & & & & & & & & (0) & $(-0.5)$ \\
\hline 347.0814 & & & & & & & & 347.0812 & 347.0815 & & \\
\hline $\mathrm{C}_{15} \mathrm{H}_{15} \mathrm{~N}_{4} \mathrm{O}_{4} \mathrm{~S}^{+}$ & & & & & & & & $(-0.6)$ & $(+0.3)$ & & \\
\hline 340.1899 & & & 340.1895 & 340.1897 & & & & & & & \\
\hline $\mathrm{C}_{19} \mathrm{H}_{24} \mathrm{~N}_{4} \mathrm{O}_{2}{ }^{+}$ & & & $(-1.2)$ & $(-0.6)$ & & & & & & & \\
\hline 339.1815 & & & & 339.1816 & 339.1815 & 339.1815 & 339.1817 & & & & \\
\hline $\mathrm{C}_{19} \mathrm{H}_{23} \mathrm{~N}_{4} \mathrm{O}_{2}^{+}$ & & & & $(+0.3)$ & (0) & (0) & $(+0.6)$ & & & & \\
\hline 327.1458 & & & 327.1464 & 327.1450 & 327.1445 & 327.1446 & 327.1472 & & & 327.1458 & 327.1453 \\
\hline $\mathrm{C}_{17} \mathrm{~N}_{19} \mathrm{~N}_{4} \mathrm{O}_{3}{ }^{+}$ & & & $(+1.8)$ & $(-2.4)$ & $(-4.0)$ & $(-3.7)$ & $(+4.3)$ & & & (0) & $(-1.5)$ \\
\hline 312.1580 & & & 312.1575 & 312.1584 & & & & & & & \\
\hline $\mathrm{C}_{17} \mathrm{H}_{20} \mathrm{~N}_{4} \mathrm{O}_{2}{ }^{+}$ & & & $(-1.6)$ & $(+1.3)$ & & & & & & & \\
\hline
\end{tabular}




\begin{tabular}{|c|c|c|c|c|c|c|c|c|c|c|c|}
\hline $\begin{array}{c}311.1502 \\
\mathrm{C}_{17} \mathrm{H}_{19} \mathrm{~N}_{4} \mathrm{O}_{2}{ }^{+}\end{array}$ & $\begin{array}{c}311.1503 \\
(+0.3)\end{array}$ & $\begin{array}{c}311.1506 \\
(+1.3)\end{array}$ & $\begin{array}{c}311.1508 \\
(+1.9)\end{array}$ & $\begin{array}{c}311.1504 \\
(+0.6)\end{array}$ & $\begin{array}{c}311.1501 \\
(-0.3)\end{array}$ & $\begin{array}{c}311.1505 \\
(+1.0)\end{array}$ & $\begin{array}{c}311.1500 \\
(+0.6)\end{array}$ & & & $\begin{array}{c}311.1510 \\
(+2.6)\end{array}$ & $\begin{array}{c}311.1503 \\
\quad(+0.3)\end{array}$ \\
\hline 299.1144 & 299.1142 & 299.1141 & 299.1137 & 299.1139 & 299.1145 & 299.1141 & 299.1138 & 299.1147 & 299.1147 & 299.1146 & 299.1143 \\
\hline $\mathrm{C}_{15} \mathrm{H}_{15} \mathrm{~N}_{4} \mathrm{O}_{3}{ }^{+}$ & $(-0.7)$ & $(-1.0)$ & $(-2.3)$ & $(-1.6)$ & $(+0.3)$ & $(-1.0)$ & $(-2.0)$ & $(+1.0)$ & $(+1.0)$ & $(+0.7)$ & $(-0.3)$ \\
\hline 284.1268 & & & 284.1272 & 284.1269 & & & & & 284.1266 & & \\
\hline $\mathrm{C}_{15} \mathrm{H}_{16} \mathrm{~N}_{4} \mathrm{O}_{2}^{+}$ & & & $(+1.4)$ & $(+0.4)$ & & & & & $(-0.7)$ & & \\
\hline 283.1190 & 283.1190 & 283.1195 & 283.1195 & 283.1191 & 283.1188 & 283.1192 & 283.1190 & 283.1198 & 283.1196 & 283.1194 & 283.1189 \\
\hline $\mathrm{C}_{15} \mathrm{H}_{15} \mathrm{~N}_{4} \mathrm{O}_{2}{ }^{+}$ & $(0)$ & $(+1.8)$ & $(+1.8)$ & $(+0.4)$ & $(-0.7)$ & $(+0.7)$ & (0) & $(+2.8)$ & $(+2.1)$ & $(+1.4)$ & $(-0.4)$ \\
\hline 166.0980 & 166.0979 & 166.0982 & 166.0985 & 166.0978 & 166.0984 & 166.0981 & 166.0973 & 166.0981 & 166.0980 & 166.0981 & 166.0973 \\
\hline $\mathrm{C}_{8} \mathrm{H}_{12} \mathrm{~N}_{3} \mathrm{O}^{+}$ & $(-0.6)$ & $(+1.2)$ & $(+3.0)$ & $(-1.2)$ & $(+2.4)$ & $(+0.6)$ & $(-4.2)$ & $(+0.6)$ & (0) & $(+0.6)$ & $(-4.2)$ \\
\hline 143.1548 & & & & & & & & & 143.1551 & & \\
\hline $\mathrm{C}_{8} \mathrm{H}_{19} \mathrm{~N}_{2}^{+}$ & & & & & & & & & $(+2.1)$ & & \\
\hline 141.1392 & & 141.1394 & 141.1392 & 141.1396 & 141.1392 & 141.1390 & 141.1391 & & 141.1392 & & 141.1392 \\
\hline $\mathrm{C}_{8} \mathrm{H}_{17} \mathrm{~N}_{2}^{+}$ & & $(+1.4)$ & (0) & $(+2.8)$ & $(0)$ & $(-1.4)$ & $(-0.7)$ & & (0) & & (0) \\
\hline 127.1235 & & 127.1238 & 127.1237 & 127.1239 & 127.1236 & 127.1234 & 127.1236 & & 127.1235 & & 127.1233 \\
\hline $\mathrm{C}_{7} \mathrm{H}_{15} \mathrm{~N}_{2}^{+}$ & & $(+2.4)$ & $(+1.6)$ & $(+3.1)$ & $(+0.8)$ & $(-0.8)$ & $(+0.8)$ & & (0) & & $(-1.6)$ \\
\hline 115.1230 & & & & & & & & 115.1235 & & & \\
\hline $\mathrm{C}_{6} \mathrm{H}_{15} \mathrm{~N}_{2}^{+}$ & & & & & & & & $(+4.3)$ & & & \\
\hline 113.1079 & 113.1077 & 113.1081 & 113.1077 & 113.1076 & 113.1079 & 113.1081 & 113.1081 & 113.1080 & 113.1084 & 113.1079 & 113.1076 \\
\hline $\mathrm{C}_{6} \mathrm{H}_{13} \mathrm{~N}_{2}^{+}$ & $(-1.8)$ & $(+1.8)$ & $(-1.8)$ & $(-2.7)$ & (0) & $(+1.8)$ & $(+1.8)$ & $(+0.9)$ & $(+4.4)$ & (0) & $(-2.7)$ \\
\hline 100.1126 & & 100.1130 & & & 100.1127 & 100.1134 & 100.1129 & & 100.1127 & & 100.1127 \\
\hline $\mathrm{C}_{6} \mathrm{H}_{14} \mathrm{~N}^{+}$ & & $(+4.0)$ & & & $(+1.0)$ & $(+8.0)$ & $(+3.0)$ & & $(+1.0)$ & & $(+1.0)$ \\
\hline 99.0922 & 99.0923 & & 99.0928 & 99.0921 & & 99.0927 & & 99.0924 & & 99.0925 & \\
\hline $\mathrm{C}_{5} \mathrm{H}_{11} \mathrm{~N}_{2}^{+}$ & $(+1.0)$ & & $(+6.1)$ & $(-1.0)$ & & $(+5.0)$ & & $(+2.0)$ & & $(+3.0)$ & \\
\hline 98.0970 & & 98.0972 & & & 98.0972 & 98.0969 & 98.0972 & & 98.0971 & & 98.0971 \\
\hline $\mathrm{C}_{6} \mathrm{H}_{12} \mathrm{~N}^{+}$ & & $(+2.0)$ & & & $(+2.0)$ & $(-1.0)$ & $(+2.0)$ & & $(+1.0)$ & & $(+1.0)$ \\
\hline 86.0970 & & 86.0973 & & & 86.0972 & 86.0976 & 86.0973 & & 86.0976 & & 86.0972 \\
\hline $\mathrm{C}_{5} \mathrm{H}_{12} \mathrm{~N}^{+}$ & & $(+3.5)$ & & & $(+2.3)$ & $(+7.0)$ & $(+3.5)$ & & $(+7.0)$ & & $(+2.3)$ \\
\hline 84.0813 & 84.0814 & 84.0818 & 84.0821 & 84.0820 & 84.0816 & 84.0816 & 84.0813 & 84.0819 & 84.0816 & 84.0816 & 84.0807 \\
\hline $\mathrm{C}_{5} \mathrm{H}_{10} \mathrm{~N}^{+}$ & $(+1.2)$ & $(+5.9)$ & $(+9.5)$ & $(+8.3)$ & $(+3.6)$ & $(+3.6)$ & (0) & $(+7.1)$ & $(+3.6)$ & $(+3.6)$ & $(-7.1)$ \\
\hline 72.0813 & & 72.0818 & & & 72.0816 & 72.0814 & 72.0812 & & 72.0815 & & 72.0816 \\
\hline $\mathrm{C}_{4} \mathrm{H}_{10} \mathrm{~N}^{+}$ & & $(+6.9)$ & & & $(+4.2)$ & $(+1.4)$ & $(-1.4)$ & & $(+2.8)$ & & $(+4.2)$ \\
\hline 71.0735 & 71.0739 & 71.0741 & 71.0737 & 71.0738 & 71.0740 & 71.0741 & 71.0741 & 71.0738 & 71.0741 & 71.0741 & 71.0740 \\
\hline $\mathrm{C}_{4} \mathrm{H}_{9} \mathrm{~N}^{+\bullet}$ & $(+5.6)$ & $(+8.4)$ & $(+2.8)$ & $(+4.2)$ & $(+7.0)$ & $(+8.4)$ & $(+8.4)$ & $(+4.2)$ & $(+8.4)$ & $(+8.4)$ & $(+7.0)$ \\
\hline
\end{tabular}




\section{B: sildenafil (Sild) and compounds 13-16}

\begin{tabular}{|c|c|c|c|c|c|}
\hline \multirow{2}{*}{$\begin{array}{c}\text { Theoretical } \\
\text { mass and } \\
\text { formula }\end{array}$} & \multicolumn{5}{|c|}{$\begin{array}{l}\text { Experimental mass of parent and fragment ions } \\
\text { (relative mass error in ppm) }\end{array}$} \\
\hline & Sild (12) & Cpd (13) & Cpd (14) & Cpd (15) & Cpd (16) \\
\hline 503.2440 & & 503.2448 & & & \\
\hline $\mathrm{C}_{24} \mathrm{H}_{35} \mathrm{~N}_{6} \mathrm{O}_{4} \mathrm{~S}^{+}$ & & $(+1.6)$ & & & \\
\hline 475.2127 & 475.2126 & 475.2119 & & & \\
\hline $\mathrm{C}_{22} \mathrm{H}_{31} \mathrm{~N}_{6} \mathrm{O}_{4} \mathrm{~S}^{+}$ & $(-0.2)$ & $(-1.7)$ & & & \\
\hline 447.1815 & & & 447.1818 & & \\
\hline $\mathrm{C}_{20} \mathrm{H}_{27} \mathrm{~N}_{6} \mathrm{O}_{4} \mathrm{~S}^{+}$ & & & $(+0.7)$ & & \\
\hline 405.1597 & & 405.1596 & & & \\
\hline $\mathrm{C}_{19} \mathrm{H}_{25} \mathrm{~N}_{4} \mathrm{O}_{4} \mathrm{~S}^{+}$ & & $(-0.2)$ & & & \\
\hline 377.1278 & 377.1270 & 377.1296 & & & \\
\hline $\mathrm{C}_{17} \mathrm{H}_{21} \mathrm{~N}_{4} \mathrm{O}_{4} \mathrm{~S}^{+}$ & $(-2.1)$ & $(+4.8)$ & & & \\
\hline 347.0814 & & & 347.0809 & & \\
\hline $\mathrm{C}_{15} \mathrm{H}_{15} \mathrm{~N}_{4} \mathrm{O}_{4} \mathrm{~S}^{+}$ & & & $(+1.4)$ & & \\
\hline 341.1978 & & & & & 341.1980 \\
\hline $\mathrm{C}_{19} \mathrm{H}_{25} \mathrm{~N}_{4} \mathrm{O}_{2}{ }^{+}$ & & & & & $(+0.6)$ \\
\hline 340.1899 & & 340.1883 & & & \\
\hline $\mathrm{C}_{19} \mathrm{H}_{24} \mathrm{~N}_{4} \mathrm{O}_{2}{ }^{+}$ & & $(-4.7)$ & & & \\
\hline 339.1815 & & 339.1816 & & & \\
\hline $\mathrm{C}_{19} \mathrm{H}_{23} \mathrm{~N}_{4} \mathrm{O}_{2}{ }^{+}$ & & $(+0.3)$ & & & \\
\hline 327.1458 & & 327.1465 & & & \\
\hline $\mathrm{C}_{17} \mathrm{H}_{19} \mathrm{~N}_{4} \mathrm{O}_{3}{ }^{+}$ & & $(+2.1)$ & & & \\
\hline 313.1658 & & & & 313.1663 & 313.1666 \\
\hline $\mathrm{C}_{17} \mathrm{H}_{21} \mathrm{~N}_{4} \mathrm{O}_{2}{ }^{+}$ & & & & $(+1.6)$ & $(+2.6)$ \\
\hline 311.1502 & 311.1504 & 311.1510 & & & \\
\hline $\mathrm{C}_{17} \mathrm{H}_{19} \mathrm{~N}_{4} \mathrm{O}_{2}{ }^{+}$ & $(+0.6)$ & $(+2.6)$ & & & \\
\hline 299.1144 & 299.1140 & 299.1151 & 299.1148 & & \\
\hline $\mathrm{C}_{15} \mathrm{H}_{15} \mathrm{~N}_{4} \mathrm{O}_{3}{ }^{+}$ & $(-1.3)$ & $(+2.3)$ & $(1.5)$ & & \\
\hline 285.1346 & & & & 285.1352 & 285.1356 \\
\hline $\mathrm{C}_{15} \mathrm{H}_{17} \mathrm{~N}_{4} \mathrm{O}_{2}{ }^{+}$ & & & & $(+2.1)$ & $(+3.5)$ \\
\hline 283.1190 & 283.1192 & 283.1194 & 283.1198 & & \\
\hline $\mathrm{C}_{15} \mathrm{H}_{15} \mathrm{~N}_{4} \mathrm{O}_{2}{ }^{+}$ & $(+0.7)$ & $(+1.4)$ & $(+2.8)$ & & \\
\hline
\end{tabular}




\begin{tabular}{|c|c|c|c|c|c|}
\hline $\begin{array}{c}166.0980 \\
\mathrm{C}_{8} \mathrm{H}_{12} \mathrm{~N}_{3} \mathrm{O}^{+}\end{array}$ & $\begin{array}{c}166.0979 \\
(-0.6)\end{array}$ & $\begin{array}{c}166.0983 \\
(+1.8)\end{array}$ & $\begin{array}{c}166.0981 \\
(+0.6)\end{array}$ & $\begin{array}{c}166.0981 \\
(+0.6)\end{array}$ & $\begin{array}{c}166.0980 \\
(0)\end{array}$ \\
\hline 163.0541 & 163.0539 & 163.0543 & 163.0549 & & \\
\hline $\mathrm{C}_{5} \mathrm{H}_{11} \mathrm{~N}_{2} \mathrm{O}_{2} \mathrm{~S}^{+}$ & $(-1.2)$ & $(+1.2)$ & $(+4.9)$ & & \\
\hline 101.1079 & & & 101.1081 & & \\
\hline $\mathrm{C}_{5} \mathrm{H}_{13} \mathrm{~N}_{2}{ }^{+}$ & & & $(+2.0)$ & & \\
\hline 100.1000 & 100.1001 & 100.1001 & 100.1001 & & \\
\hline $\mathrm{C}_{5} \mathrm{H}_{12} \mathrm{~N}_{2}{ }^{+\bullet}$ & $(+1.0)$ & $(+1.0)$ & $(+1.0)$ & & \\
\hline 99.0922 & 99.0923 & 99.0924 & 99.0925 & & \\
\hline $\mathrm{C}_{5} \mathrm{H}_{11} \mathrm{~N}_{2}{ }^{+}$ & $(+1.0)$ & $(+2.0)$ & $(+3.0)$ & & \\
\hline 84.0688 & 84.0691 & 84.0688 & & & \\
\hline $\mathrm{C}_{4} \mathrm{H}_{8} \mathrm{~N}_{2}{ }^{+\bullet}$ & $(+3.6)$ & $(0)$ & & & \\
\hline $70.0657^{a}$ & 70.0662 & 70.0662 & 70.0658 & & \\
\hline $\mathrm{C}_{4} \mathrm{H}_{8} \mathrm{~N}^{+}$ & $(+7.1)$ & $(+7.1)$ & $(+1.4)$ & & \\
\hline $58.0661^{\mathrm{a}}$ & 58.0664 & 58.0662 & 58.0661 & & \\
\hline $\mathrm{C}_{3} \mathrm{H}_{8} \mathrm{~N}^{+}$ & $(+5.2)$ & $(+1.7)$ & $(0)$ & & \\
\hline
\end{tabular}

a The ions at $\mathrm{m} / \mathrm{z} 70$ and 58 are also observed in the degradation pathways of

methisosildenafil (MSild) and compounds 2-11 although not mentioned in Table 3A. 
Table 4. Accurate mass data of parent and fragment ions in negative ESI mode for sildenafil (Sild) and some of its analogues found in the dietary supplement analyzed. Mass of parent ion is indicated in bold. Cpd: compound; MSild: methisosildenafil.

\begin{tabular}{|c|c|c|c|c|c|c|c|c|c|c|}
\hline \multirow{2}{*}{$\begin{array}{c}\text { Theoretical } \\
\text { mass }\end{array}$} & \multirow{2}{*}{ Formula } & \multicolumn{9}{|c|}{ Experimental mass (relative mass error in ppm) } \\
\hline & & MSild (1) & Cpd (2) & Cpd (8) & Cpd (9) & Cpd (10) & Cpd (11) & Sild (12) & Cpd (14) & Cpd (15) \\
\hline 515.2440 & $\mathrm{C}_{25} \mathrm{H}_{35} \mathrm{~N}_{6} \mathrm{O}_{4} \mathrm{~S}^{-}$ & & $\begin{array}{c}\mathbf{5 1 5 . 2 4 4 8} \\
(+1.6)\end{array}$ & & & & $\begin{array}{c}\mathbf{5 1 5 . 2 4 4 2} \\
(+0.4)\end{array}$ & & & \\
\hline 487.2127 & $\mathrm{C}_{23} \mathrm{H}_{31} \mathrm{~N}_{6} \mathrm{O}_{4} \mathrm{~S}^{-}$ & $\begin{array}{c}\mathbf{4 8 7 . 2 1 3 3} \\
(+1.2)\end{array}$ & $\begin{array}{c}487.2124 \\
(-0.6)\end{array}$ & & $\begin{array}{c}\mathbf{4 8 7 . 2 1 3 0} \\
(+0.6)\end{array}$ & $\begin{array}{c}\mathbf{4 8 7 . 2 1 4 4} \\
(+3.5)\end{array}$ & $\begin{array}{c}487.2124 \\
\quad(-0.6)\end{array}$ & & & \\
\hline 473.1971 & $\mathrm{C}_{22} \mathrm{H}_{29} \mathrm{~N}_{6} \mathrm{O}_{4} \mathrm{~S}^{-}$ & & & & & & & $\begin{array}{c}\mathbf{4 7 3 . 1 9 7 9} \\
(+1.7)\end{array}$ & & \\
\hline 459.1814 & $\mathrm{C}_{21} \mathrm{H}_{27} \mathrm{~N}_{6} \mathrm{O}_{4} \mathrm{~S}^{-}$ & $\begin{array}{c}459.1810 \\
(-0.9)\end{array}$ & & $\begin{array}{c}\mathbf{4 5 9 . 1 8 1 3} \\
(-0.2)\end{array}$ & & $\begin{array}{c}459.1817 \\
(+0.7)\end{array}$ & & & & \\
\hline 445.1658 & $\mathrm{C}_{20} \mathrm{H}_{25} \mathrm{~N}_{6} \mathrm{O}_{4} \mathrm{~S}^{-}$ & & & & & & & $\begin{array}{c}445.1652 \\
(-1.3)\end{array}$ & $\begin{array}{c}\mathbf{4 4 5 . 1 6 5 3} \\
(-1.1)\end{array}$ & \\
\hline 326.1379 & $\mathrm{C}_{17} \mathrm{H}_{18} \mathrm{~N}_{4} \mathrm{O}_{3}{ }^{-}$ & & & & & $\begin{array}{c}326.1386 \\
(+2.1)\end{array}$ & $\begin{array}{c}326.1373 \\
(-1.8)\end{array}$ & & & \\
\hline 311.1508 & $\mathrm{C}_{17} \mathrm{H}_{19} \mathrm{~N}_{4} \mathrm{O}_{2}^{-}$ & & & & & & & & & $\begin{array}{c}311.1509 \\
(+0.3)\end{array}$ \\
\hline 310.1430 & $\mathrm{C}_{17} \mathrm{H}_{18} \mathrm{~N}_{4} \mathrm{O}_{2}{ }^{-\bullet}$ & $\begin{array}{c}310.1427 \\
(-1.0)\end{array}$ & $\begin{array}{c}310.1422 \\
(-2.6)\end{array}$ & & & $\begin{array}{c}310.1431 \\
(+0.3)\end{array}$ & $\begin{array}{c}310.1426 \\
(-1.3)\end{array}$ & $\begin{array}{c}310.1436 \\
(+1.9)\end{array}$ & & \\
\hline 298.1066 & $\mathrm{C}_{15} \mathrm{H}_{14} \mathrm{~N}_{4} \mathrm{O}_{3}^{-}$ & $\begin{array}{c}298.1073 \\
(+2.3)\end{array}$ & $\begin{array}{c}298.1074 \\
(+2.7)\end{array}$ & $\begin{array}{c}298.1062 \\
(-1.3)\end{array}$ & $\begin{array}{c}298.1072 \\
(+2.0)\end{array}$ & $\begin{array}{c}298.1066 \\
(0)\end{array}$ & $\begin{array}{c}298.1075 \\
(+3.0)\end{array}$ & $\begin{array}{c}298.1062 \\
(-1.3)\end{array}$ & $\begin{array}{c}298.1071 \\
(+1.7)\end{array}$ & \\
\hline 283.1195 & $\mathrm{C}_{15} \mathrm{H}_{15} \mathrm{~N}_{4} \mathrm{O}_{2}^{-}$ & & & & & & & & & $\begin{array}{c}283.1192 \\
(-1.1)\end{array}$ \\
\hline 282.1117 & $\mathrm{C}_{15} \mathrm{H}_{14} \mathrm{~N}_{4} \mathrm{O}_{2}{ }^{-\bullet}$ & $\begin{array}{c}282.1114 \\
(-1.1)\end{array}$ & $\begin{array}{c}282.1114 \\
(-1.1)\end{array}$ & $\begin{array}{c}282.1117 \\
(0)\end{array}$ & $\begin{array}{c}282.1119 \\
(+0.7)\end{array}$ & $\begin{array}{c}282.1112 \\
(-1.8)\end{array}$ & $\begin{array}{c}282.1116 \\
(-0.4)\end{array}$ & $\begin{array}{c}282.1115 \\
(-0.7)\end{array}$ & $\begin{array}{c}282.1114 \\
(-1.1)\end{array}$ & \\
\hline
\end{tabular}


Table 5. ${ }^{1} \mathrm{H}$ and ${ }^{13} \mathrm{C}$ NMR data of methisosildenafil (MSild), sildenafil (Sild) and their related compounds purified from the dietary supplement analyzed. $\delta$ were measured in $\mathrm{CD}_{3} \mathrm{CN}: \mathrm{D}_{2} \mathrm{O}(80: 20)$.

\begin{tabular}{|c|c|c|c|c|c|c|c|c|c|c|c|c|c|c|c|c|}
\hline \multirow[b]{2}{*}{$\mathrm{N}^{\circ}$ (a) } & \multicolumn{4}{|c|}{ MSild (1) } & \multicolumn{4}{|c|}{ MSildEt $^{\mathrm{N} 4}(3)$} & \multicolumn{4}{|c|}{ MSildEt $^{\mathrm{N6}}(4)$} & \multicolumn{4}{|c|}{$\mathrm{MSildEt}^{\mathrm{O7}}(\mathbf{6})$} \\
\hline & $\begin{array}{c}{ }^{1} \mathrm{H} \\
(\mathrm{ppm}) \\
\end{array}$ & & $\begin{array}{c}\begin{array}{c}\text { Multiplicity }{ }^{(\mathrm{b})} \\
(\mathrm{J}, \mathrm{Hz})\end{array} \\
\end{array}$ & $\begin{array}{c}\delta^{13} \mathrm{C} \\
(\mathrm{ppm}) \\
\end{array}$ & $\delta{ }^{1} \mathrm{H}(\mathrm{ppm})$ & & $\begin{array}{c}\begin{array}{c}\text { Multiplicity }{ }^{(b)} \\
(\mathrm{J}, \mathrm{Hz})\end{array} \\
\end{array}$ & $\begin{array}{c}\delta^{13} \mathrm{C} \\
(\mathrm{ppm})\end{array}$ & $\begin{array}{c}{ }^{1} \mathrm{H} \\
(\mathrm{ppm})\end{array}$ & & $\begin{array}{c}\begin{array}{c}\text { Multiplicity }{ }^{(\mathrm{b})} \\
(\mathrm{J}, \mathrm{Hz})\end{array} \\
\end{array}$ & $\begin{array}{c}\delta^{13} \mathrm{C} \\
(\mathrm{ppm})\end{array}$ & $\begin{array}{c}{ }^{1} \mathrm{H} \\
(\mathrm{ppm}) \\
\end{array}$ & & $\begin{array}{c}\begin{array}{c}\text { Multiplicity }{ }^{(b)} \\
(\mathrm{J}, \mathrm{Hz})\end{array} \\
\end{array}$ & $\begin{array}{c}\delta^{13} \mathrm{C} \\
(\mathrm{ppm}) \\
\end{array}$ \\
\hline 3 & - & - & - & 148.9 & - & - & - & 140.7 & - & - & - & 148.2 & - & - & - & 148.3 \\
\hline 5 & - & - & - & 150.7 & - & - & - & 158.4 & - & - & - & 153.1 & - & - & & 158.4 \\
\hline 7 & - & - & - & 157.0 & - & - & - & 164.7 & - & - & - & 157.1 & - & - & - & 159.1 \\
\hline 8 & - & - & - & 127.4 & - & - & & 129.4 & - & - & - & 127.5 & - & - & - & 124.2 \\
\hline 9 & - & - & - & 141.0 & - & - & - & 130.5 & - & - & - & 138.9 & - & - & - & 146.2 \\
\hline 10 & 4.20 & $3 \mathrm{H}$ & $\mathrm{s}$ & 40.4 & 4.24 & $3 \mathrm{H}$ & $\mathrm{s}$ & 40.5 & 4.21 & $3 \mathrm{H}$ & $\mathrm{s}$ & 40.4 & 4.20 & $3 \mathrm{H}$ & $\mathrm{s}$ & 41.0 \\
\hline 11 & 2.89 & $2 \mathrm{H}$ & $\mathrm{t}(7.4)$ & 29.9 & $2.91_{2} / 2.91_{5}$ & $2 \mathrm{H}$ & 2*app t (7.5) & 31.8 & 2.79 & $2 \mathrm{H}$ & $\mathrm{t}(7.4)$ & 29.6 & 2.94 & $2 \mathrm{H}$ & $\mathrm{t}(7.5)$ & 30.2 \\
\hline 12 & 1.81 & $2 \mathrm{H}$ & sext (7.4) & 24.8 & $1.79_{7} / 1.79_{9}$ & $2 \mathrm{H}$ & $2 *$ app sext (7.5) & 25.8 & 1.70 & $2 \mathrm{H}$ & sext (7.4) & 25.0 & 1.81 & $2 \mathrm{H}$ & sext (7.5) & 25.0 \\
\hline 13 & 0.98 & $3 \mathrm{H}$ & $t(7.4)$ & 15.9 & 1.02 & $3 \mathrm{H}$ & $t(7.5)$ & 15.9 & 0.92 & $3 \mathrm{H}$ & $t(7.4)$ & 15.8 & 0.96 & $3 \mathrm{H}$ & $\mathrm{t}(7.5)$ & 16.0 \\
\hline 14 & - & - & & 124.7 & - & - & - & 126.3 & - & - & - & 128.1 & - & - & - & 132.1 \\
\hline 15 & 8.24 & $1 \mathrm{H}$ & $\mathrm{d}(2.4)$ & 133.0 & 7.82 & $1 \mathrm{H}$ & $\mathrm{d}(2.4)$ & 132.4 & 7.81 & $1 \mathrm{H}$ & $\mathrm{d}(2.4)$ & 132.4 & 8.00 & $1 \mathrm{H}$ & $d(2.5)$ & 133.8 \\
\hline 16 & & & & 130.2 & & - & - & 130.0 & - & & - & 129.2 & & & - & 128.8 \\
\hline 17 & 7.89 & $1 \mathrm{H}$ & dd (8.9; 2.4) & 134.7 & 7.94 & $1 \mathrm{H}$ & dd (8.9; 2.4) & 134.8 & 7.96 & $1 \mathrm{H}$ & dd (8.9; 2.4) & 134.6 & 7.87 & $1 \mathrm{H}$ & dd $(8.8 ; 2.5)$ & 133.5 \\
\hline 18 & 7.35 & $1 \mathrm{H}$ & $\mathrm{d}(8.9)$ & 116.3 & 7.35 & $1 \mathrm{H}$ & d (8.9) & 116.0 & 7.35 & $1 \mathrm{H}$ & d (8.9) & 116.0 & 7.32 & $1 \mathrm{H}$ & d (8.8) & 116.4 \\
\hline 19 & - & - & - & 162.8 & - & - & - & 161.9 & - & - & - & 162.8 & - & - & - & 163.9 \\
\hline 20 & 4.33 & $2 \mathrm{H}$ & $q(7.0)$ & 68.5 & 4.23 & $2 \mathrm{H}$ & $q(7.0)$ & 68.1 & 4.21 & $2 \mathrm{H}$ & $q(7.0)$ & 68.0 & 4.21 & $2 \mathrm{H}$ & $q(7.0)$ & 67.9 \\
\hline 21 & 1.47 & $3 \mathrm{H}$ & $\mathrm{t}(7.0)$ & 16.5 & 1.29 & $3 \mathrm{H}$ & $\mathrm{t}(7.0)$ & 16.5 & 1.26 & $3 \mathrm{H}$ & $t(7.0)$ & 16.4 & 1.33 & $3 \mathrm{H}$ & $t(7.0)$ & 16.8 \\
\hline $24 / 28^{\text {eq }(c)}$ & 3.60 & $2 \mathrm{H}$ & $\mathrm{dm}(11.3)$ & 54.0 & 3.58 & $2 \mathrm{H}$ & $\mathrm{dm}(11.2)$ & $54.0 / 53.9$ & 3.86 & $2 \mathrm{H}$ & $\operatorname{dm}(13.0)$ & $50.9_{5} / 50.9_{3}$ & 3.87 & $2 \mathrm{H}$ & $\operatorname{dm}(13.0)$ & 51.0 \\
\hline $24 / 28^{\text {ax (c) }}$ & 1.94 & $2 \mathrm{H}$ & app t (11.3) & 54.0 & $2.02 / 1.93$ & $2 \mathrm{H}$ & 2*app t (11.2) & $54.0 / 53.9$ & $2.46 / 2.38$ & $2 \mathrm{H}$ & $2 * \operatorname{dd}(13.0 ; 11.4)$ & $50.9_{5} / 50.9_{3}$ & 2.43 & $2 \mathrm{H}$ & $\mathrm{dd}(13.0 ; 11.6)$ & 51.0 \\
\hline $25 / 27$ & 2.88 & $2 \mathrm{H}$ & $\mathrm{m}$ & 52.7 & 2.90 & $2 \mathrm{H}$ & $\mathrm{m}$ & $53.0 / 52.9$ & 3.40 & $2 \mathrm{H}$ & $\mathrm{m}$ & $54.2 / 54.3$ & 3.40 & $2 \mathrm{H}$ & $\mathrm{m}$ & 54.5 \\
\hline $29 / 30$ & 1.01 & $6 \mathrm{H}$ & d (6.4) & 20.5 & $1.04 / 1.01$ & $6 \mathrm{H}$ & $2 * d(6.5)$ & 20.5 & $1.26 / 1.24$ & $6 \mathrm{H}$ & $2 * d(6.8)$ & 17.7 & 1.24 & $6 \mathrm{H}$ & $d(6.6)$ & 17.8 \\
\hline 31 & - & - & - & - & $4.14 / 3.96$ & $2 \mathrm{H}$ & $2 *$ qd (15.0; 7.2$)$ & 47.8 & 4.12/3.62 & $2 \mathrm{H}$ & $2 *$ qd $(14.0 ; 7.1)$ & 43.5 & 4.65 & $2 \mathrm{H}$ & $\mathrm{q}(7.1)$ & 66.4 \\
\hline 32 & - & - & - & - & 1.20 & $3 \mathrm{H}$ & $t(7.2)$ & 17.5 & 1.07 & $3 \mathrm{H}$ & $t(7.1)$ & 16.1 & 1.50 & $3 \mathrm{H}$ & $\mathrm{t}(7.1)$ & 16.5 \\
\hline
\end{tabular}




\begin{tabular}{|c|c|c|c|c|c|c|c|c|c|c|c|c|}
\hline \multirow[b]{2}{*}{$\mathrm{N}^{\circ \text { (a) }}$} & \multicolumn{4}{|c|}{ MSildEt $^{\mathrm{N} 26}$ (2) } & \multicolumn{4}{|c|}{ MSildEt ${ }^{\mathrm{N} 6} \mathrm{Et}^{\mathrm{N} 26}(5)$} & \multicolumn{4}{|c|}{ MSildEt ${ }^{\mathrm{O} 7} \mathrm{Et}^{\mathrm{N} 26}(7)$} \\
\hline & $\begin{array}{r}\begin{array}{r}\delta^{1} \mathrm{H} \\
(\mathrm{ppm})\end{array} \\
\end{array}$ & & $\begin{array}{c}\text { Multiplicity }^{(\mathrm{b})} \\
\text { (J, Hz) }\end{array}$ & $\begin{array}{l}{ }^{13} \mathrm{C} \\
(\mathrm{ppm}) \\
\end{array}$ & $\begin{array}{c}{ }^{1}{ }^{1} \mathrm{H} \\
(\mathrm{ppm})\end{array}$ & & $\begin{array}{c}\text { Multiplicity }^{(\mathrm{b})} \\
(\mathrm{J}, \mathrm{Hz})\end{array}$ & $\begin{array}{c}\delta^{13} \mathrm{C} \\
(\mathrm{ppm})\end{array}$ & $\begin{array}{r}\delta^{1} \mathrm{H} \\
(\mathrm{ppm}) \\
\end{array}$ & & $\begin{array}{c}\text { Multiplicity }{ }^{(b)} \\
\text { (J, Hz) }\end{array}$ & $\begin{array}{l}\begin{array}{l}\delta^{13} \mathrm{C} \\
(\mathrm{ppm})\end{array} \\
\end{array}$ \\
\hline 3 & - & - & - & 148.9 & - & - & - & 148.3 & - & - & - & 148.3 \\
\hline 5 & - & - & - & 150.9 & - & - & - & 153.1 & - & - & - & 158.3 \\
\hline 7 & - & - & - & 157.1 & - & - & - & 157.2 & - & - & - & 159.0 \\
\hline 8 & - & - & - & 127.5 & - & - & - & 127.5 & - & - & - & 124.1 \\
\hline 9 & - & - & - & 141.1 & - & - & - & 139.1 & - & - & - & 146.4 \\
\hline 10 & 4.20 & $3 \mathrm{H}$ & $\mathrm{s}$ & 40.5 & 4.23 & $3 \mathrm{H}$ & $\mathrm{s}$ & 40.4 & 4.21 & $3 \mathrm{H}$ & $\mathrm{s}$ & 40.9 \\
\hline 11 & 2.89 & $2 \mathrm{H}$ & $\mathrm{t}(7.4)$ & 30.0 & 2.81 & $2 \mathrm{H}$ & $\mathrm{t}(7.4)$ & 29.6 & 2.96 & $2 \mathrm{H}$ & $\mathrm{t}(7.4)$ & 30.2 \\
\hline 12 & 1.80 & $2 \mathrm{H}$ & sext (7.4) & 24.9 & 1.73 & $2 \mathrm{H}$ & sext (7.4) & 25.0 & 1.84 & $2 \mathrm{H}$ & sext (7.4) & 24.9 \\
\hline 13 & 0.98 & $3 \mathrm{H}$ & $\mathrm{t}(7.4)$ & 16.0 & 0.94 & $3 \mathrm{H}$ & $\mathrm{t}(7.4)$ & 15.8 & 0.98 & $3 \mathrm{H}$ & $\mathrm{t}(7.4)$ & 16.0 \\
\hline 14 & - & - & - & 124.9 & - & - & - & 129.6 & - & - & - & 129.1 \\
\hline 15 & 8.22 & $1 \mathrm{H}$ & d (2.4) & 133.2 & 7.78 & $1 \mathrm{H}$ & $\mathrm{d}(2.4)$ & 132.5 & 8.01 & $1 \mathrm{H}$ & $\mathrm{d}(2.5)$ & 133.9 \\
\hline 16 & - & - & - & 130.1 & - & - & - & 128.0 & - & - & - & 131.9 \\
\hline 17 & 7.89 & $1 \mathrm{H}$ & dd (8.8; 2.4) & 134.9 & 7.92 & $1 \mathrm{H}$ & dd (8.9; 2.4) & 134.4 & 7.83 & $1 \mathrm{H}$ & dd $(8.8 ; 2.5)$ & 133.3 \\
\hline 18 & 7.35 & $1 \mathrm{H}$ & $\mathrm{d}(8.8)$ & 116.4 & 7.33 & $1 \mathrm{H}$ & $\mathrm{d}(8.9)$ & 115.8 & 7.31 & $1 \mathrm{H}$ & d (8.8) & 116.1 \\
\hline 19 & - & - & - & 163.0 & - & - & & 162.4 & - & - & - & 163.4 \\
\hline 20 & 4.32 & $2 \mathrm{H}$ & $q(7.0)$ & 68.6 & 4.22 & $2 \mathrm{H}$ & q (7.0) & 67.9 & 4.22 & $2 \mathrm{H}$ & $q(7.0)$ & 67.7 \\
\hline 21 & 1.47 & $3 \mathrm{H}$ & $\mathrm{t}(7.0)$ & 16.6 & 1.28 & $3 \mathrm{H}$ & $\mathrm{t}(7.0)$ & 16.4 & 1.35 & $3 \mathrm{H}$ & $\mathrm{t}(7.0)$ & 16.8 \\
\hline $24 / 28^{\mathrm{eq}(\mathrm{c})}$ & 3.54 & $2 \mathrm{H}$ & $\operatorname{dm}(11.3)$ & 54.8 & 3.52 & $2 \mathrm{H}$ & $\mathrm{dm}(11.5)$ & $54.8 / 54.9$ & 3.53 & $2 \mathrm{H}$ & $\mathrm{dm}(11.2)$ & 54.9 \\
\hline $24 / 28^{\operatorname{ax}(c)}$ & 2.14 & $2 \mathrm{H}$ & app t (11.3) & 54.8 & $2.17 / 2.11$ & $2 \mathrm{H}$ & 2*app t (11.1) & $54.8 / 54.9$ & 2.14 & $2 \mathrm{H}$ & app t (11.2) & 54.9 \\
\hline $25 / 27$ & 2.74 & $2 \mathrm{H}$ & $\mathrm{m}$ & 54.9 & 2.72 & $2 \mathrm{H}$ & $\mathrm{m}$ & $54.75 / 54.7$ & 2.73 & $2 \mathrm{H}$ & $\mathrm{m}$ & 54.8 \\
\hline $29 / 30$ & 1.04 & $6 \mathrm{H}$ & d (6.4) & 18.9 & $1.05 / 1.02$ & $6 \mathrm{H}$ & $2 * d(6.4)$ & 18.9 & 1.04 & $6 \mathrm{H}$ & $d(6.2)$ & 19.0 \\
\hline 31 & 2.84 & $2 \mathrm{H}$ & $q(7.2)$ & 42.5 & $4.15 / 3.63$ & $2 \mathrm{H}$ & $2 *$ qd $(14.1 ; 7.1)$ & 43.4 & 4.67 & $2 \mathrm{H}$ & $\mathrm{q}(7.1)$ & 66.2 \\
\hline 32 & 0.86 & $3 \mathrm{H}$ & $\mathrm{t}(7.2)$ & 8.6 & 1.09 & $3 \mathrm{H}$ & $\mathrm{t}(7.1)$ & 16.1 & 1.51 & $3 \mathrm{H}$ & $\mathrm{t}(7.1)$ & 16.5 \\
\hline 33 & - & - & - & - & 2.84 & $2 \mathrm{H}$ & $\mathrm{q}(7.2)$ & 42.4 & 2.83 & $2 \mathrm{H}$ & $q(7.2)$ & 42.5 \\
\hline 34 & - & - & - & - & 0.87 & $3 \mathrm{H}$ & $\mathrm{t}(7.2)$ & 8.5 & 0.86 & $3 \mathrm{H}$ & $\mathrm{t}(7.2)$ & 8.6 \\
\hline
\end{tabular}




\begin{tabular}{|c|c|c|c|c|c|c|c|c|c|c|c|c|c|c|c|c|}
\hline \multirow[b]{2}{*}{$\mathrm{N}^{\circ}$ (a) } & \multicolumn{4}{|c|}{ MSildOH (8) } & \multicolumn{4}{|c|}{ MSildOHEt $^{\mathrm{N26}}(\mathbf{9})^{(\mathrm{d})}$} & \multicolumn{4}{|c|}{ MSildOHEt $^{07}$ (10) } & \multicolumn{4}{|c|}{ MSildOHEt ${ }^{\mathrm{O} 7} \mathrm{Et}^{\mathrm{N} 26}(\mathbf{1 1})$} \\
\hline & $\begin{array}{c}{ }^{1} \mathrm{H} \\
(\mathrm{ppm})\end{array}$ & & 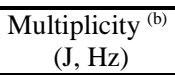 & $\begin{array}{c}\delta^{13} \mathrm{C} \\
(\mathrm{ppm})\end{array}$ & $\begin{array}{l}{ }^{\delta^{1} \mathrm{H}} \\
(\mathrm{ppm})\end{array}$ & & $\begin{array}{c}\text { Multiplicity }^{(\mathrm{b})} \\
\text { (J, Hz) }\end{array}$ & $\begin{array}{c}\delta^{13} \mathrm{C} \\
\text { (ppm) }\end{array}$ & $\begin{array}{c}{ }^{1}{ }^{1} \mathrm{H} \\
(\mathrm{ppm})\end{array}$ & & $\begin{array}{l}\text { Multiplicity }{ }^{(\mathrm{b})} \\
(\mathrm{J}, \mathrm{Hz})\end{array}$ & $\begin{array}{l}\delta^{13} \mathrm{C} \\
(\mathrm{ppm})\end{array}$ & 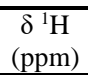 & & $\begin{array}{l}\text { Multiplicity (b) }^{(\mathrm{b})} \\
\text { (J, Hz) }\end{array}$ & $\begin{array}{c}\delta^{13} \mathrm{C} \\
(\mathrm{ppm})\end{array}$ \\
\hline 3 & - & - & - & 147.8 & - & - & - & 147.7 & - & - & - & 147.2 & - & - & - & 147.4 \\
\hline 5 & - & - & - & 155.5 & - & - & - & 156.7 & - & - & - & 158.8 & - & - & - & 158.9 \\
\hline 7 & - & - & - & 158.1 & - & - & - & 159.1 & - & - & - & 159.3 & - & - & - & 159.5 \\
\hline 8 & - & - & - & 127.3 & - & - & - & 127.6 & - & - & - & 124.0 & - & - & - & 124.8 \\
\hline 9 & - & - & - & 141.8 & - & - & - & 142.2 & - & - & - & 143.5 & - & - & - & 143.6 \\
\hline 10 & 4.17 & $3 \mathrm{H}$ & $\mathrm{s}$ & 40.3 & 4.18 & $3 \mathrm{H}$ & $\mathrm{s}$ & 40.4 & 4.21 & $3 \mathrm{H}$ & $\mathrm{s}$ & 41.0 & 4.22 & $3 \mathrm{H}$ & $\mathrm{s}$ & 41.1 \\
\hline 11 & 2.89 & $2 \mathrm{H}$ & $\mathrm{t}(7.4)$ & 30.0 & 2.90 & $2 \mathrm{H}$ & $\mathrm{t}(7.4)$ & 30.2 & 2.97 & $2 \mathrm{H}$ & $\mathrm{t}(7.4)$ & 30.2 & 2.99 & $2 \mathrm{H}$ & $\mathrm{t}(7.4)$ & 30.3 \\
\hline 12 & 1.81 & $2 \mathrm{H}$ & sext (7.4) & 24.7 & 1.84 & $2 \mathrm{H}$ & sext (7.4) & 24.9 & 1.85 & $2 \mathrm{H}$ & sext (7.4) & 24.6 & 1.86 & $2 \mathrm{H}$ & sext (7.4) & 24.8 \\
\hline 13 & 0.99 & $3 \mathrm{H}$ & $t(7.4)$ & 16.0 & 1.00 & $3 \mathrm{H}$ & $t(7.4)$ & 16.2 & 1.00 & $3 \mathrm{H}$ & $t(7.4)$ & 16.0 & 1.00 & $3 \mathrm{H}$ & $t(7.4)$ & 16.1 \\
\hline 14 & - & - & - & 119.3 & - & - & - & 119.8 & - & - & - & 122.3 & - & - & - & 122.5 \\
\hline 15 & 8.59 & $1 \mathrm{H}$ & $\mathrm{d}(2.7)$ & 132.0 & 8.50 & $1 \mathrm{H}$ & $\mathrm{br}$ & 132.3 & 8.79 & $1 \mathrm{H}$ & d (2.4) & 132.2 & 8.82 & $1 \mathrm{H}$ & d (2.4) & 132.4 \\
\hline 16 & - & - & - & 120.3 & - & - & - & $\mathrm{ND}^{(\mathrm{e})}$ & - & - & - & 128.7 & - & - & - & 128.7 \\
\hline 17 & 7.54 & $1 \mathrm{H}$ & $\mathrm{dd}(8.9 ; 2.7)$ & 133.7 & 7.46 & $1 \mathrm{H}$ & dd (8.9; 2.6) & 133.7 & 7.73 & $1 \mathrm{H}$ & dd $(8.7 ; 2.4)$ & 133.9 & 7.75 & $1 \mathrm{H}$ & dd (8.7; 2.4) & 134.2 \\
\hline 18 & 6.83 & $1 \mathrm{H}$ & $\mathrm{d}(8.9)$ & 125.1 & 6.75 & $1 \mathrm{H}$ & $\mathrm{d}(8.9)$ & 125.0 & 7.18 & $1 \mathrm{H}$ & $\mathrm{d}(8.7)$ & 121.1 & 7.20 & $1 \mathrm{H}$ & $\mathrm{d}(8.7)$ & 121.3 \\
\hline 19 & - & - & - & 176.0 & - & - & - & 176.3 & - & - & - & 165.9 & - & - & - & 166.1 \\
\hline 20 & - & - & - & - & - & - & - & - & - & - & - & - & - & - & - & - \\
\hline 21 & - & - & - & - & - & - & - & - & - & - & - & - & - & - & - & - \\
\hline $24 / 28^{\text {eq (c) }}$ & 3.81 & $2 \mathrm{H}$ & dm (11.9) & 53.7 & 3.49 & $2 \mathrm{H}$ & $\mathrm{dm}(11.3)$ & 55.1 & 3.61 & $2 \mathrm{H}$ & $\mathrm{dm}(11.2)$ & 54.5 & 3.57 & $2 \mathrm{H}$ & $\mathrm{dm}(11.2)$ & 55.0 \\
\hline $24 / 28^{\operatorname{ax~(c)}}$ & 2.32 & $2 \mathrm{H}$ & app t (11.5) & 53.7 & 2.12 & $2 \mathrm{H}$ & app t (11.3) & 55.1 & 1.90 & $2 \mathrm{H}$ & app t (11.0) & 54.5 & 2.15 & $2 \mathrm{H}$ & app t (11.0) & 55.0 \\
\hline $25 / 27$ & 3.30 & $2 \mathrm{H}$ & $\mathrm{m}$ & 53.0 & 2.73 & $2 \mathrm{H}$ & $\mathrm{m}$ & 54.9 & 2.85 & $2 \mathrm{H}$ & $\mathrm{m}$ & 52.8 & 2.73 & $2 \mathrm{H}$ & $\mathrm{m}$ & 54.9 \\
\hline $29 / 30$ & 1.21 & $6 \mathrm{H}$ & $\mathrm{d}(6.5)$ & 20.1 & 1.03 & $6 \mathrm{H}$ & $\mathrm{d}(6.2)$ & 19.1 & 0.99 & $6 \mathrm{H}$ & $\mathrm{d}(6.4)$ & 20.8 & 1.03 & $6 \mathrm{H}$ & d (6.3) & 19.1 \\
\hline 31 & - & - & - & - & 2.83 & $2 \mathrm{H}$ & $\mathrm{q}(7.1)$ & 42.6 & 4.80 & $2 \mathrm{H}$ & $q(7.1)$ & 67.0 & 4.82 & $2 \mathrm{H}$ & $\mathrm{q}(7.1)$ & 67.1 \\
\hline 32 & - & - & - & - & 0.86 & $3 \mathrm{H}$ & brt (7.1) & 8.7 & 1.58 & $3 \mathrm{H}$ & $\mathrm{t}(7.1)$ & 16.3 & 1.58 & $3 \mathrm{H}$ & $\mathrm{t}(7.1)$ & 16.3 \\
\hline 33 & - & - & - & - & - & - & - & - & - & - & - & - & 2.82 & $2 \mathrm{H}$ & $q(7.2)$ & 42.6 \\
\hline 34 & - & - & - & - & - & - & - & - & - & - & - & - & 0.84 & $3 \mathrm{H}$ & $\mathrm{t}(7.1)$ & 8.8 \\
\hline
\end{tabular}




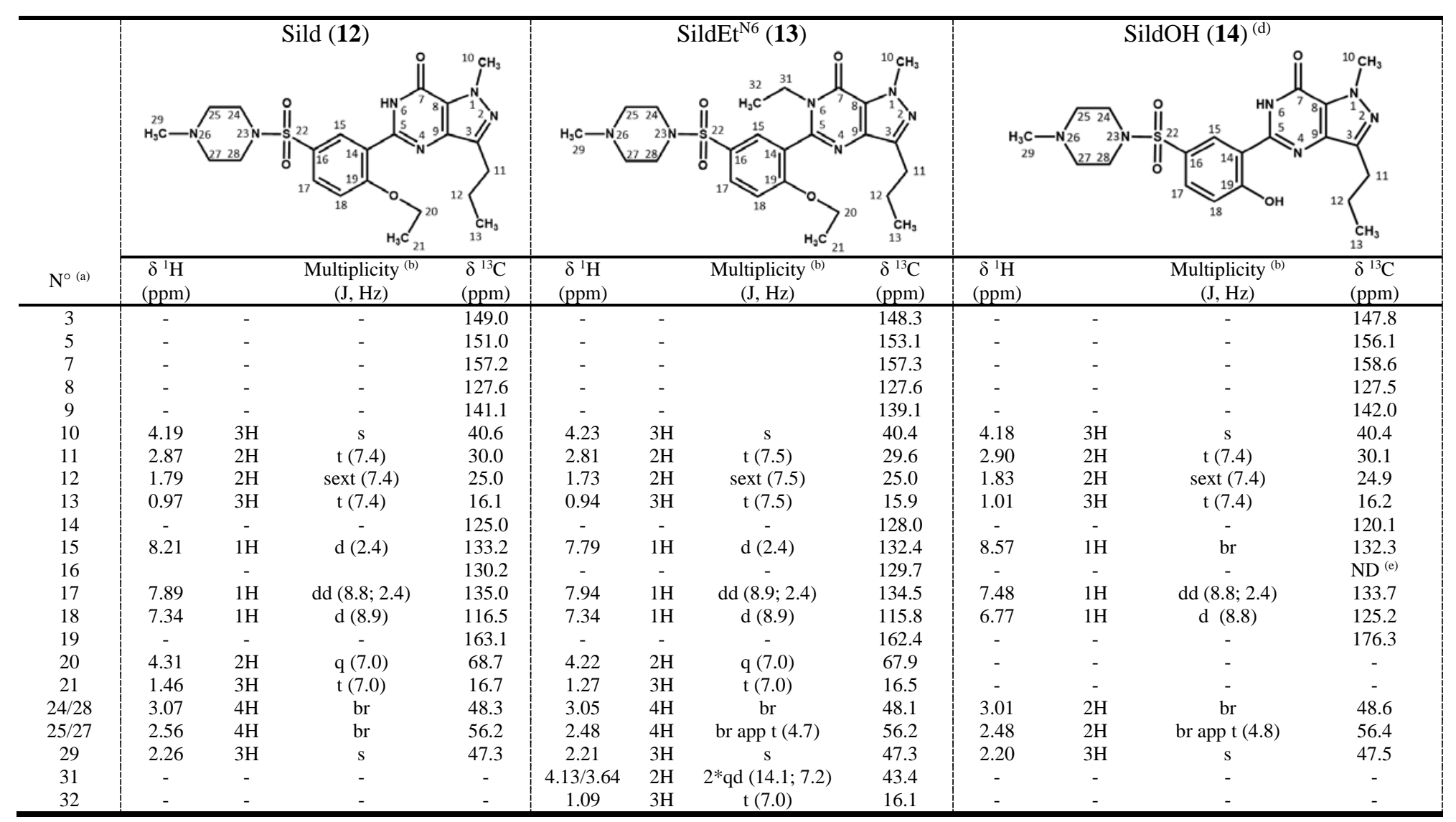




\begin{tabular}{|c|c|c|c|c|c|c|c|c|}
\hline \multirow[b]{2}{*}{$\mathrm{N}^{\circ}$ (a) } & \multicolumn{4}{|c|}{ DeSild (15) ${ }^{(\mathrm{f})}$} & \multicolumn{4}{|c|}{$\operatorname{DeSildEt}^{\mathrm{N6}}(\mathbf{1 6})^{(\mathrm{f})}$} \\
\hline & $\begin{array}{c}{ }^{1} \mathrm{H} \\
(\mathrm{ppm}) \\
\end{array}$ & & $\begin{array}{c}\begin{array}{c}\text { Multiplicity }{ }^{(\mathrm{b})} \\
(\mathrm{J}, \mathrm{Hz})\end{array} \\
\end{array}$ & $\begin{array}{c}\delta^{13} \mathrm{C} \\
(\mathrm{ppm}) \\
\end{array}$ & $\begin{array}{c}\delta^{1} \mathrm{H} \\
(\mathrm{ppm})\end{array}$ & & $\begin{array}{c}\begin{array}{c}\text { Multiplicity }{ }^{(\mathrm{b})} \\
(\mathrm{J}, \mathrm{Hz})\end{array} \\
\end{array}$ & $\begin{array}{c}\delta^{13} \mathrm{C} \\
(\mathrm{ppm})\end{array}$ \\
\hline 3 & - & - & - & 148.7 & - & - & - & 148.2 \\
\hline 5 & - & - & - & 152.0 & - & - & - & 153.5 \\
\hline 7 & - & - & - & 157.0 & - & - & - & 158.5 or 157.4 \\
\hline 8 & - & - & - & 127.2 & - & - & - & 127.4 \\
\hline 9 & - & - & - & 141.3 & - & - & - & 139.2 \\
\hline 10 & 4.19 & $3 \mathrm{H}$ & $\mathrm{s}$ & 40.4 & 4.22 & $3 \mathrm{H}$ & $\mathrm{s}$ & 40.3 \\
\hline 11 & 2.89 & $2 \mathrm{H}$ & $\mathrm{t}(7.4)$ & 29.9 & 2.79 & $2 \mathrm{H}$ & $t(7.5)$ & 29.7 \\
\hline 12 & 1.81 & $2 \mathrm{H}$ & sext (7.4) & 24.8 & 1.73 & $2 \mathrm{H}$ & sext (7.5) & 24.9 \\
\hline 13 & 0.99 & $3 \mathrm{H}$ & $\mathrm{t}(7.4)$ & 15.9 & 0.94 & $3 \mathrm{H}$ & $t(7.5)$ & 15.9 \\
\hline 14 & - & - & - & 123.2 & - & - & - & 124.8 \\
\hline 15 & 8.10 & $1 \mathrm{H}$ & dd $(7.8 ; 1.7)$ & 133.3 & 7.37 & $1 \mathrm{H}$ & $\mathrm{dd}(7.4 ; 1.8)$ & 132.6 \\
\hline 16 & 7.15 & $1 \mathrm{H}$ & $\operatorname{td}(7.5 ; 1.0)$ & 124.0 & 7.12 & $1 \mathrm{H}$ & $\operatorname{td}(7.5 ; 0.9)$ & 123.4 \\
\hline 17 & $7.55_{2}$ & $1 \mathrm{H}$ & ddd (8.5; 7.4; 1.8$)$ & 135.5 & $7.54_{9}$ & $1 \mathrm{H}$ & os & 134.2 \\
\hline 18 & 7.19 & $1 \mathrm{H}$ & $d(8.5)$ & 115.9 & 7.16 & $1 \mathrm{H}$ & os & 115.1 \\
\hline 19 & - & - & - & 159.4 & - & - & - & 158.5 or 157.4 \\
\hline 20 & 4.27 & $2 \mathrm{H}$ & $q(7.0)$ & 67.8 & 4.11 & $2 \mathrm{H}$ & $q(7.0)$ & 66.8 \\
\hline 21 & 1.48 & $3 \mathrm{H}$ & $\mathrm{t}(7.0)$ & 16.7 & 1.23 & $3 \mathrm{H}$ & $\mathrm{t}(7.0)$ & 16.7 \\
\hline 31 & - & - & - & - & 4.15/3.65 & $2 \mathrm{H}$ & $2 * q d(14.0 ; 7.0)$ & 43.1 \\
\hline 32 & - & - & - & - & 1.06 & $3 \mathrm{H}$ & $\mathrm{t}(7.0)$ & 15.9 \\
\hline
\end{tabular}

a Position number indicates either hydrogen or carbon.

${ }^{\mathrm{b}}$ Multiplicity: s, singlet; d, doublet; dd, doublet of doublet; ddd, doublet of doublet of doublet; t, triplet; td, triplet of doublet; q, quartet; qd: quartet of doublet; sext: sextet; m: multiplet; dm: doublet of multiplet; app: apparent; br: broad; os overlapped signal.

c ax: axial; eq: equatorial.

${ }^{\mathrm{d}}$ Due to the low solubility of the compound, $\delta$ were measured in $\mathrm{CD}_{3} \mathrm{CN}: \mathrm{D}_{2} \mathrm{O}(80: 20)$ after basification of the medium by $5 \mu \mathrm{L}$ of $0.5 \mathrm{M}$ NaOD added in the NMR tube.

e ND: not detected.

${ }^{\mathrm{f}}$ Compounds 15 and 16 were not separated. 
Isolation and identification of ten new sildenafil derivatives in an alleged herbal supplement for sexual enhancement

\section{Supplementary information}

Gaëtan Assemat ${ }^{1}$, Stéphane Balayssac ${ }^{1}$, Véronique Gilard ${ }^{1}$, Nathalie Martins-Froment ${ }^{2}$, Isabelle Fabing ${ }^{3}$, Frédéric Rodriguez ${ }^{4}$, Yves Génisson ${ }^{5}$, Robert Martino ${ }^{1}$, Myriam Malet-Martino ${ }^{1, *}$

${ }^{1}$ Equipe RMN Biomédicale, ${ }^{3}$ Plate-forme Chromatographie, ${ }^{4}$ Bio-informatique, ${ }^{5}$ Equipe MoNALISA, Laboratoire SPCMIB (UMR CNRS 5068), Université Paul Sabatier, 118 route de Narbonne, 31062 Toulouse cedex, France

${ }^{2}$ Service Commun de Spectrométrie de Masse, Université Paul Sabatier, 118 route de Narbonne, 31062 Toulouse cedex, France

* Corresponding author martino@chimie.ups-tlse.fr (M. Malet-Martino) Equipe RMN Biomédicale, Laboratoire SPCMIB (UMR CNRS 5068), Université Paul Sabatier, 118 route de Narbonne, 31062 Toulouse cedex, France 
Figure S1. (A) HRMS/MS spectra in negative ESI mode of two methisosildenafil-related compounds (2, 11) purified from the dietary supplement analyzed. The formulae shown represent the molecules and not the ions. Proposed structures of fragment ions of (B) compounds with an ethoxy group on the benzene ring, $(C)$ compounds with a hydroxyl group on the benzene ring.

(A)

MSildEt $^{\mathrm{N26}}$ (2)
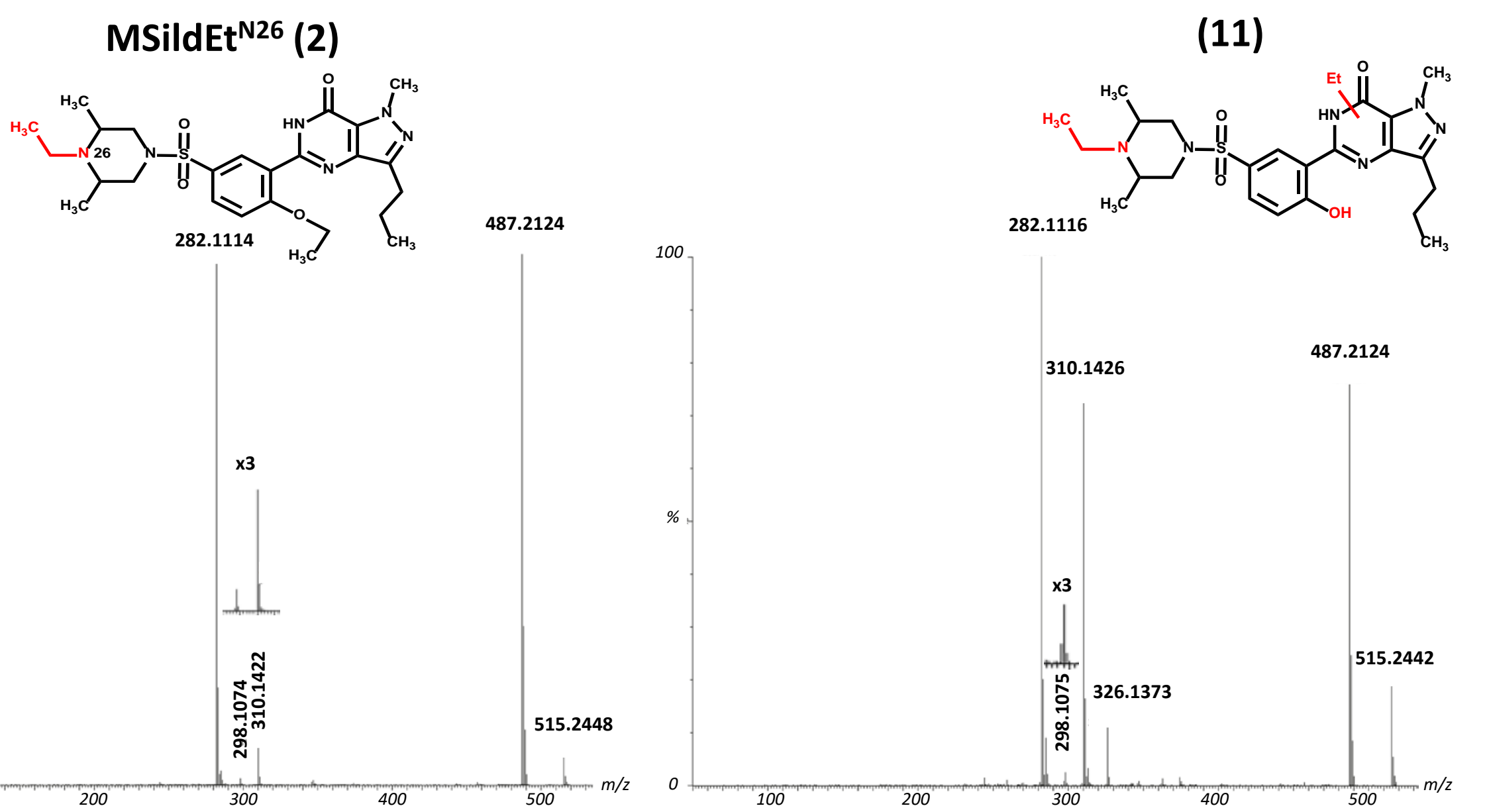
(B)

Pip A: 2,6-dimethylpiperazine

Pip B: N1-ethyl-2,6-dimethylpiperazine Pip C: N-methylpiperazine
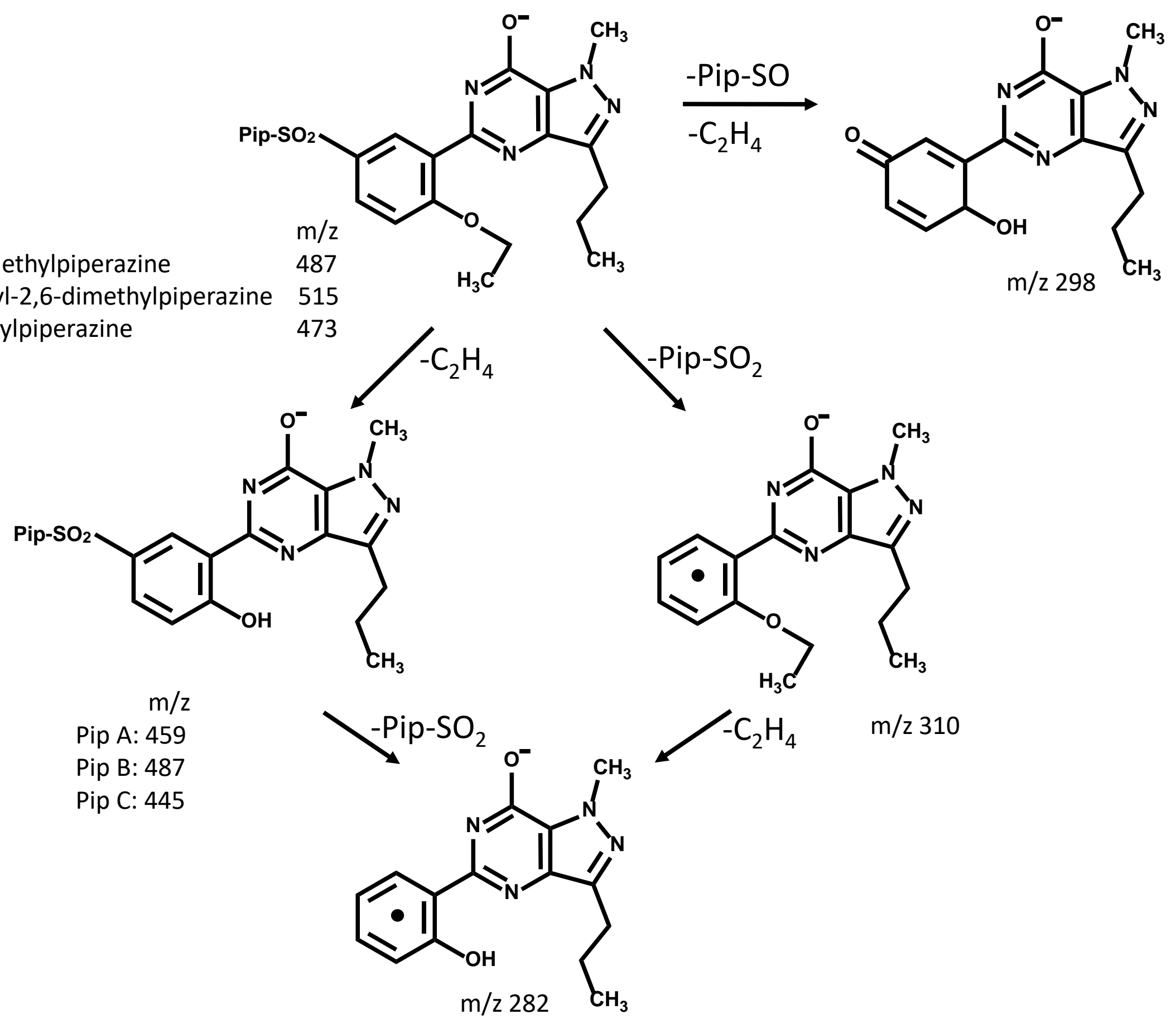
(C)

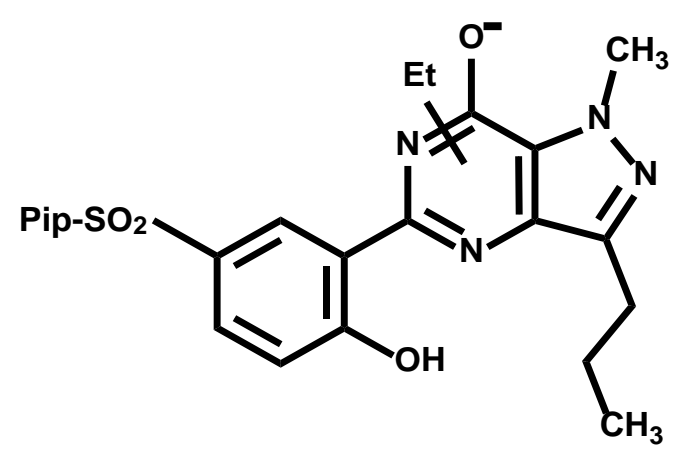

-Pip-SO

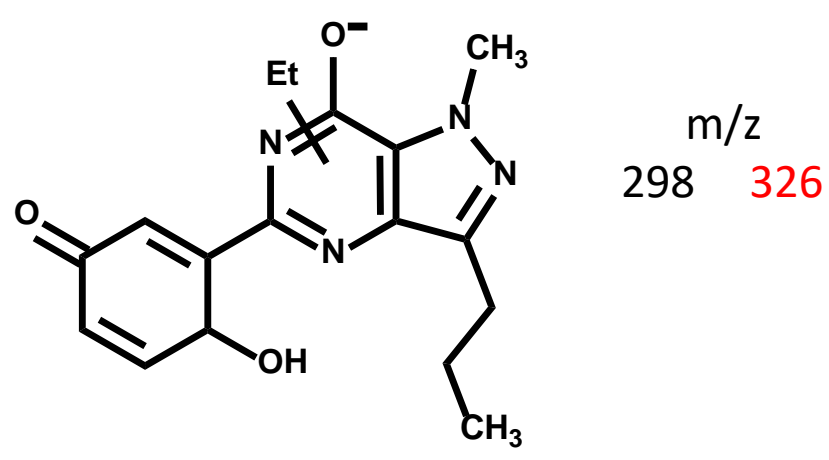

$\mathrm{m} / \mathrm{z}$ without ethyl group on the pyrazolopyrimidine moiety

459

487

Pip A: 2,6-dimethylpiperazine

$\mathrm{m} / \mathrm{z}$ with ethyl group

Pip B: N1-ethyl-2,6-dimethylpiperazine

487

515

$445 \quad$ Pip C: N-methylpiperazine

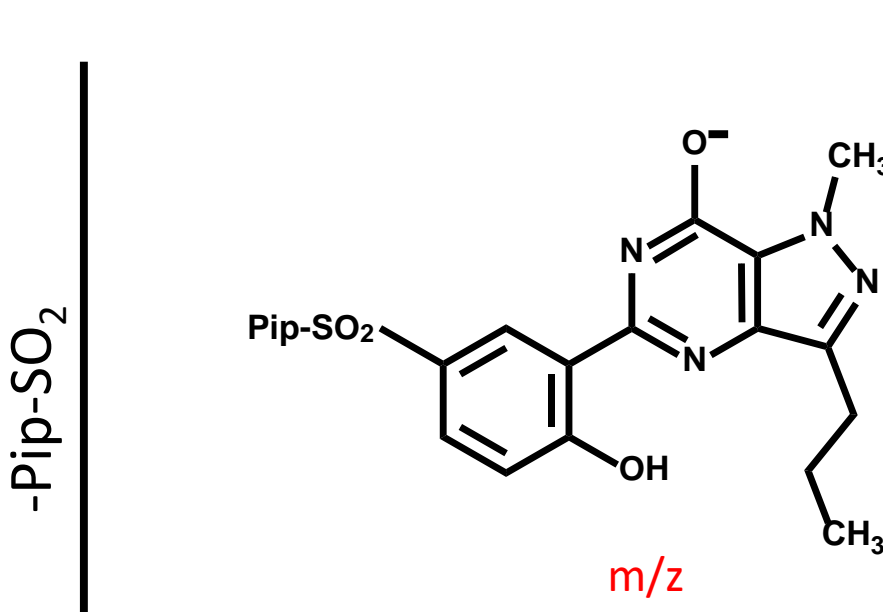

Pip A: 459

Pip B: 487
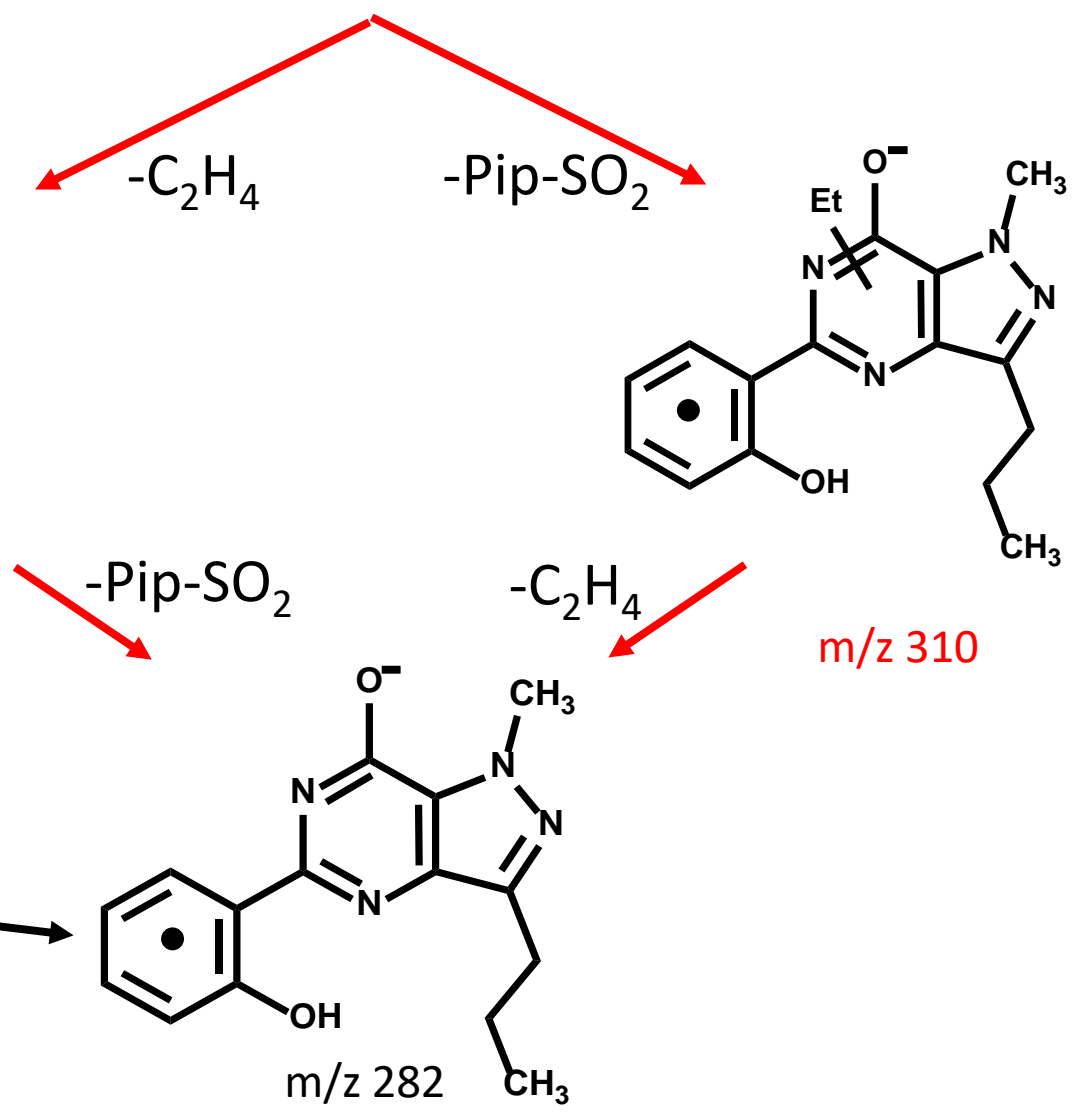

$\mathrm{m} / \mathrm{z} 310$ 
Figure S2. Parts of 2D NOESY spectra showing the spatial correlations between $\mathrm{CH}_{2} 11,12$ and $\mathrm{H} 31$ for compound 3 (MSildEt ${ }^{\mathrm{N} 4}$, N4-ethyl-methisosildenafil) and between $\mathrm{H} 15$ and $\mathrm{CH}_{2} 31$ for compound 4

(MSildEt ${ }^{\mathrm{N} 6}$, N6-ethyl-methisosildenafil).
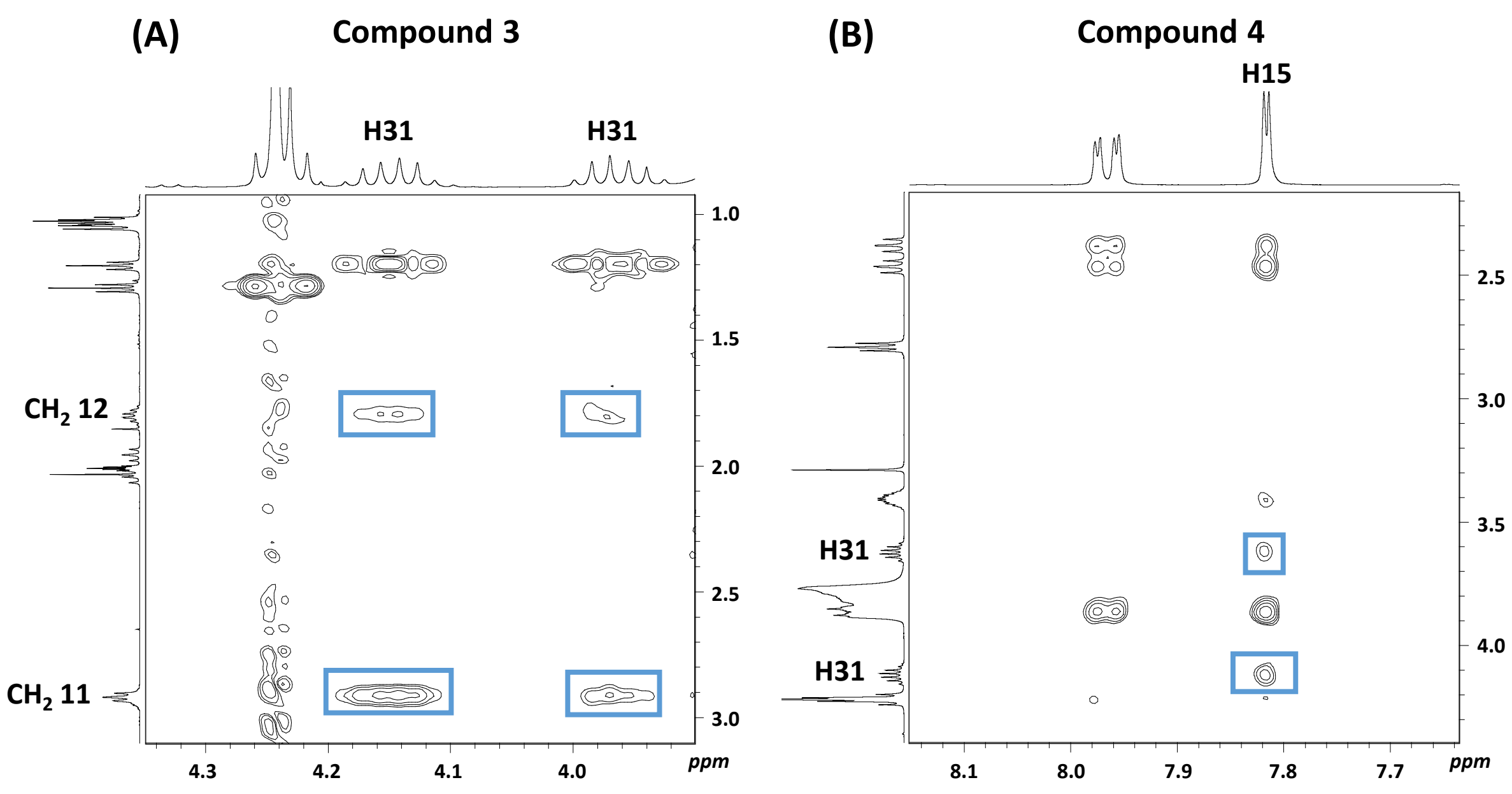
Figure S3. Representation of a privileged conformation calculated for compound 3 (MSildEt ${ }^{\mathrm{N} 4}$, N4-ethylmethisosildenafil) and interatomic distances between protons of interest.

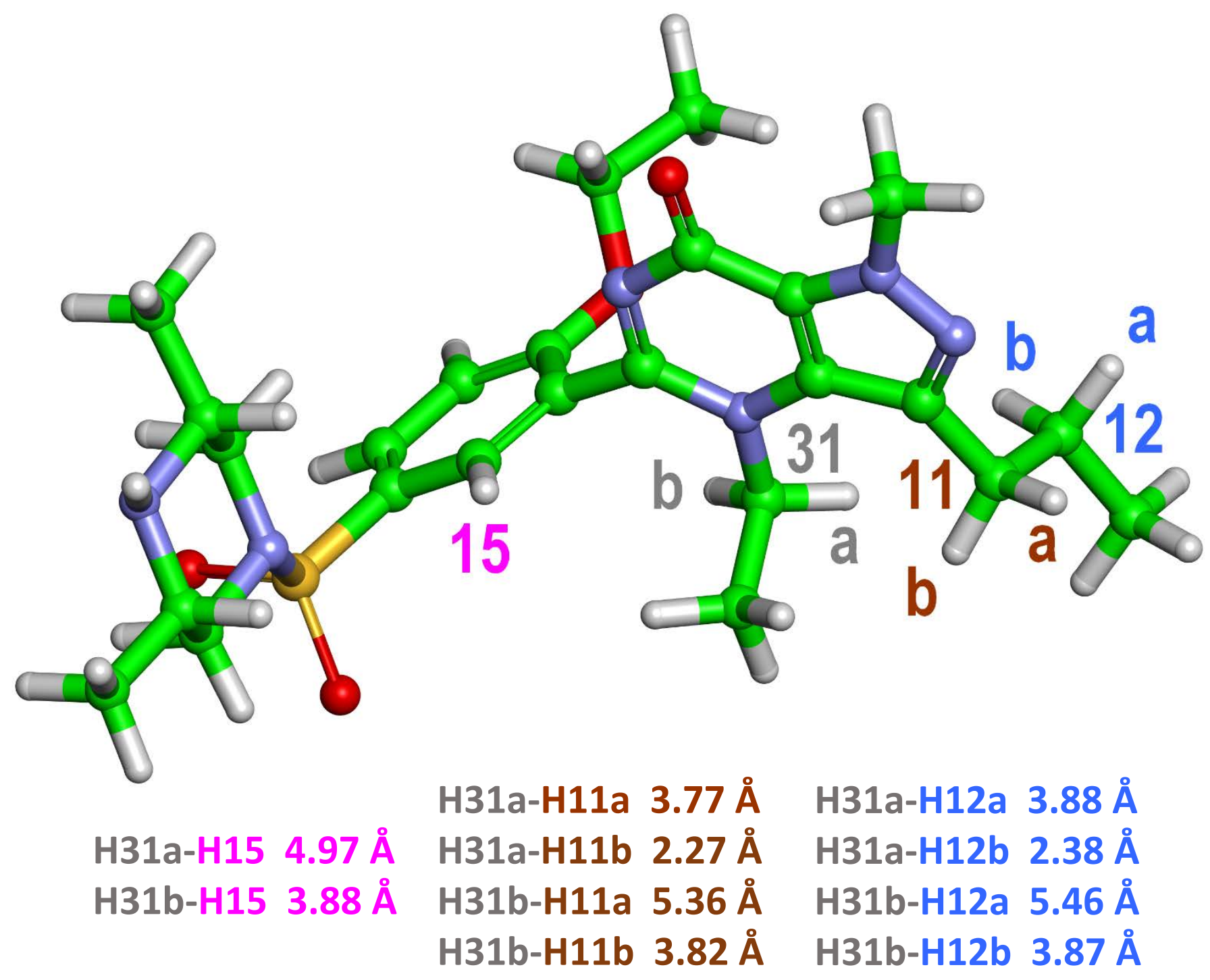


Figure S4. Part (6.7-8.9 ppm) of the ${ }^{1} \mathrm{H}$ NMR spectrum with ${ }^{13} \mathrm{C}$ GARP broadband decoupling of the dietary supplement recorded in $\mathrm{CD}_{3} C N / \mathrm{D}_{2} \mathrm{O}(80: 20, \mathrm{v} / \mathrm{v})$ with attribution of the signals of the identified compounds.

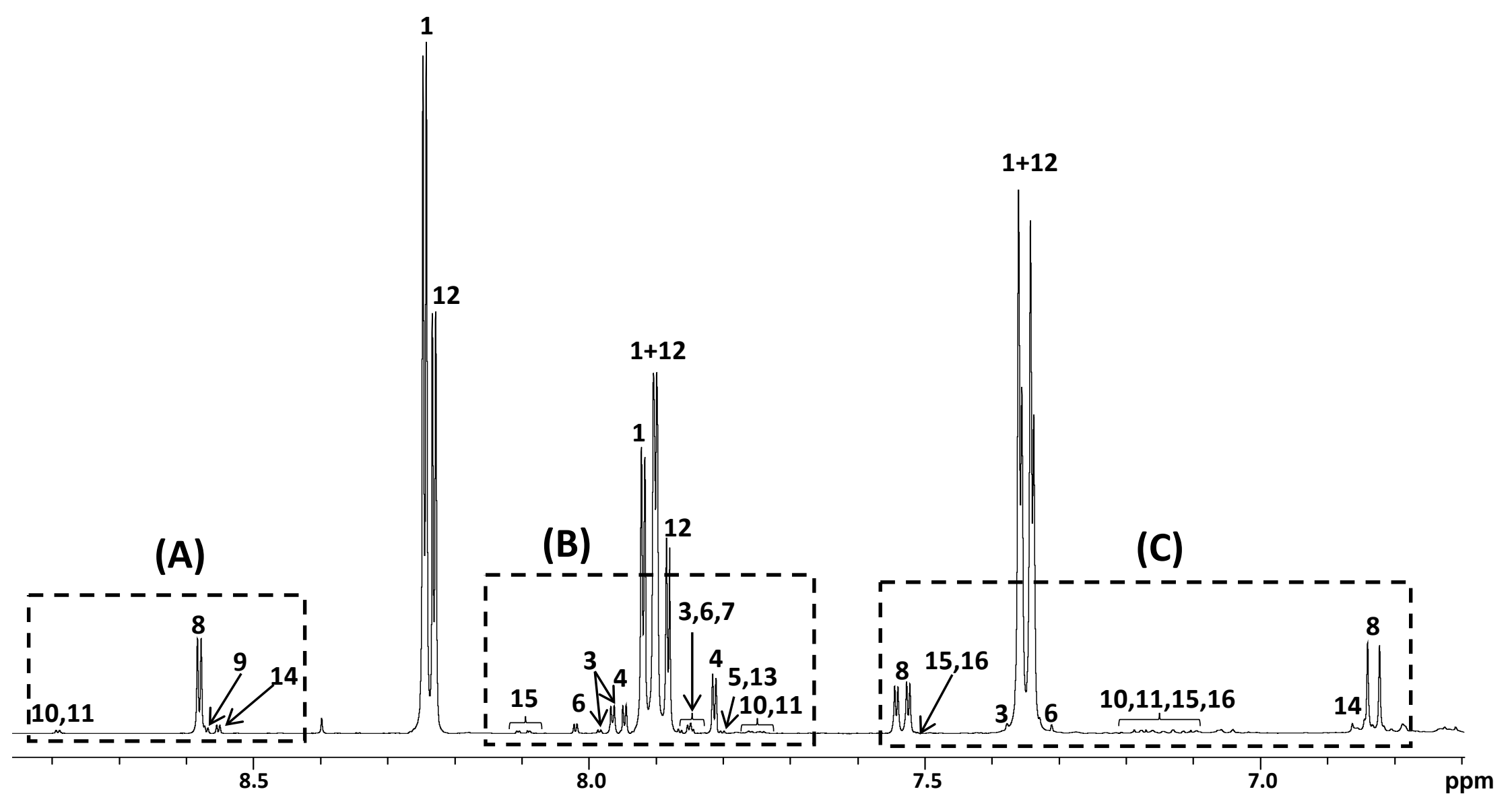




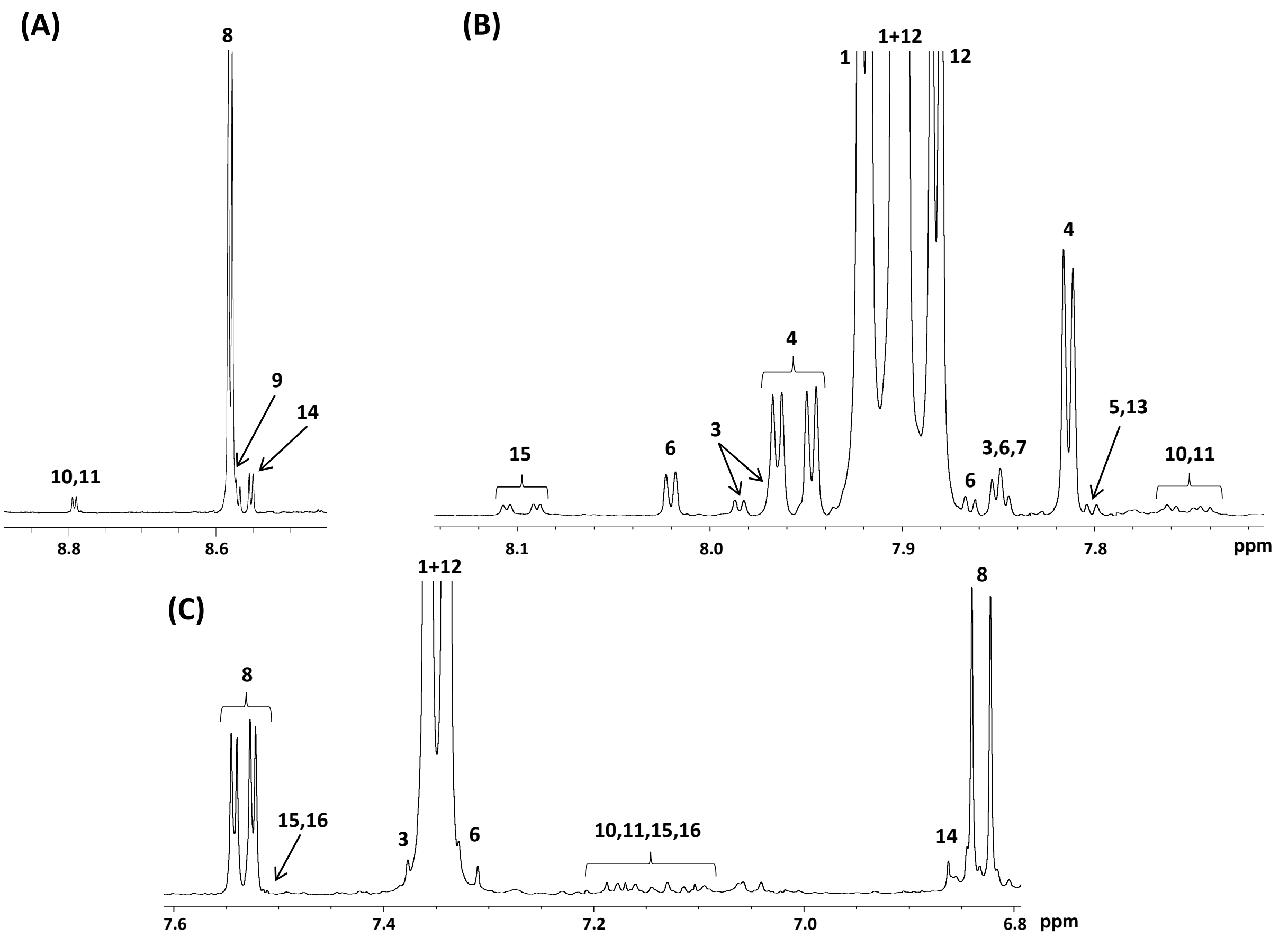

